Luciano Carli Moreira de Andrade

\title{
Abordagem Neurofuzzy Para Previsão de Demanda de Energia Elétrica no Curtíssimo Prazo
}

Dissertação de Mestrado apresentada à Escola de Engenharia de São Carlos da Universidade de São Paulo, sendo parte dos requisitos para obtenção do título de Mestre em Ciências, Programa de Engenharia Elétrica, Área de Concentração em Sistemas Dinâmicos.

Orientador: Prof. Dr. Ivan Nunes da Silva 
"O Senhor é meu pastor, nada me faltará."

SALMOS 23,1 


\section{Agradecimentos}

Primeiramente gostaria de lembrar que posso cometer omissões e, portanto, gostaria de pedir sinceras desculpas aqueles que eu possa ter deixado sem o devido reconhecimento.

Gostaria de agradecer a todos que colaboraram de alguma forma na execução desse trabalho. Aos docentes do Instituto de Ciências Matemáticas e de Computação - USP, onde conclui a graduação e, conseqüentemente, adquiri toda base de conhecimento para o desenvolvimento não apenas desse como de todos outros trabalhos na área de Ciências da Computação ou Engenharia Elétrica. Particularmente, ao professor Ph. D. André Carlos Ponce de Leon Ferreira de Carvalho pela orientação durante a graduação onde iniciei pesquisa na área de inteligência computacional.

Meus agradecimentos, em especial, ao meu orientador Prof. Dr. Ivan Nunes da Silva, pela oportunidade que me concedeu de fazer parte do programa de mestrado do Departamento de Engenharia Elétrica da Escola de Engenharia de São Carlos - USP, pelas orientações e correções dos artigos escritos durante o desenvolvimento do mestrado, pela orientação no desenvolvimento da presente dissertação e pelo exemplo de competência que é como docente e pesquisador.

Agradeço também ao Laboratório de Automação Inteligente de Processos e Sistemas (LAIPS) pela infra-estrutura fornecida, assim como seus integrantes, especialmente o Mestre Marcelo Suetake e o Mestre Ricardo Augusto Souza Fernandes, pelas sugestões no desenvolvimento desse trabalho e pelo companheirismo durante o decorrer do mestrado.

A todos os funcionários e docentes do programa de pós-graduação da Escola de Engenharia de São Carlos - USP, cujo compromisso com a pesquisa em engenharia possibilitou o desenvolvimento desse trabalho. 
Aos proprietários da empresa onde trabalho, Paulo Mascarenhas e Yvone Maria Mascarenhas, por permitirem que eu me ausentasse da empresa em horários comerciais a fim de cumprir as disciplinas e outros compromissos do curso.

Aos meus pais, Sudário Pinto de Andrade e Vandete Carli Moreira de Andrade, cuja dedicação e sacrifício permitiram que eu me tornasse bacharel em Ciências da Computação e à minha irmã Juliana Carli Moreira de Andrade, Mestre em Letras, que me motivou a cursar pós-graduação.

E também, à minha namorada, Daniela Oliveira Francisco, pela compreensão nos meus momentos de ausência para me dedicar aos diversos trabalhos desenvolvidos durante o mestrado.

Finalmente, a todos que de alguma maneira contribuíram para minha formação profissional e minha formação como cidadão. 


\section{Sumário}

Resumo ix

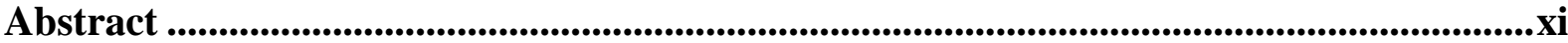

Lista de Siglas e Abreviaturas ....................................................................................

Lista de Figuras

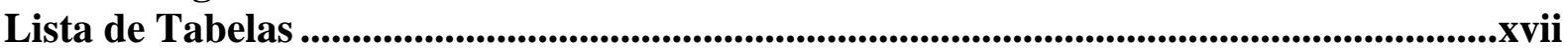

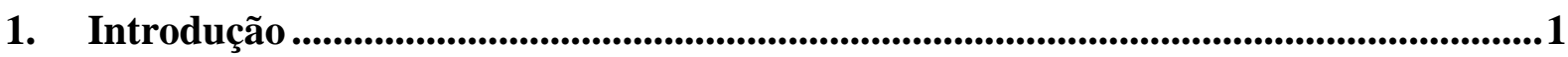

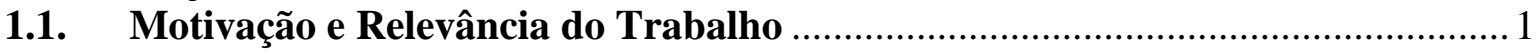

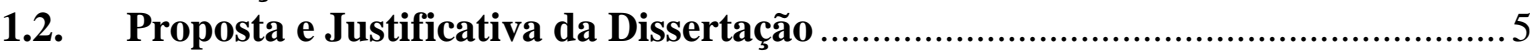

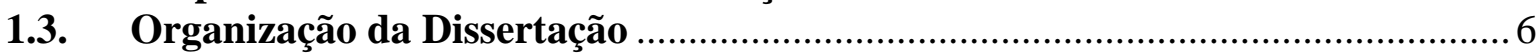

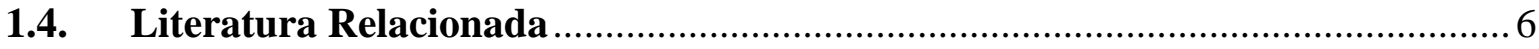

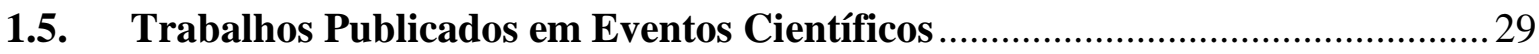

2. Aspectos de Previsão de Demanda de Energia Elétrica em Sistemas Elétricos de

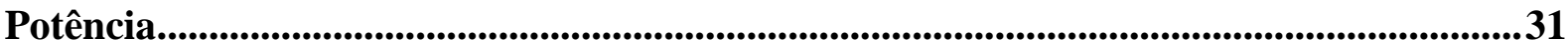

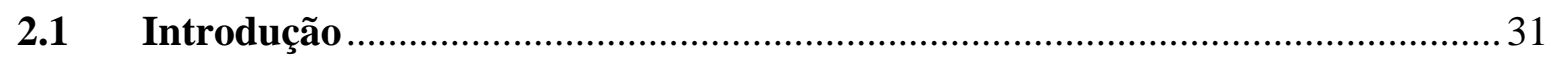

2.2 Aspectos da Constituição dos Sistemas Elétricos de Potência ........................... 31

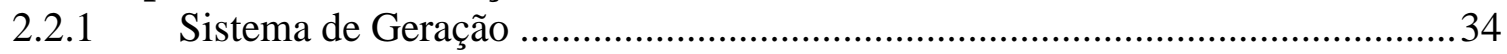

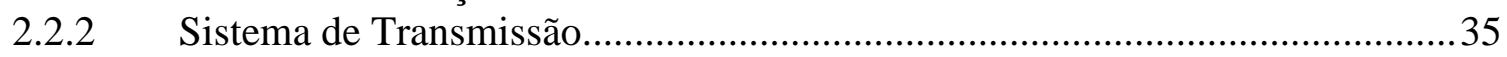

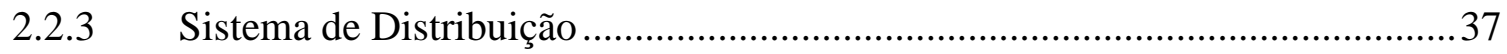

2.3 Aspectos de Previsão de Demanda de Energia Elétrica ................................... 38

2.4 Principais Abordagens Inteligentes Utilizadas em Previsão de Demanda ........ 40

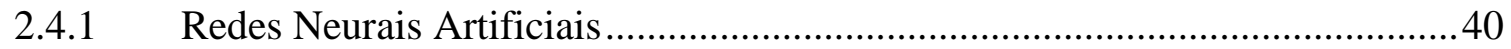

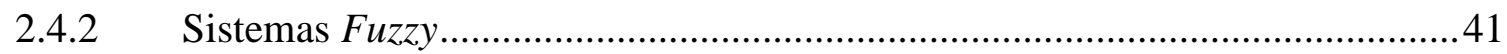

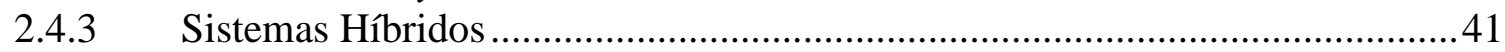

3. Aspectos de Sistemas Neurofuzzy .........................................................................43

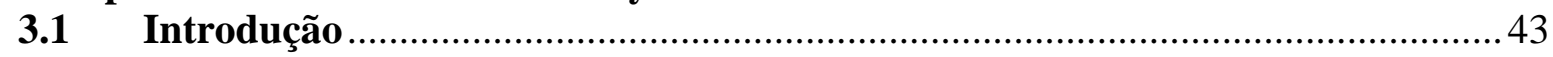

3.2 Aspectos de Sistemas de Inferência Fuzzy ................................................... 43

3.2.1 Grau de Pertinência Fuzzy ............................................................................ 44

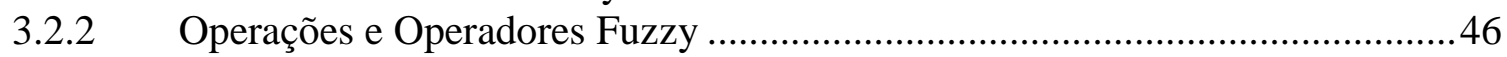

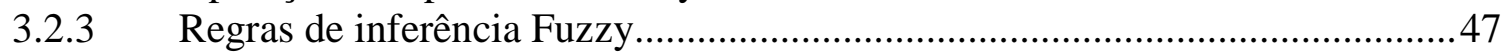

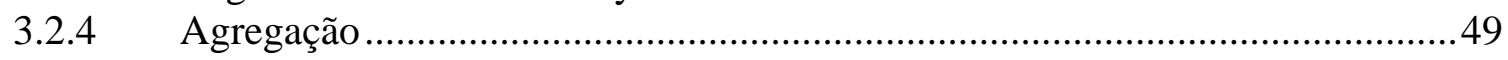

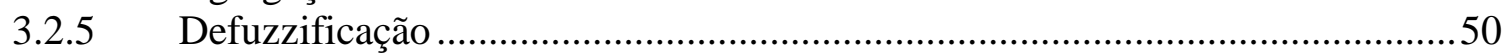

3.2.6 Método de Implicação de Mandani .................................................................50

3.3 Composição dos Sistemas de Inferência Fuzzy …...........................................53

3.4 Sistema de Inferência no Modelo de Takagi-Sugeno …......................................54

3.5 Sistema ANFIS (Adaptive Neuro-Fuzzy Inference System) ..............................55

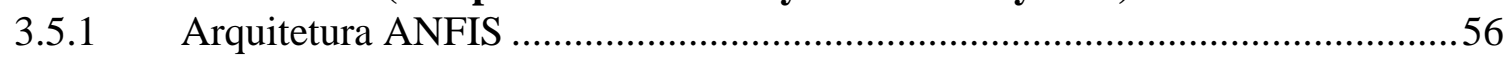

4. Previsão de Demanda de Energia Elétrica Utilizando o Sistema ANFIS ....................59

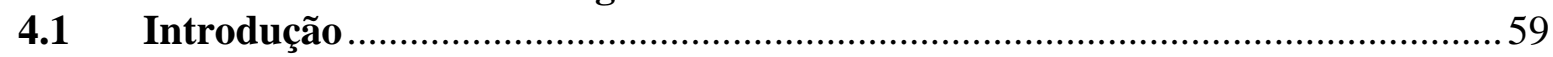

4.2 Abordagem ANFIS Para Previsão de Demanda de Energia Elétrica ...............59

4.2.1 Aspectos sobre a Validação Cruzada............................................................59

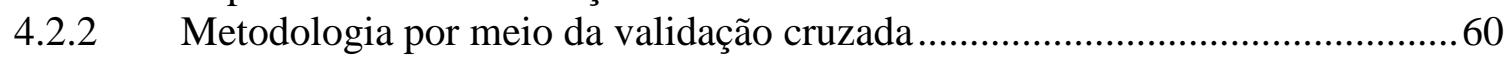

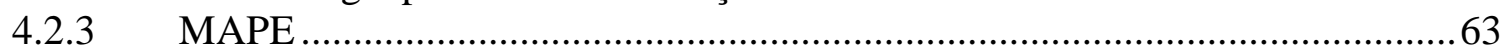

4.3 Aspectos dos Dados Utilizados na Previsão de Demanda de Energia Elétrica.63

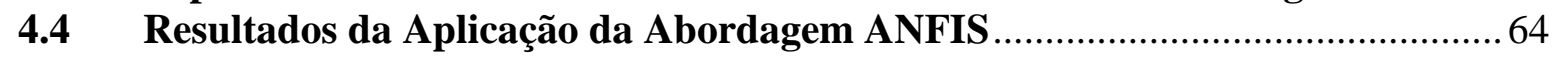

4.4.1 Gráficos e histograma dos resultados de Cordeirópolis ...................................65

4.4.2 Gráficos e histograma dos resultados de Mogi-Guaçu .....................................67

4.4.3 Gráficos e histograma dos resultados de Ubatuba..........................................69

4.4.4 Gráficos e histograma dos resultados de Votuporanga .................................... 71 
4.4.5 Tabela com o MAPE e variância ………........................................................ 73

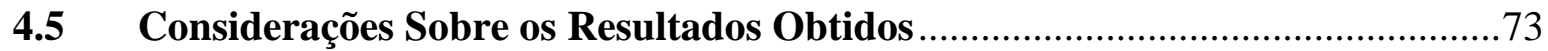

5. Conclusões Gerais e Trabalhos Futuros ............................................................................... 77

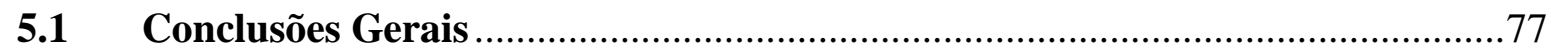

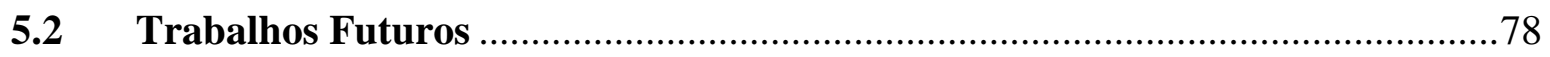

Referências Bibliográficas.................................................................................................................... 79

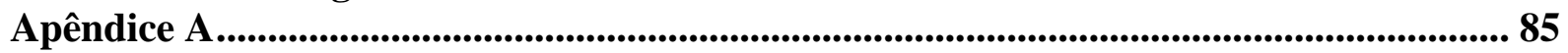

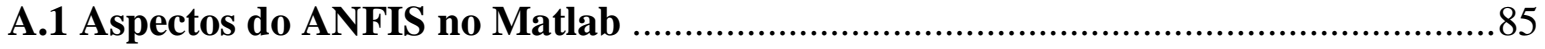

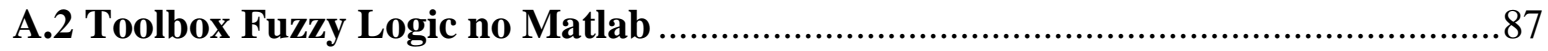




\section{Resumo}

Andrade, L. C. M. (2010). Abordagem Neurofuzzy Para Previsão de Demanda de Energia Elétrica no Curtíssimo Prazo. Dissertação (Mestrado) - Escola de Engenharia de São Carlos, Universidade de São Paulo, 2010.

Uma vez que sistemas de inferência neuro-fuzzy adaptativos são aproximadores universais que podem ser usados em aplicações de aproximação de funções e de previsão, este trabalho tem por objetivo determinar seus melhores parâmetros e suas melhores arquiteturas com o propósito de se executar previsão de demanda de energia elétrica no curtíssimo prazo em subestações de distribuição. Isto pode possibilitar o desenvolvimento de controles automáticos de carga mais eficientes para sistemas elétricos de potência. As entradas do sistema são séries temporais de demanda de energia elétrica, compostas por dados mensurados em intervalos de cinco minutos ao longo de sete dias em subestações localizadas em cidades do interior do estado de São Paulo. Diversas configurações de entrada e diferentes arquiteturas foram examinadas para se fazer a previsão de um passo a frente. Os resultados do sistema de inferência neuro-fuzzy adaptativo frente às abordagens encontradas na literatura foram promissores.

Palavras Chave: Demanda de eletricidade, previsão de curtíssimo prazo, sistemas neurofuzzy. 


\section{Abstract}

Andrade, L. C. M. (2010). Neurofuzzy Approach for Very-Short Term Load Demand Forecasting. Dissertation (Master's Degree) - Escola de Engenharia de São Carlos, Universidade de São Paulo, 2010.

Since adaptive neuro-fuzzy inference systems are universal approximators that can be used in functions approximation and forecasting applications, this work has the objective to determine their best parameters and best architectures with the purpose to execute very short term load forecasting in distribution substations. This can allow the development of more efficient load automatic control for power systems. The system inputs are load demand time series, which are composed of data measured at each five minutes interval, during seven days, from substations located in cities from São Paulo state countryside. Several input configurations and different architectures were examined to make a prediction aiming one step forecasting. The Adaptive neuro-fuzzy inference system results in comparison with other approaches found in literature were promising.

Keywords: Load demand; very short-term forecasting; neuro-fuzzy system. 


\section{Lista de Siglas e Abreviaturas}

$\begin{array}{ll}\text { AGC } & \text { Automatic Generation Control } \\ \text { AR } & \text { Auto Regressive Model } \\ \text { ANFIS } & \text { Adaptive Neuro-Fuzzy Inference System } \\ \text { ARMA } & \text { Auto Regressive Moving Average } \\ \text { ARIMA } & \text { Auto Regressive Integrated Moving Average } \\ \text { GA } & \text { Gaussian Adaptive Resonance Theory } \\ \text { GM } & \text { Grey Model } \\ \text { GRD } & \text { Gaussian Regression with Dynamic Decay } \\ \text { GRNN } & \text { Generalized Regression Neural Network } \\ \text { MAPE } & \text { Mean Absolute Percentage Error } \\ \text { MLR } & \text { Multi-Linear Regression } \\ \text { PNN } & \text { Probabilistic Neural Network } \\ \text { PSO } & \text { Particle Swarm Optimization } \\ \text { RBF } & \text { Radial Basis Function } \\ \text { RMS } & \text { Root Mean Squared Error } \\ \text { SARIMA } & \text { Sazonal Auto Regressive Integrated Moving Average } \\ \text { SVM } & \text { Support Vector Machine }\end{array}$




\section{Lista de Figuras}

Figura 1.1 - Distribuição setorial da demanda de energia elétrica no Brasil em 2008..............2

Figura 2.1 - Diagrama de blocos do sistema elétrico de potência. ........................................32

Figura 2.2 - Diagrama unifilar de um sistema elétrico de potência...........................................33

Figura 2.3 - Linhas de transmissão e bacias hidrográficas brasileiras (www.ons.org.br)........ 36

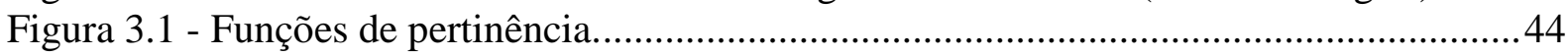

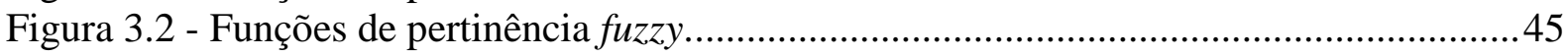

Figura 3.3 - Representação da variável ligüística temperatura...............................................48

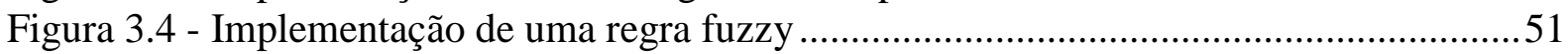

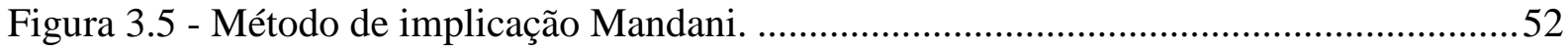

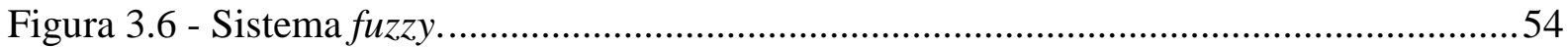

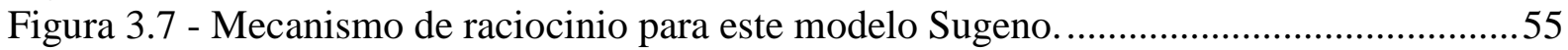

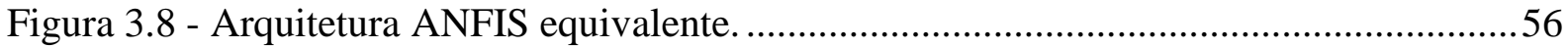

Figura 4.1 - Fluxograma da validação cruzada empregada nesse trabalho .............................62

Figura 4.2 - Séries temporais mensuradas nas subestações de Cordeirópolis, Mogi-Guaçu,

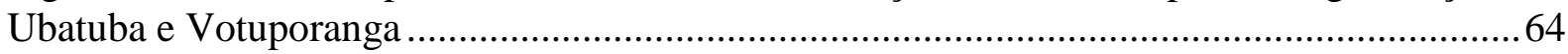

Figura 4.3 - Gráfico das curvas de treinamento do ANFIS para Cordeirópolis .......................65

Figura 4.4 - Gráfico das curvas mensurada e prevista para Cordeirópolis ................................66

Figura 4.5 Histograma dos erros relativos para Cordeirópolis ...............................................66

Figura 4.6 - Gráfico das curvas de treinamento do ANFIS para Mogi-Guaçu........................67

Figura 4.7 - Gráfico das curvas mensurada e prevista para Mogi-Guaçu ................................68

Figura 4.8 - Histograma dos erros relativos para Mogi-Guaçu ..............................................68

Figura 4.9 - Gráfico das curvas de treinamento para Ubatuba ...............................................69

Figura 4.10 - Gráfico das curvas mensurada e prevista para Ubatuba ....................................70

Figura 4.11 - Histograma dos erros relativos para Ubatuba ....................................................... 70

Figura 4.12 - Gráfico das curvas de treinamento para Votuporanga ....................................... 71

Figura 4.13 - Gráfico das curvas mensurada e prevista para Votuporanga ............................. 72

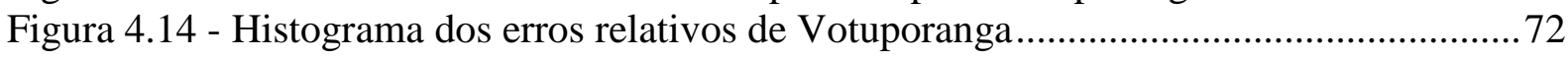

Figura A.1 - Interface gráfica do ANFIS no Matlab ............................................................ 86

Figura A.2 - Parâmetros de inicialização do sistema de inferência fuzzy ................................. 86

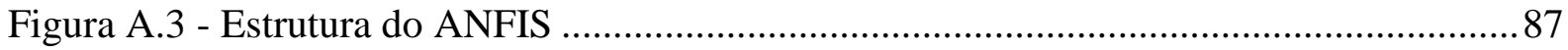

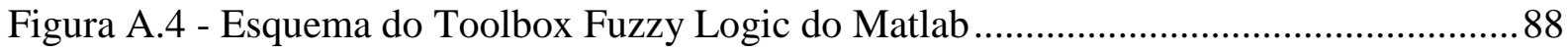

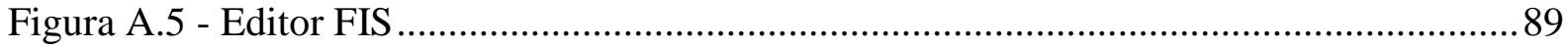

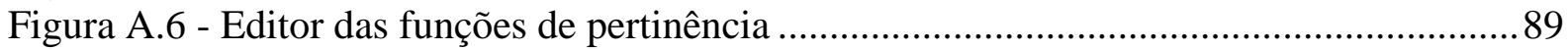

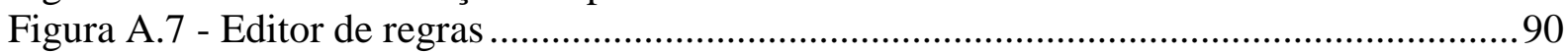

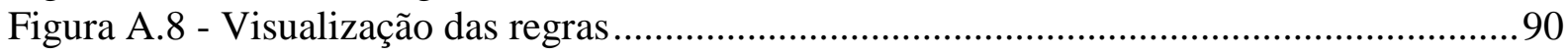

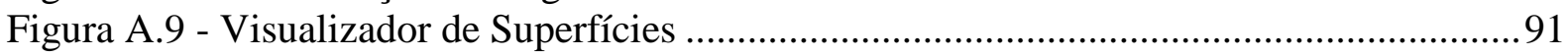




\section{Lista de Tabelas}

Tabela 4.1- Tabela dos erros e variância para Cordeirópolis, Mogi-Guaçu, Ubatuba e Votuporanga 



\section{Introdução}

\subsection{Motivação e Relevância do Trabalho}

Segundo o Balanço Energético Nacional de 2008, a energia elétrica foi a modalidade energética mais consumida no Brasil em 2007, considerando-se o desmembramento do petróleo em seus derivados como óleo diesel, gasolina e GLP. O volume absorvido correspondeu a uma participação de $17,6 \%$ no volume total e a um aumento de $5,7 \%$ sobre o ano anterior. Desde 2003, a tendência de crescimento continua acentuada.

Por setores, o industrial continua a liderar o ranking dos maiores consumidores de energia elétrica, como pode ser observado na Figura 1.1 a seguir. É importante mencionar que esse setor se caracteriza por uma tendência que tem evoluído nos últimos anos: a autoprodução de energia, ou então, os investimentos realizados em usinas geradoras por consumidores de grande porte para consumo próprio e venda excedente no mercado. Segundo o Balanço Energético Nacional de 2008, essa atividade apresentou um crescimento de $262 \%$ entre os anos de 1992 e 2007.

É importante também comentar que essa expansão é acentuada nos últimos 5 anos da década de 90, pois, por meio da constituição do mercado livre de energia elétrica, os investidores foram estimulados a negociar seus excedentes.

O setor residencial se destaca pelo volume absorvido, segundo maior do país, e também pelo acentuado crescimento. O consumo de todos os setores está também ilustrado na Figura 1.1. Esses dados demonstram a importância do consumo de energia elétrica para a manutenção e o desenvolvimento dos diversos setores da sociedade brasileira.

Depois de mais de 50 anos de controle estatal, o setor elétrico brasileiro passou por uma liberalização. A maioria das atividades era estritamente regulamentada e as companhias operadoras eram controladas pelo estado (federal e estadual) e verticalizadas (atuantes na 
geração, transmissão e distribuição). Ao longo da década de 90 as companhias sofreram uma cisão em geradoras, transmissoras e distribuidoras. As atividades de distribuição e transmissão continuaram totalmente regulamentadas. Mas, a produção das geradoras passou a ser negociada no mercado livre, onde compradores e vendedores acertam entre si as condições através de contratos bilaterais.

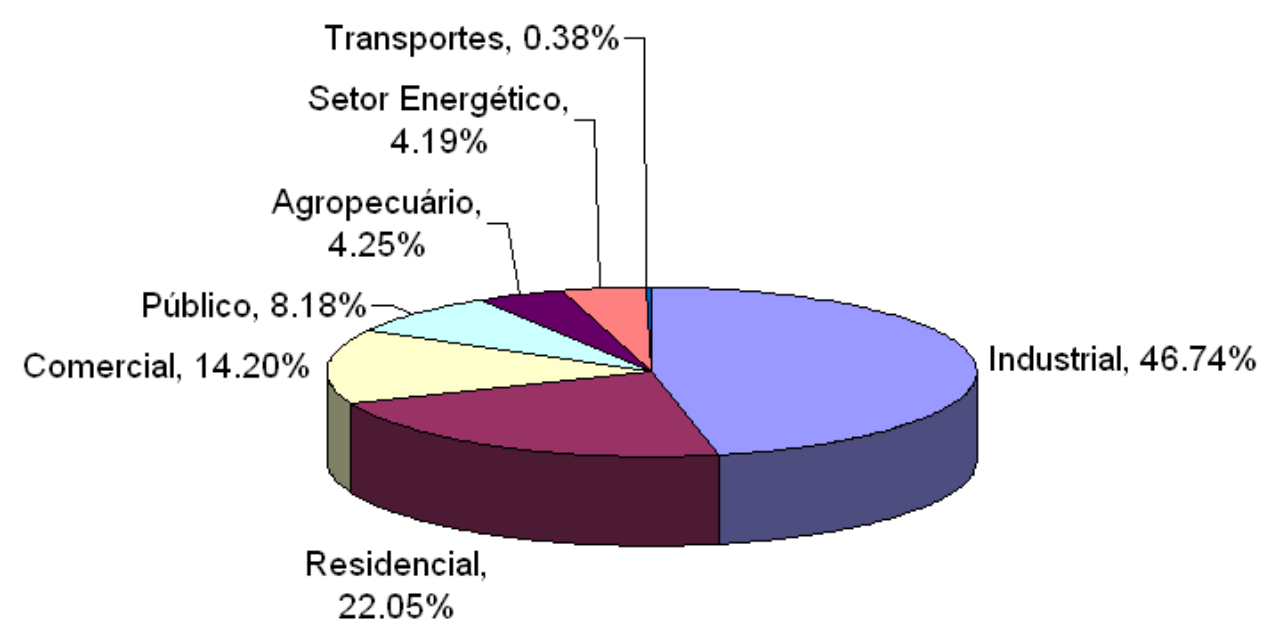

Figura 1.1 - Distribuição setorial da demanda de energia elétrica no Brasil em 2008.

Fonte: Balanço Energético Nacional, 2008.

Em 2004, ocorreu a introdução do Novo Modelo do Setor Elétrico, com o objetivo de garantir a segurança no suprimento, promover a modicidade tarifária e promover a inserção social. Sua implantação marcou a retomada da responsabilidade do planejamento do setor de energia elétrica pelo Estado.

O modelo introduzido em 2004 restringiu, mas não acabou com o mercado livre, que em 2008 respondia por 30\% da energia elétrica negociada no país.

No mercado livre, a compra e venda de energia elétrica funciona através de leilões, nos quais, na parte compradora participam apenas as distribuidoras, sendo que as vendedoras de energia são as geradoras. A entrega ocorre em um, três ou cinco anos após a data de realização do leilão. 
Como são realizados com antecedência de vários anos, esses leilões são também indicadores do cenário da oferta e da procura no médio e longo prazo.

No mercado livre, as vendedoras e compradoras negociam entre si as cláusulas dos contratos, como preço, prazo e condições de entrega.

Os contratos têm prazos que podem chegar a vários anos. O comprador, portanto, baseia-se em previsão de demanda de energia elétrica no longo prazo, enquanto o vendedor na previsão do volume que irá produzir.

Assim, com a introdução da desregulamentação na indústria de eletricidade, previsões precisas de demanda futura por energia passaram a ter um papel mais importante no que se refere aos investimentos na área de sistemas de distribuição, planejamento em energia elétrica e estratégias de gerenciamento em sistemas regionais e nacionais. Previsões imprecisas de energia podem aumentar os custos operacionais. Já a super estimação na demanda futura resulta em uma reserva girante desnecessária. Por outro lado, a subestimação pode causar falhas no fornecimento (Pai et al., 2005).

Existem abordagens distintas no que se refere à previsão de demanda de energia elétrica. Os horizontes de previsão podem variar de alguns minutos a vários anos ou décadas. Existem objetivos particulares no que se refere a cada um desses horizontes, o que levou a classificação da previsão de demanda de energia em previsão de longo prazo, previsão de médio prazo, previsão de curto prazo e previsão de curtíssimo prazo.

A previsão de longo prazo tem como horizonte anos ou décadas e tem como objetivo prover para produtores e distribuidores a evolução da demanda, o que permite a definição de estratégias para aumentar a capacidade das linhas de distribuição e construir novas plantas de produção.

A previsão de médio prazo tem como horizonte algumas semanas ou meses e seu objetivo é permitir o planejamento de manutenções nas redes elétricas, programar a compra 
de combustível e servem como pesquisa de mercado para produtores e revendedores negociarem contratos com outras empresas reduzindo-se os riscos financeiros (Romera et al., 2008).

A previsão de curto prazo é o horizonte mais pesquisado no que se refere à previsão de demanda de energia elétrica e tem como horizonte algumas horas. Muitas decisões podem ser tomadas com uma previsão precisa no curto prazo, como análises de confiabilidade, avaliação de segurança, planejamento de manutenção de geradores, etc.

O último horizonte de previsão é o horizonte de curtíssimo prazo, ou seja, previsão de alguns minutos à frente.

Sistemas geradores de energia procuram regular a demanda e a oferta por energia elétrica para minimizar flutuações, ajustando a geração de energia a constantes mudanças, ou seja, é indispensável se fazer uma previsão precisa minutos à frente para se evitar distúrbios indesejáveis em operações envolvendo sistemas elétricos de potência (Yang et al., 2006).

Para atender esse objetivo deve-se empregar um eficiente controle automático de geração de energia. Este deve, periodicamente, atualizar a geração de energia baseado em exemplos obtidos no próprio sistema de carga e freqüência elétricas. Em sistemas típicos, a taxa de controle varia de horizontes de um a dez minutos.

O controle de frequiência de carga e funções de despacho econômicas também requerem previsões de alguns minutos a vários minutos à frente. Previsões no curtíssimo prazo, integradas com informações sobre transações programadas de energia elétrica, disponibilidade de transmissão, custo de geração, preço das ações no mercado de energia e requisitos de reserva girante, são usadas para determinar a melhor estratégia das concessionárias de energia (Charytoniuk e Chen, 2000).

Previsão de demanda de energia elétrica no curtíssimo prazo requer uma abordagem cujo o foco está na análise do comportamento das medidas recentemente observadas para se 
prever o futuro próximo, diferentemente das abordagens empregadas em horizontes mais distantes, em que se deve extrair informações de fatores que afetam o comportamento da demanda como condições meteorológicas, tempo, etc.

Assim, para uma eficiente comercialização da energia elétrica, como também seu consumo econômico, são necessárias previsões de demanda de energia elétrica em vários horizontes, especialmente no horizonte de curtíssimo prazo.

\subsection{Proposta e Justificativa da Dissertação}

Este trabalho tem como proposta empregar o Sistema Adaptativo de Inferência Fuzzy (ANFIS) para previsão de demanda de energia elétrica no curtíssimo prazo.

Apesar de o ANFIS possuir a capacidade de efetuar a previsão de séries temporais e de existirem inúmeros trabalhos que empregam sistemas inteligentes nessa tarefa, não são muitos os trabalhos que fazem uso dessa ferramenta em previsão de demanda de energia elétrica no curtíssimo prazo.

Pode-se verificar por meio da Seção 1.4, referente à literatura relacionada, que a grande maioria dos trabalhos fazem previsão de demanda de energia elétrica no curto prazo com uso de diversos tipos de redes neurais artificiais. Existem poucos trabalhos de previsão de demanda de energia elétrica no curtíssimo prazo e nenhum deles aplicou o ANFIS como ferramenta de previsão.

De qualquer forma, sistemas de potência modernos consistem de centenas de geradores conectados por milhares de quilômetros de linhas de transmissão. O objetivo fundamental em controle é manter a sintonia entre a carga gerada pelo sistema e sua demanda. O controle primário usado para atender esse objetivo é baseado num controle integral e é chamado Controle Automático de Geração (CAG). O CAG periodicamente atualiza a carga dos geradores utilizando exemplos de carga-freqüência do sistema elétrico de potência. Em 
sistemas típicos, os exemplos da taxa de controle utilizados variam de horizontes de um a dez minutos (Trudnowsk, 2001).

Para melhorar seu desempenho, novas estratégias do CAG, apresentados em Schulte (1996), empregam um algoritmo de controle de antecipação que requer estimativas futuras de carga (em tempo real) de trinta a cento e vinte minutos, com uma taxa de um a dez minutos. Tais estratégias têm sido aplicadas satisfatoriamente no sistema operado pela Bonneville Power Administration (BPA) nos Estados Unidos (Trudnowsk, 2001).

O objetivo primordial desse trabalho de Mestrado é fornecer uma ferramenta para previsão eficiente de demanda de energia elétrica no curtíssimo prazo, baseado no Sistema Adaptativo de Inferência Fuzzy, a qual terá também potencialidade para ser empregada em Controles Automáticos de Geração de sistemas elétricos de potência.

\subsection{Organização da Dissertação}

A dissertação está organizada em cinco capítulos. O conteúdo de cada um dos capítulos está descrito na seqüência.

O Capítulo 2 apresenta alguns aspectos de demanda de energia elétrica em sistemas de distribuição. O Capítulo 3 apresenta informações sobre os sistemas neuro-fuzzy, do qual faz parte o sistema ANFIS empregado nesse trabalho. O Capítulo 4 apresenta informações sobre previsão de demanda empregando o ANFIS e o Capítulo 5 apresenta as conclusões do trabalho.

\subsection{Literatura Relacionada}

Papalexopoulos e Hesterberg (1990) descrevem a previsão de demanda de energia elétrica no curto prazo como necessária para determinar os custos e efeitos da capacidade estimada e de trocas de energia. Os autores também mencionam que, baseado na informação de previsão, operadores podem empreender ações preventivas ou corretivas em operações 
seguras e econômicas em sistemas elétricos de potência. Dessa forma, os autores criaram um modelo baseado em regressão linear para ser usado em sistemas de previsão de demanda de energia elétrica. Eles relatam que esse modelo foi aplicado em uma empresa americana do ramo de geração e distribuição de energia elétrica e comprovam, através da estimação dos erros de previsão, que seu desempenho foi bem superior ao modelo anteriormente empregado.

Rahman e Hazim (1993) fizeram previsão de demanda de energia elétrica no curto prazo, utilizando uma abordagem que faz uso de bases de conhecimentos de condições climáticas, carga e técnicas estatísticas. Os autores classificaram as técnicas usadas para previsão no curto prazo em duas categorias; técnicas estatísticas e técnicas baseadas em sistemas inteligentes. Descreveram a primeira categoria como aquela que exige atualização frente às mudanças das condições climáticas ao longo das estações e a segunda como aquela que melhor responde a essas mudanças. Eles também citaram redes neurais artificiais como uma técnica de grande interesse para previsão de demanda de energia elétrica no curto prazo, mas de difícil atualização e de re-treinamento oneroso. Os autores também indicaram que a relação entre demanda de energia e condições climáticas é o parâmetro mais importante para previsão de demanda no curto prazo. Os resultados que eles obtiveram, para 24 passos à frente, estão entre um MAPE (Mean Absolute Percentage Error) de 1,22\% e 2,7\% para todas as estações do ano.

Charytoniuk e Chen (2000) desenvolveram um método de previsão no curtíssimo prazo para ser utilizado num sistema de gerenciamento de energia de uma empresa americana. Segundo seu trabalho, quando empregadas redes neurais artificiais na solução deste tipo de problema, são apresentadas informações de tempo, carga e dados meteorológicos para se estimar a demanda futura. Seu trabalho reduziu as entradas das redes neurais artificiais apenas para o que eles chamaram de incremento relativo de previsão, que consiste na diferença entre duas medidas consecutivas dividido pela primeira delas. Esse método foi implementado para 
permitir um melhor controle da carga-frequência e tornar as funções de distribuição mais econômicas. Os autores classificam a previsão de demanda de energia no curtíssimo prazo, ou seja, de alguns minutos a vários minutos à frente, como necessária para determinar a melhor estratégia para utilização de recursos e de grande importância no mercado desregulamentado de energia. Em função dos resultados obtidos, o trabalho reforça que, em se tratando de previsão de demanda de energia elétrica no curtíssimo prazo, o foco deve ser voltado para o padrão apresentado pelas últimas leituras observadas e não para a relação da demanda com fatores que a influenciariam como condições meteorológicas.

Trudnowsk et al. (2001) afirmaram que o objetivo fundamental na operação de um sistema de potência é manter o equilíbrio entre a geração e a demanda de energia, e que para atender esse objetivo é usado um sistema de controle integral denominado Controle de Geração Automático. Os autores afirmaram que esse sistema funciona atualizando periodicamente o ponto de ajuste de potência de geradores usando exemplos de carga e de frequiências elétricas, e que para aumentar o desempenho, o AGC se utiliza de algoritmos que requerem estimativas futuras da carga do sistema, com uma frequiência de 1 a 10 minutos, ou seja, previsão no curtíssimo prazo. A abordagem de Trudnowsk et al. (2001) empregou estimadores de Kalman para a previsão com freqüência de 5 minutos e horizonte de duas horas com considerável precisão e baixa sensibilidade.

O trabalho de Carmona et al. (2002) afirma que previsão de demanda de energia elétrica é estrategicamente fundamental para empresas que trabalham com produção e distribuição, diferenciando previsão de demanda de energia elétrica no curto e no longo prazo. Os autores descreveram a primeira como aquela que prevê num horizonte de algumas horas, dias ou semanas e permitem que empresas que geram e distribuem energia elétrica controlem seus estoques e coordenem o fornecimento e a demanda, descrevem a segunda como aquela que trabalha com um horizonte de meses e fornece a produtores e distribuidores uma previsão 
da evolução da demanda, permitindo a definição de estratégias que aumentem a capacidade das linhas de transmissão e a construção de usinas geradoras e políticas para obter novos clientes. Carmona et al. (2002) também afirmaram que a previsão no curto prazo exige modelos mais robustos devido a presença de perturbações causadas por imprevistos e devido ao fato de que tal horizonte de previsão é sensível a distorções na demanda causadas pela hora do dia, o dia da semana, queda ou aumento da temperatura, dentre outros fenômenos climáticos, enquanto a previsão no longo prazo trabalha com dados que raramente apresentam distorções e apresentam picos e vales diluídos, portanto, sua influência é pequena. Depois dessa introdução, Carmona et al. (2002) desenvolveram um modelo de previsão no longo prazo com o uso de redes neurais artificiais, destacando-se o pré-processamento da série para eliminação de sua tendência de crescimento, fator este frequientemente presente na previsão a longo prazo.

Senjyu et al. (2002) propõem um estudo sobre dias similares para fazer previsão de demanda no curto prazo baseado em redes neurais artificiais. Através do uso da norma Euclidiana com fatores ponderados, os autores determinam a similaridade entre o dia a ser previsto e os dias precedentes. Os autores mencionam que quanto menor a norma Euclidiana, maior a similaridade entre os dias. Determinados os 5 dias mais similares, sua média, a diferença de temperatura entre o dia a ser previsto e os dias similares, e a diferença entre a carga do dia atual e dos dias similares, são usados como entrada para as redes neurais artificiais. Os autores conseguiram um MAPE de 1,18\% com o método elaborado.

Cottet e Smith (2003) propuseram um modelo regressivo de equações múltiplas, com um vetor auto-regressivo estacionário diagonal de primeira ordem, para previsão de carga de energia elétrica com frequiência de meia hora. Os autores analisam a estrutura de correlação dos distúrbios do vetor auto-regressivo e do subconjunto de regressores usando a metodologia de seleção Modelo Bayesiano. Cottet e Smith (2003) afirmaram que modelar e prever carga 
elétrica que ocorrem durante o curso de um dia é uma atividade chave na indústria de eletricidade. Eles também mencionaram que sistemas de gerenciamento de potência necessitam de previsões com freqüência de cinco minutos a uma semana para assegurar estabilidade e que os equipamentos precisam de previsões de longo prazo para programas de manutenção e planejamento de investimentos. Cottet e Smith (2003) citaram que na Inglaterra, por exemplo, o regulador do mercado de energia penaliza os participantes que não fazem uma previsão precisa. O MAPE médio do trabalho de Cottet e Smith (2003) variou de $2,27 \%$ a $4,53 \%$.

Taylor (2003), para realizar previsão no curtíssimo e no curto prazo, estendeu a formulação exponencial de Holt-Winters para acomodar duas sazonalidades e corrigiu a autocorrelação residual usando um modelo auto-regressivo simples. O autor afirma que a previsão de demanda de energia elétrica, de minutos a dias à frente, é necessária para o controle e programação de sistemas elétricos de potência e cita a National Grid, empresa responsável pela transmissão de eletricidade na Inglaterra e País de Gales, como aquela que executa previsões online baseadas em medidas coletadas com frequiência de 30 minutos. Ele também afirma que a formulação Holt-Winters é uma abordagem popular para previsão de séries temporais sazonais e que, a robustez e precisão dos métodos de alisamento exponencial, têm conduzido para sua extensa aplicação na previsão online de demanda de eletricidade. $\mathrm{O}$ trabalho de Taylor (2003) também descreve como o modelo ARIMA (Auto Regressive Integrated Moving Average) foi adaptado para tratar múltiplas sazonalidades em séries de demanda. Taylor (2003) apresenta os gráficos do MAPE para os métodos utilizados e conclui que seus resultados ficaram muito próximos, com um desempenho levemente melhor para o método desenvolvido por ele.

Karayiannis et al. (2003) compararam o uso de redes neurais feedforward e redes neurais de base radial para previsão de demanda de energia elétrica no curto prazo. Ambas as 
redes neurais foram treinadas com medidas passadas de demanda e de dados meteorológicos. Os autores afirmaram que previsão de demanda de energia elétrica é de grande importância para empresas de geração e distribuição nos seguintes aspectos: distribuição econômica das unidades geradoras, intercâmbio de energia entre empresas, programação da produção que pode resultar em economia para consumidores, redução do consumo de energia e diminuição da poluição. Karayiannis et al. (2003) lembraram que previsão de demanda de energia elétrica foi umas das primeiras aplicações de redes neurais artificiais e afirmaram que a maioria dos sistemas de previsão de demanda é baseado em redes neurais feedfoward de gradiente descendente. Eles também mencionaram em seu trabalho que obtiveram melhores resultados na previsão da diferença na demanda entre dias consecutivos e não na previsão dos valores absolutos de demanda, utilizando-se então a primeira abordagem. Os resultados de Karayiannis et al. (2003) demonstraram desempenho semelhante durante o treinamento para os dois modelos de redes neurais artificiais, mas identificaram melhor generalização por parte das redes neurais de base radial.

Topalli e Erkmen (2003) utilizaram redes neurais recorrentes e agrupamento para fazer previsão de demanda de energia elétrica no curto prazo. A rede neural proposta apresenta recorrência da saída para a camada escondida e da saída da camada escondida para a camada de entrada. No trabalho de Topalli e Erkmen (2003) o agrupamento se dá no sentido de que para cada hora do dia é utilizada uma rede neural diferente, treinada com dados de entrada específicas daquela hora do dia. Para Topalli e Erkmen (2003) preverem a demanda um dia à frente para uma hora do dia específica, eles utilizaram como entrada a demanda daquela hora, do dia presente e dos dois dias precedentes, como também, a informação de qual dia da semana está sendo previsto. Os autores demonstram que sua abordagem tem desempenho consideravelmente melhor do que o uso de uma mesma rede neural artificial para previsão de 
todas as horas do dia e concluem que o modelo pode ser usado em aplicações para previsão em tempo real.

Khoa et al. (2004) afirmaram em seu trabalho que a previsão de demanda de energia elétrica no longo prazo se tornou o primeiro passo para o planejamento e para o desenvolvimento da geração, transmissão e distribuição de energia elétrica. Os autores apontaram as redes neurais artificiais como, particularmente, atrativas para previsão, devido a sua habilidade em tratar o relacionamento entre a carga e os fatores históricos que a afetam diretamente. Khoa et al. (2004) avaliaram três modelos de redes neurais em seu trabalho: Functional Link Networks, Multi-Layer Perceptron e Wavelet Networks. Eles apontaram que os resultados dos testes se mostraram satisfatórios, pois seu trabalho apresentou erro percentual médio de 3\%. Como conclusão, o trabalho de Khoa et al. (2004) indicou o uso dos três modelos de redes neurais para resolver problemas de previsões no longo prazo.

Becalli et al. (2004) combinaram a abordagem supervisionada e não supervisionada das redes neurais para previsão de demanda de energia elétrica no curto prazo. Os autores realizaram uma classificação prévia dos dados históricos de demanda durante o estágio não supervisionado, com uso dos mapas auto-organizáveis de Kohonen, e fizeram o treinamento de uma rede neural multi-layer perceptron durante o estágio supervisionado para concluir o processo de previsão. Becalli et al. (2004) também fizeram uso de informações de clima, como temperatura, umidade relativa do ar e radiação solar. O resultado obtido pela abordagem empregada pelos autores foi de um erro médio de 1,97\%, erro máximo de 3,81\% e erro mínimo de $0,09 \%$. Baseados nisso, os autores classificaram as redes neurais artificiais como um instrumento útil para previsão de demanda de energia elétrica no curto prazo.

Já Mandal et al. (2004) utilizaram o método elaborado por eles e descrito em Senjyu et al. (2002), citado anteriormente, para determinar a similaridade entre dias, a fim de se fazer previsão de demanda de energia elétrica. Nesse novo trabalho os autores também consideram 
a influência de fatores climáticos, mas diferentemente do trabalho anterior, a previsão aqui analisada foi de um a seis passos à frente. Mandal et al. (2004) também fizeram uso de redes neurais artificiais e justificaram seu emprego lembrando da habilidade das mesmas em se adaptar, frente à relacionamentos complexos e não-lineares. Os autores afirmaram que previsão de demanda de energia elétrica pode reduzir custos operacionais e tornar mais confiáveis operações com sistemas elétricos de potência. O trabalho de Mandal et al. (2004) apresentou um MAPE entre 0,98\%, para um passo à frente, e 2,43\% para seis passos à frente.

Saksornchai et al (2004) afirmaram que a alocação de unidades geradoras de energia elétrica depende, dentre outros fatores, da previsão de demanda no curto prazo. Os autores tomaram como exemplo uma empresa local que informou que a diferença dos custos com combustível pode chegar à casa dos milhões de dólares por dia com as diferentes alocações das unidades geradoras. Os autores mencionaram que as redes neurais artificiais podem determinar os coeficientes das relações lineares e não lineares entre a temperatura do ar e a saída de previsão de demanda. O trabalho de Saksornchai et al (2004) apresentou resultados superiores com uso de redes neurais artificiais em comparação com o método de regressão linear antes empregado na empresa onde foi aplicado o novo modelo. O MAPE dos custos caiu, em média, 0,10\%, 0,20\% e 3,29\% para os meses estudados de agosto, fevereiro e abril, respectivamente.

González e Zamarreño (2004) apresentaram uma nova abordagem para previsão de demanda de energia elétrica em edifícios. Os autores definiram um edifício inteligente como aquele que maximiza a eficiência dos serviços com custo mínimo, e citaram o sistema de gerenciamento de energia como seu componente mais importante. A abordagem de González e Zamarreño (2004) foi baseada em redes neurais artificiais recorrentes e informações de previsão de temperatura, hora do dia, dia da semana e de dados históricos de demanda de energia, pois segundo eles o uso de redes neurais artificiais é a técnica de maior sucesso para 
previsão de demanda de energia elétrica em áreas distintas, como países e edifícios. Os autores obtiveram, com essa abordagem, um MAPE médio de 1,95\% e concluíram afirmando que seus resultados foram excelentes para previsão de demanda em edifícios.

Phinphachan et al. (2004) desenvolveram um modelo baseado em redes neurais artificiais para previsão de demanda de energia elétrica no longo prazo, em que foram selecionados e empregados fatores meteorológicos e econômicos de acordo com seus coeficientes de correlação. Os autores afirmaram que previsões precisas de demanda de energia e dos picos de demanda são essenciais para um sistema de planejamento eficaz, incluindo a determinação da capacidade de geração, transmissão e distribuição de energia elétrica. O modelo de Phinphachan (2004) apresentou desempenho superior quando comparado a um modelo de regressão linear múltipla, com MAPE entre 3,6\% e 8,66\% para previsão de demanda, e MAPE entre $0,20 \%$ e $5,12 \%$ para previsão do pico de demanda. A conclusão dos autores é de que seu modelo é apropriado para seleção de variáveis de entrada e algoritmo de treinamento, e também apresenta curto tempo de treinamento.

Segundo Kawauchi et al. (2004), os centros de distribuição procuram minimizar as flutuações entre demanda e fornecimento ajustando continuamente a geração de energia elétrica. Para Kawauchi et al. (2004), previsões precisas de demanda de energia elétrica no curtíssimo prazo são indispensáveis para evitar distúrbios nesses centros de distribuição. Seu trabalho apresentou um método, baseado na teoria do caos, para previsão de passos de 30 segundos e horizonte de 10 minutos. Kawauchi et al. (2004) apresentaram gráficos ilustrando os erros obtidos e concluíram afirmando que seu trabalho apresentou bons resultados para previsão de vários passos à frente.

Hippert et al. (2005) compararam inúmeros métodos de previsão de demanda de energia elétrica no curto prazo, com o intuito de identificar overfitting em redes neurais artificiais. Os métodos utilizados no trabalho foram: métodos naïve, métodos baseados em 
apenas um tipo de filtro de alisamento, métodos baseados na combinação de dois filtros de alisamento, métodos baseados em filtros de alisamento com regressão linear, métodos baseados na combinação de filtros de alisamento com redes neurais artificiais e apenas redes neurais artificiais. Os autores compararam os erros produzidos, no que se refere a sua média e propagação, e identificaram que o desempenho das redes neurais artificiais foi superior aos outros métodos. Hippert et al. (2005) concluíram afirmando que a questão de uma rede neural sofrer de overfitting ou não, é difícil de ser respondida.

Pai e Hong (2005) afirmaram que, com a desregulamentação na indústria de eletricidade, a previsão precisa de demanda de energia elétrica passou a ter papel importante na área de investimentos em sistemas de distribuição, planejamento de fornecimento de energia e estratégias de gerenciamento em sistemas regionais e nacionais. Os autores afirmaram também, que a superestimação de demanda futura resulta em uma reserva girante desnecessária e excesso de suprimento e, que por outro lado, subestimação de demanda futura pode causar falhas no fornecimento de energia. Para tratar o problema de previsão de demanda de energia elétrica no longo prazo, os autores aplicaram Support Vector Machines e algoritmos genéticos para determinar o ajuste dos pesos entre os nós de uma rede neural recorrente do tipo Jordan. O MAPE encontrado pela abordagem de Pai e Hong (2005) ficou entre $0,75 \%$ e $1,90 \%$.

O trabalho de Cavallaro (2005) baseou-se no uso de redes neurais artificiais para previsão de demanda de energia elétrica no curto prazo. O autor justificou seu trabalho afirmando que previsão de demanda de energia elétrica é de crucial importância para o mercado desregulamentado atual e tem o propósito de otimizar e racionalizar o fornecimento de energia. Ele lembrou que energia elétrica é um produto que não pode ser estocado e que, portanto, balancear seu fornecimento e demanda é fundamental. Cavallaro (2005) apresentou os diferentes tipos de consumidores de energia elétrica, isto é usuários domésticos, indústrias 
e empresas prestadoras de serviço público, e atribuiu aos usuários domésticos a maior parcela do consumo de energia elétrica. Ele classificou os principais fatores que devem ser considerados no que se refere ao consumo de energia elétrica em: fatores temporais (estações do ano, hora do dia, dia da semana, feriados, etc), fatores econômicos (recessão ou expansão, mudanças no preço da eletricidade, etc), fatores meteorológicos (temperatura, umidade, etc) e eventos ocasionais (eventos esportivos, programas de televisão populares, etc). Também apresentou, de acordo com o período de previsão, as diferentes classificações para previsão de demanda de energia elétrica, ou seja, previsão no curtíssimo prazo, no curto prazo, no médio prazo e no longo prazo. Depois de todas essas informações, o trabalho de Cavallaro (2005) descreveu o uso de uma rede neural perceptron multicamadas, com algoritmo de aprendizado backpropagation, para previsão da demanda de energia elétrica no curto prazo para a rede elétrica de uma ilha italiana. Os resultados obtidos por ele, para 24 passos à frente, foram um RMS (Root Mean Squared Error) de 2,0\% para o treinamento e de 2,6\% para os testes.

Yao et al. (2006) combinaram o uso de redes neurais artificiais RBF, com regressão multipla linear (MLR), com o modelo auto-regressivo integrado de médias móveis (ARIMA) e com o modelo Grey (GM) para previsão de demanda de energia elétrica no curto prazo. Os autores afirmaram que seu objetivo é apresentar uma abordagem que tenha desempenho superior ao modelo baseado apenas em redes neurais RBF, ou baseado em redes neurais RBF combinadas com um modelo simples de correção. Yao et al. (2006) apresentaram um estudo de caso para avaliar seu novo modelo. Eles utilizaram informações de tempo (hora do dia) e informações climáticas (temperatura, humidade e intensidade solar) para prever o consumo de energia elétrica em um sistema de ar condicionado. Segundo Yao et al. (2006), a partir de seu trabalho, pode-se concluir que a precisão na previsão de demanda de energia elétrica com redes neurais RBF aumenta quando combinada com a correção de erros residuais. 
Mizutani et al. (2005) propôs um método de otimização, baseado na razão ponderada de dados meteorológicos de algumas regiões, o qual é determinado através do uso do algoritmo de busca dispersa. Os autores encontraram os índices que apresentaram melhor coeficiente de correlação entre as médias das temperaturas máximas e uma função quadrática determinada. Mizutani et al. (2005) apresentaram então para uma rede neural informações de histórico dos picos diários de demanda de energia elétrica, razão ponderada dos valores máximos e mínimos de temperatura das diferentes regiões, umidade mínima do ar e uma flag indicando se é dia útil ou final de semana, e fizeram a previsão de demanda de energia elétrica no curto prazo. O método proposto pelos autores apresentou desempenho bem superior quando comparado ao método empregado por uma concessionária de energia elétrica japonesa que cobre diferentes regiões.

Karayiannis et al. (2005) compararam o uso de redes neurais artificiais feedforward e redes neurais de base radial para previsão de demanda de energia elétrica no curto prazo. Os autores afirmaram que o aperfeiçoamento da previsão de demanda de energia elétrica se tornou mais importante após a desregulamentação do mercado, pois introduziu varejistas que não estão envolvidos com a produção de energia, forçando as concessionárias a trabalhar com a maior eficiência possível. Segundo os autores, a previsão de demanda de energia elétrica depende de vários fatores como temperatura, sazonalidade, ondas de calor, frentes frias e feriados. Assim, Karayiannis et al. (2005) treinaram as redes neurais com a diferença das medidas de demanda de energia elétrica entre dias consecutivos e com as condições climáticas desses dias, como temperatura e umidade. Baseado nos resultados obtidos, Karayiannis et al. (2005) concluíram que, para essa aplicação em particular, a rede neural de base radial possui melhor capacidade de aprendizado e generalização.

Yang et al. (2006) empregaram um sistema neural fuzzy para previsão de demanda de energia elétrica no curtíssimo prazo. Segundo eles, esse tipo de previsão pode ajudar num 
melhor planejamento de estratégias de controle de freqüência de carga, sendo a mesma indispensável a fim de evitar distúrbios indesejáveis no sistema. Yang et al. (2006) afirmaram que, embora previsão de demanda de energia elétrica receber atenção crescente, poucos trabalhos estudaram previsão de demanda de energia elétrica no curtíssimo prazo. A partir disso, os autores desenvolveram um novo framework onde técnicas de reconstrução dinâmica são empregadas para determinar o melhor sistema neural fuzzy a fim de tratar o problema. Yang et al. (2006) obtiveram um MAPE médio de 0,88\% para previsões com freqüência de quinze minutos e horizonte de um dia, e um MAPE de $0,89 \%$ com essa freqüência, mas com horizonte de duas semanas. Os resultados demonstraram que a abordagem proposta pode tratar previsão com freqüência de quinze minutos com bom desempenho.

Ghiassi et al. (2006) fizeram uso de um modelo de rede neural artificial dinâmica para previsão de demanda de energia elétrica no médio prazo. Segundo os autores, previsão de demanda de energia elétrica no médio prazo é importante, pois fornece informações úteis para o planejamento e para as operações em sistemas de potência, e oferece benefícios significativos para as empresas que operam no mercado regulamentado ou desregulamentado. Dentre os benefícios citados por Ghiassi et al. (2006), estão os seguintes: o melhor planejamento da expansão de geração de energia elétrica, o uso de melhores estratégias em atividades de manutenção, a realização de melhorias no sistema, uma melhor negociação em contratos antecipados e o desenvolvimento de estratégias para compra de combustível com menor custo. A rede neural artificial utilizada por Ghiassi et al. (2006) é composta por camadas intermediárias, geradas dinamicamente, até que um nível de precisão seja obtido, ou seja, a seleção da melhor arquitetura acontece durante o treinamento. Agora, para determinação da melhor formação de entrada, Ghiassi et al. (2006) fizeram uso de ferramentos estatísticas de pré-processamento dos dados e efetuaram a análise da autocorrelação e da autocorrelação parcial entre as medidas. O trabalho de Ghiassi et al. 
(2006) também apresentou comparações entre o uso ou não de dados meteorológicos e também comparações entre a rede neural artificial proposta, redes neurais perceptron multicamadas, regressão e modelo ARIMA. Os resultados demonstraram que a rede neural proposta apresentou melhor desempenho e foi eficiente, pois seu MAPE médio ficou abaixo de $1 \%$.

Findlay e Liu (2006) empregaram redes neurais artificiais na previsão de demanda de energia elétrica no curto prazo. Os autores aplicaram o algoritmo de treinamento LevenbergMarquardt, devido a sua robustez e rápida convergência, e utilizaram inspeção visual e técnicas estatísticas para validar o modelo. Segundo Findlay and Liu (2006), uma precisa e confiável previsão de demanda no curto prazo é um aspecto importante no gerenciamento de sistemas de potência, pois previsões imprecisas podem causar sérios distúrbios nas operações. Os autores concluíram afirmando que os resultados obtidos são aceitáveis na prática.

Romera et al (2006) dividiram a previsão de demanda de energia elétrica no médio prazo em duas etapas complementares: previsão de tendência e previsão de flutuação da série temporal. Segundo os autores, previsão de demanda de energia elétrica é uma ferramenta interessante para planejamento em sistemas elétricos de potência, principalmente para operação e planejamento de manutenções e para avaliação da capacidade da rede. Romera et al (2006) também afirmaram que, com a desregulamentação do mercado de energia elétrica implantada em muitos países, esta também se tornou uma ferramenta interessante para os agentes que exercem atividades de compra e venda, tais como produtores e revendedores. Romera et al (2006), através do uso de alisamento, extraíram tendência e flutuação de uma série temporal de demanda mensal de energia elétrica espanhola e aplicaram redes neurais para previsão de cada uma delas em separado. Seus resultados indicaram que, dessa forma, a previsão da demanda de energia elétrica possui desempenho superior ao modelo ARIMA ou àquele que emprega uma rede neural para previsão da demanda como um todo. 
Já Nahi (2006) aplicou redes neuro-fuzzy para previsão de demanda de energia elétrica no curto prazo para dias especiais ou feriados. Segundo o autor, a presença de condições especiais como feriados, mudança nas operações e mudanças nos hábitos dos consumidores, para diminuir os custos com energia, afetam a previsão de demanda e, portanto, uma precisa previsão em tais dias tem como conseqüência grande economia na produção de energia elétrica. Nahi (2006) apresentou gráficos que ilustram o comportamento diário da demanda de energia elétrica em subestações, influenciados pela hora do dia, como também, gráficos que ilustram o comportamento anual da demanda influenciada pelas estações do ano. O autor também traçou gráficos da demanda de energia elétrica em dias especiais e feriados, comparando com a previsão obtida por seu método.

Yap et al. (2006) combinaram uma nova rede neural híbrida, conhecida como Gaussian Regression, com dynamic decay (GRD), para previsão de demanda de energia elétrica no curto prazo. Segundo os autores, a previsão de demanda de energia elétrica no curto prazo é muito importante em redes elétricas de potência do ponto de vista de operação, pois previsões precisas beneficiariam as provedoras de energia em termos de segurança e estabilidade da rede, assegurando-se fornecimento adequado para a demanda de energia. Yap et al. (2006) descrevem a rede neural Gaussian Regression como uma combinação de duas redes neurais, que são a Gaussian Adaptive Resonance Theory (GA) e a Generalized Regression Neural Network (GRNN), a qual resulta em uma rede neural com capacidade de treinamento incremental e ajuste dos pesos em tempo real para solução de problemas de regressão. Os autores obtiveram como resultado um MAPE de 1,2\% para previsão de 30 minutos à frente e um MAPE médio de 1,65\% para previsão de um dia (24 horas) à frente.

Erdogdu (2007) apresentou uma análise interessante sobre a reação dos consumidores de energia elétrica em função das mudanças em sua renda e nas tarifas cobradas pelas concessionárias na Turquia, e comparou as projeções oficiais na demanda de energia elétrica 
para os próximos anos com as previsões resultantes do uso do modelo ARIMA. Na primeira parte da pesquisa, Erdogdu (2007) chegou à conclusão de que os consumidores não reagem rapidamente com relação ao consumo de energia elétrica, às mudanças em sua renda e nas tarifas de energia elétrica; contudo, no longo prazo, as mudanças no consumo de energia elétrica são impressionantes. $\mathrm{O}$ autor, por exemplo, afirmou que se a renda dos consumidores dobra, o consumo de energia elétrica mais do que dobra e, se o preço da tarifa de energia elétrica cai pela metade, o consumo também quase que duplica. Na segunda parte da pesquisa, o autor fez uma projeção do consumo de energia elétrica na Turkia até 2014 e os resultados demonstraram que as projeções oficiais estão superestimadas, pois, segundo o modelo ARIMA, o crescimento médio seria de 3,3\% ao ano, enquanto as projeções oficiais estimam um crescimento entre $6,3 \%$ e $8,2 \%$.

Suzuki et al. (2007) criaram modelos baseados em redes neurais artificiais para previsão de temperatura e previsão de demanda de energia elétrica no curto prazo, com diferentes configurações dos dados de entrada. Os modelos de Suzuki et al. (2007) foram projetados para fazerem parte de um controle automático de carga reativa e tensão de sistemas de gerenciamento de energia. Os autores concluem seu trabalho afirmando ser eficaz a instalação de sistemas inteligentes avançados de controle, baseados em redes neurais, a fim de se coordenar tensão e potência reativa em sistemas de potência locais e principais. Segundo eles, sistemas de potência requerem os benefícios de funções inteligentes.

Romera et al. (2007) empregaram redes neurais perceptron multicamadas, com algoritmo de aprendizado Levenber-Marquadt, para previsão de demanda de energia elétrica no longo prazo. Os autores afirmaram que previsão de demanda de energia elétrica no longo prazo é importante para planejamento de manutenções na rede e como pesquisa de mercado para os produtores e revendedores. Segundo Romera et al. (2007), para uma boa previsão de demanda de energia elétrica no curto prazo, é necessário considerar outras informações como 
temperatura, umidade, hora do dia e dia da semana, enquanto que na previsão de demanda de energia elétrica no longo prazo a influência de tais informações está diluída nos valores da série. O processo de Romera et al. (2007) para previsão consistiu em dividir a série temporal original em duas séries, uma com a tendência e outra com a flutuação, e empregar redes neurais para previsão de cada uma delas em separado. De acordo com os autores, esse processo é muito interessante para as companhias de energia elétrica, pois, dessa forma, o comportamento do mercado é apresentado com clareza e sua evolução ajudará as empresas de produção e de distribuição a planejar suas estratégias visando adaptar sua oferta às necessidade do mercado. O MAPE médio obtido por Romera et al. (2007) em seu trabalho foi de aproximadamente $2 \%$.

Campbell (2007) apresentou um estudo comparativo entre diferentes sistemas inteligentes, tais como, redes neurais perceptron multicamadas, redes neurais parcialmente recorrentes, redes neurais de base radial, sistemas de inferência fuzzy e sistema adaptativo neuro-fuzzy, para previsão de demanda de energia elétrica no curto prazo. Segundo o autor, previsão de demanda de energia elétrica é elemento crítico para operação de um sistema elétrico de potência, pois serve como base para o planejamento do fornecimento e da demanda. Campbell (2007) também afirma que previsão de demanda permite o planejamento nas instalações de transmissão e distribuição, assim como a construção de novas instalações. $\mathrm{O}$ autor atentou para o fato de que um desafio para o desenvolvimento de um modelo apropriado para previsão de demanda de energia elétrica no curto prazo depende de uma eficiente identificação de variáveis de entrada, a qual depende de experiência e é obtida quase que inteiramente por meio de tentativa e erro, ou através do auxílio de análises estatísticas. Campbell (2007), baseado em seus resultados, afirmou que o sistema adaptativo neuro-fuzzy e as redes neurais de base radial foram mais precisas e efetivas quando comparadas com redes neurais perceptron multicamadas, redes neurais parcialmente recorrentes e sistemas fuzzy. 
Abdel-Aal (2007) comparou abductive networks e redes neurais artificiais para previsão de demanda de energia elétrica no médio prazo. Segundo o autor, a demanda de energia elétrica muda com o tempo, clima, variáveis sócio-econômicas e mudanças demográficas e, no médio prazo, sua previsão é importante para a compra de combustíveis e para a revisão das tarifas de energia elétrica. Abdel-Aal (2007) afirmou que o uso apenas da série temporal de demanda, tem provado maior precisão do que o uso de outras variáveis na previsão mensal do consumo de energia na Arábia Saudita e que, além disso, usando-se apenas a série temporal de demanda pode-se reduzir as dimensões do problema, o que pode aprimorar a generalização e o desempenho da previsão. Abdel-Aal (2007) menciona que apesar do extenso uso de redes neurais artificiais, essa técnica sofre algumas limitações como, por exemplo, a dificuldade em se determinar uma topologia ótima para a rede e para os parâmetros de treinamento. O trabalho de Abdel-Aal (2007) apresentou duas abordagens para cada um dos dois paradigmas mencionados: na primeira, foi aplicado o uso iterativo de um modelo singular para previsão de demanda um mês à frente por doze vezes e, no segundo, foram aplicados doze modelos dedicados, cada um para previsão de demanda de um determinado mês ao longo de um ano. Os resultados obtidos demonstraram que a primeira abordagem foi mais eficiente tanto para as abductive networks como para as redes neurais artificiais, cujos MAPE foram de 3,2\% e 3,8\%, respectivamente.

Alsayegh et al. (2007) investigaram alguns fatores sócio-econômicos que influenciam no comportamento da demanda de energia elétrica no longo prazo no Kuwait, como população, número de famílias, número de edifícios, produto interno bruto, atividades industriais, mudança nas tarifas e a importação de equipamentos de ar-condicionado. Os autores descobriram o forte impacto na demanda de energia elétrica motivado pela utilização de equipamentos de ar-condicionado durante o verão e identificaram a influência do aumento do seu uso no crescimento da demanda de energia elétrica no longo prazo nesse país. O 
processo de previsão de Alsayegh et al. (2007) foi baseado em redes neurais artificiais e seus resultados indicaram que um aumento de $1 \%$ acima do crescimento normal na importação desses equipamentos leva a um aumento de 1,1\% acima do crescimento esperado na demanda por energia elétrica. Outro resultado interessante de Alsayegh et al. (2007) foi que um aumento de $1 \%$ acima do esperado no número de construções leva a uma aumento de $0,5 \%$ acima do crescimento esperado na demanda de energia elétrica. Ainda, segundo Alsayegh et al. (2007), a tendência crescente de construção de edifícios verticais é um dos fatores que influenciam o crescimento no consumo de energia elétrica.

Methaprayoonn et al. (2007) utilizaram redes neurais artificiais para previsão de demanda de energia elétrica no curto prazo. Segundo os autores, uma porção significativa nos custos operacionais das fornecedoras de serviços resulta da produção de energia. Methaprayoonn et al. (2007) afirmaram então que, para minimizar o custo, deve ser utilizada uma programação adequada para determinar a melhor alocação de unidades geradoras de energia. Portanto, a previsão de demanda de energia elétrica é pré-requisito para a organização das mesmas. Os autores também afirmaram que as prestadoras de serviço precisam preparar recursos suficientes para transmissão e geração de energia a fim de atender a flutuação na demanda, e que isso deve ser feito concorrentemente com análises econômicas para aperfeiçoar os custos operacionais. Segundo Methaprayoonn et al. (2007), desde que a operação e controle de sistemas elétricos de potência é sensível à demanda, muita economia pode ser obtida a partir do aumento da precisão na previsão de demanda de energia elétrica. As informações de entrada para as redes neurais artificiais do trabalho de Methaprayoonn et al. (2007) foram o tempo, temperatura e o histórico da demanda. Eles também fizeram uma análise do impacto que o erro na previsão de temperatura pode causar na previsão da demanda de energia elétrica, e para contornar esse problema, propuseram o uso de fontes diversas de previsão da temperatura para minimizar o problema. Com o uso de apenas uma fonte de 
previsão de temperatura, os resultados de Methaprayoonn et al. (2007) foram de um MAPE de $3 \%$ para previsão de uma hora à frente e de $8 \%$ para previsão de um dia à frente. Agora, com o uso de fontes diversas de previsão de temperatura, o MAPE para previsão de uma hora à frente foi de $1,09 \%$ e para de um dia à frente foi de $2,81 \%$.

O trabalho de Haydari et al. (2007) aplicou o Sistema Neuro-Fuzzy Adaptativo (ANFIS) para previsão de demanda de energia elétrica no longo prazo. Segundo os autores, demanda de energia elétrica é uma série temporal e a metodologia proposta por eles se utiliza desse fato. Os autores afirmaram que o ANFIS mostrou boa capacidade para previsão de séries temporais e, portanto, pode ser aplicado na previsão de demanda de energia elétrica no longo prazo. Além disso, os resultados simulados demonstraram que modelagem de séries temporais e estimação inteligente podem ajudar a se obter uma previsão de demanda de energia elétrica mais precisa.

Romera et al. (2008) extraíram tendência e flutuação da série temporal de demanda de energia elétrica no médio prazo e aplicaram dois métodos distintos no processo de previsão para cada uma delas. Para a previsão da flutuação, os autores aplicaram séries de Fourier e, para previsão de tendência, eles empregaram redes neurais artificiais. Segundo os autores, demanda de energia elétrica é altamente influenciada por fatores sociais e meteorológicos. Contudo, previsão de demanda no médio prazo trabalha com dados mensais e a influência dos fatores mencionados está diluída no valor geral que representa o montante mensal de consumo da mesma. Portanto, o trabalho de Romera et al. (2008) utilizou apenas os dados passados de demanda para obter sua previsão. Os autores apresentaram o MAPE obtido através de outras abordagens para confirmar o bom desempenho no uso das Séries de Fourier. Segundo eles, o uso de redes neurais artificiais na previsão da demanda sem extração de tendência e flutuação apresentou um MAPE de 2,11\%, o uso de redes neurais artificiais para previsão da flutuação e da tendência apresentou um MAPE de 1,95\% e o uso do modelo 
ARIMA para previsão apresentou um MAPE de 4,19\%, enquanto que na sua nova abordagem o MAPE foi de $1,74 \%$. Portanto, o uso das Séries de Fourier, na previsão da flutuação da demanda de energia elétrica, proporcionou um melhor resultado do que aquele obtido com uso de redes neurais artificiais ou com uso do modelo ARIMA.

Tripathi et al. (2008) aplicaram redes neurais GRNN (Generalized Regression Neural Network) e PNN (Probabilistic Neural Network) para previsão de demanda de energia elétrica no curto prazo. Segundo eles, previsão de demanda de energia elétrica adquiriu importante papel para operação econômica e segura de sistemas elétricos de potência. Os autores afirmaram que com uma previsão precisa da demanda, se pode operar no mercado de maneira econômica, sendo que as provedoras do serviço podem otimizar seus recursos de forma mais eficiente. Seu trabalho empregou como entradas para ambas as redes neurais, os indicadores de hora e dia, temperatura e preço, pois os autores asseguraram que estas variáveis são as que mais afetam a previsão e que existe uma forte correlação entre estas e a demanda. O MAPE obtido foi de 2,34\% e 2,96\% com uso da GRNN e PNN, respectivamente. Os autores ainda comparam seu resultado com aqueles obtidos em pesquisas anteriores e asseguraram que a abordagem com redes neurais GRNN é melhor do que todos esses métodos.

O trabalho de Soares e Medeiros (2008) teve como objetivo descrever um modelo de previsão de demanda de energia elétrica no curto prazo. Seu modelo é construído para cada hora do dia separadamente e é baseado na decomposição das séries diárias de carga em duas componentes. A primeira componente de Soares e Medeiros (2008) é puramente determinística e é utilizada para obter tendência, sazonalidade e a influência de dias especiais. Sua segunda componente é estocástica e segue um modelo linear, podendo ser um modelo auto-regressivo (AR) ou redes neurais artificiais. Os autores afirmaram que sua metodologia é simples e pode ser utilizada de forma eficiente em tempo real para previsões de demanda online. Os autores também afirmaram que, para se fazer comparação entre modelos diferentes, 
estes devem se aplicados nas mesmas séries temporais de carga, pois estas têm comportamentos diferentes quando medidas em subestações do Brasil, ou de países como os EUA. Em seu trabalho, os autores utilizaram como referência o Modelo Integrado Autoregressivo de Médias Móveis Sazonal (SARIMA) para efeito de comparação. Os resultados obtidos por Soares e Medeiros (2008) foram de um MAPE entre 2,86\% e 3,56\%, enquanto o modelo SARIMA apresentou um MAPE entre 5,04\% e 15,72\%.

Bashir e Hawary (2009) demonstraram a habilidade de um método de inteligência artificial para previsão de demanda de energia elétrica no curto prazo. Seu método aplicou três promissoras técnicas (Wavelets, Redes Neurais e PSO) que combinadas resultaram em melhora de capacidade de previsão. Segundo os autores, a previsão de demanda de energia elétrica no curto prazo tem impacto significativo na eficiência da operação das provedoras do serviço, pois muitas decisões operacionais como programação da geração, gerenciamento da carga e avaliação da segurança do sistema são baseadas em tais previsões. Os autores afirmaram que existe uma forte correlação entre o comportamento do consumo de eletricidade e variáveis meteorológicas como temperatura, cobertura das nuvens, velocidade do vento e umidade. Por isso, eles apresentaram dados meteorológicos para a rede neural, combinado com dados históricos de carga, a fim de se prever demanda futura. Bashir e Hawary (2009) também apresentaram aspectos diversos dos seus experimentos, variando-se os dados meteorológicos a serem apresentados para a rede neural, ou dividindo-os de acordo com as estações do ano, e a fim de tabular o MAPE obtido em cada caso. O trabalho de Bashir e Hawary (2009) apresentou um MAPE de $2 \%$ com uso de carga, temperatura e umidade como entradas para sua rede neural.

Xiao et al. (2009) apresentaram uma técnica baseada em redes neurais backpropagation com conjuntos aproximativos para previsão de demanda de energia elétrica no curto prazo. Segundo os autores, o tipo de previsão mencionado tem papel importante no 
gerenciamento de sistemas elétricos de potência de países e regiões onde a energia elétrica é insuficiente devido sua necessidade crescente. Eles ainda afirmaram que previsão de demanda tem como objetivo o melhor uso da energia elétrica e a atenuação do conflito entre fornecimento e consumo, como também, é crucial para o planejamento operacional de sistemas elétricos de potência. Xiao et al. (2009) adicionaram uma camada de préprocessamento com conjuntos aproximativos à estrutura das redes neurais para filtrar os ruídos e dados com interdependência fraca, a fim de melhorar seu desempenho, ou seja, a influência causada pelo ruído e por dados redundantes é eliminada. Os autores concluem atestando a superioridade da sua abordagem frente às redes neurais com treinamento backpropagation.

Mamlook et al. (2009) utilizaram lógica fuzzy para elaborar o controle de um sistema elétrico de potência que fosse mais eficiente do que o controle convencional, baseado em técnicas de modelagem estatística, para previsão de demanda de energia elétrica no curto prazo. Segundo os autores, previsão de demanda é um elemento importante para operação econômica e eficiente, assim como para o controle efetivo de sistemas elétricos de potência, e uma previsão precisa é necessária para se evitar alto custo de geração e de reserva girante. Os autores também afirmaram que a subestimação da demanda leva para uma insuficiente preparação de capacidade de reserva, ameaçando a estabilidade do sistema. Por outro lado, a superestimação da demanda leva a uma reserva desnecessária e que gera um alto custo. Como resultado do trabalho de Mamlook et al. (2009), o sistema convencional utilizado para previsão de demanda foi substituído por um modelo baseado em lógica fuzzy que utiliza dados meteorológicos para aprimorar os sistemas de potência. O MAPE apresentado pelo modelo convencional ficou entre $2 \%$ e 7,6\%, e o MAPE do seu modelo baseado em lógica fuzzy ficou entre $1,2 \%$ e $3,2 \%$. 
Amjady e Keynia (2009) propuseram um método híbrido para previsão de demanda de energia elétrica no curto prazo, composto de transformada wavelet, redes neurais artificiais e algoritmos evolutivos. Segundo os autores, a transformada wavelet é empregada na decomposição da série original em quatro componentes, sendo que a previsão de cada componente é realizada através da combinação de redes neurais e algoritmos evolutivos e, através da inversa da transformada wavelet, a previsão da demanda é obtida. Os autores afirmaram que previsão de demanda de energia elétrica no curto prazo sempre foi assunto chave para sistemas elétricos de potência. Segundo eles, muitas decisões operacionais são baseadas na previsão de demanda no curto prazo, como por exemplo, planejamento da distribuição da capacidade de geração, avaliação da segurança e planejamento de manutenções dos geradores. Amjady e Keynia (2009) também afirmaram que com a desregulamentação e livre competição na indústria de energia, previsão de demanda se tornou importante como nunca, pois esta tem importância vital nas transações em mercados de energia competitivos. Ainda segundo Amjady e Keynia (2009), seu modelo apresentou desempenho superior quando comparado a modelos anteriores e o MAPE obtido por eles ficou entre $0,61 \%$ e 0,94\% para uma hora à frente, e 1,41\% e 2,56\% para seis horas à frente.

\subsection{Trabalhos Publicados em Eventos Científicos}

Os seguintes trabalhos relacionados a essa dissertação foram publicados em anais de congressos científicos:

- ANDRADE, L. C. M.; SILVA, I. N., Very Short-Term Load Forecasting Based on ARIMA Model and Intelligent Systems. In: The 15th International Conference on Intelligent System Applications to Power Systems, ISAP 2009, 2009, Curitiba, Brazil. Proceedings of the 15th International Conference on Intelligent System 
Applications to Power Systems. Piscataway, New Jersey : IEEE Power \& Energy Society, 2009.

- ANDRADE, L. C. M.; SILVA, I. N., Análise Comparativa Envolvendo Modelos ARIMA e Sistemas Inteligentes para Previsão de Demanda de Energia Elétrica no Curtíssimo Prazo. In: IX Congresso Brasileiro de Redes Neurais/Inteligência Computacional, 2009, Ouro Preto. Anais do IX Congresso Brasileiro de Redes Neurais/Inteligência Computacional, 2009.

- ANDRADE, L. C. M.; SILVA, I. N., Análise Comparativa de Redes Neurais Artificiais e de Sistemas Neuro-Fuzzy para Previsão de Demanda de Energia Elétrica no Curtíssimo Prazo. In: VIII Congresso Brasileiro de Dinâmica, Controle e Aplicações - DINCON`09, 2009, Bauru. Anais do VIII Congresso Brasileiro de Dinâmica, Controle e Aplicações - DINCON`09. Bauru: Divisão Técnica de Biblioteca e Documentação UNESP.

- ANDRADE, L. C. M.; FlAUZINO, R. A.; SILVA, I. N., Sistemas Fuzzy para Previsão de Demanda de Energia Elétrica no Curtíssimo Prazo. In: IX Congresso Brasileiro de Dinâmica, Controle e Aplicações - DINCON’10. Serra Negra. Anais do IX Congresso Brasileiro de Dinâmica, Controle e Aplicações - DINCON’10. Rio Claro: Divisão Técnica de Biblioteca e Documentação UNESP.

- ANDRADE, L. C. M., SILVA, I. N., Very Short-Term Load Forecasting Using a Hybrid Neuro-Fuzzy Approach. In: The 11st Brazilian Symposium on Neural Networks. SBRN 2010, 2010, São Bernardo, Brazil. Proceedings of the 11st Brazilian Symposium on Neural Networks. Los Alamitos, California: IEEE Computer Society 2010. 


\section{Aspectos de Previsão de Demanda de Energia Elétrica em Sistemas Elétricos de Potência}

\subsection{Introdução}

Nesse tópico serão apresentados alguns aspectos dos sistemas elétricos de potência (geração, transmissão e distribuição), aspectos de previsão de demanda de energia elétrica e aspectos dos sistemas inteligentes aplicados nesta, como redes neurais artificiais, sistemas fuzzy e sistemas híbridos.

\subsection{Aspectos da Constituição dos Sistemas Elétricos de Potência}

A função principal dos Sistemas Elétricos de Potência (SEP) é fornecer energia elétrica aos usuários, com qualidade apropriada, na medida em que essa for solicitada. $\mathrm{O}$ sistema tem como função transformar energia de natureza hidráulica, mecânica, térmica etc. em energia elétrica e de distribuí-la aos consumidores, a todo instante, em função de sua demanda. O sistema deve atender ao suprimento, em dado intervalo de tempo, da energia consumida e à máxima solicitação instantânea de potência ativa, uma vez que não é possível o armazenamento de energia elétrica. Portanto, deve-se ter à disposição sistemas de controle da produção de forma que em cada instante seja produzida a energia necessária a atender à demanda e às perdas de produção e de transporte (Kagan et al, 2005).

No Brasil, uma vez que existe um grande potencial hídrico, ocorre a predominância na produção de energia elétrica a partir de energia hidráulica, ou por meio de usinas hidrelétricas. O sistema também deve estar apto a transportar energia por longas distâncias, pois os centros de produção são normalmente afastados dos centros de consumo.

Devido à grande diversidade no montante de potência consumida pelos vários consumidores, é inviável o suprimento de todos os usuários na mesma tensão de transmissão. 
Portanto, ocorrem abaixamentos no nível de tensão para valores compatíveis com as características dos variados tipos de consumidores. O diagrama de blocos da Figura 2.1 apresenta as etapas desde a geração até o consumo da energia elétrica para as diversas classes de consumidores (Kagan et al, 2005).

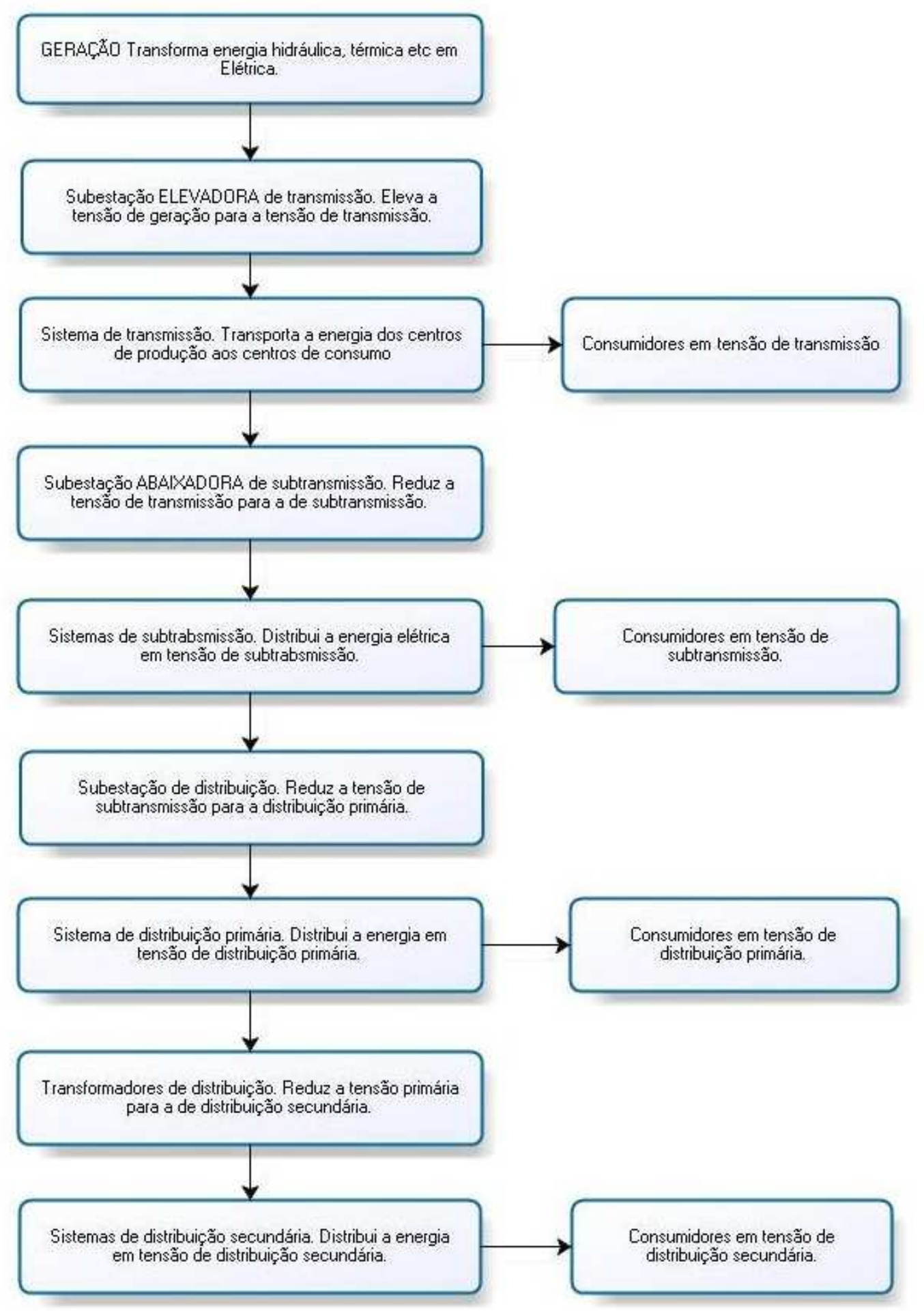

Figura 2.1 - Diagrama de blocos do sistema elétrico de potência. 
Portanto, conforme ilustrado na Figura 2.1, os sistemas elétricos de potência são divididos nos seguintes blocos:

- Geração - Converte alguma forma de energia em energia elétrica.

- Transmissão - Transporta a energia elétrica dos centros de produção para os de consumo.

- Distribuição - Distribui a energia elétrica recebida do sistema de transmissão aos grandes, médios e pequenos consumidores.

Um diagrama unifilar típico de um sistema elétrico de potência é apresentado na Figura 2.2 a seguir. Este é formado por três usinas, um conjunto de linhas de transmissão, uma rede de subtransmissão, uma de distribuição primária e três de distribuição secundária. Pode-se também observar que o sistema de transmissão opera em malha, o de subtransmissão opera radialmente, podendo também operar em malha. A forma de operação do sistema de distribuição primária é radial e o de distribuição secundária é em malha ou radial (Kagan et al, 2005).

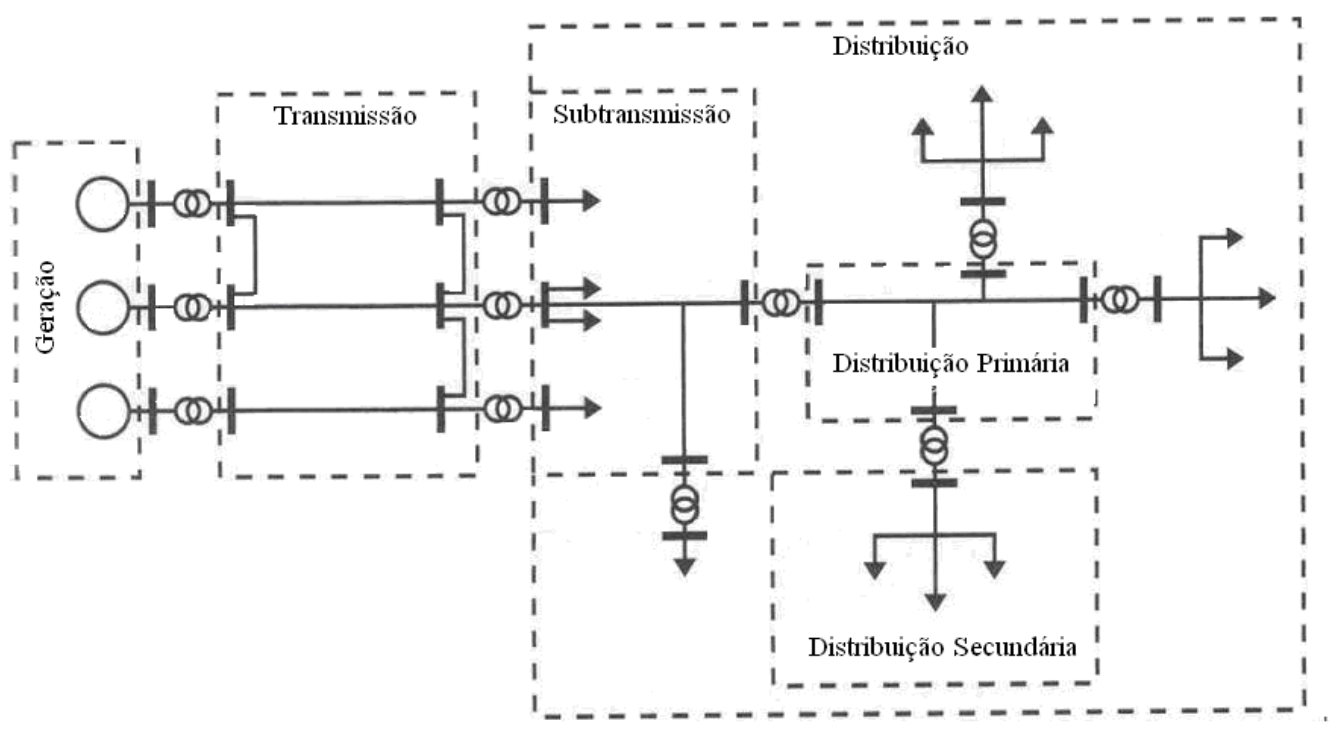

Figura 2.2 - Diagrama unifilar de um sistema elétrico de potência. 


\subsubsection{Sistema de Geração}

A geração de energia elétrica ocorre mediante diferentes tecnologias. As principais fazem uso de máquinas elétricas rotativas, geradores síncronos ou alternadores, utilizando turbinas hidráulicas, a vapor ou eólicas.

As usinas hidráulicas apresentam um tempo de construção bastante longo, com custo de investimento elevado; no entanto, seu custo operacional é extremamente baixo. Já as usinas térmicas apresentam tempo de construção e custo de investimento sensivelmente menores, mas custo operacional elevado devido ao alto custo dos combustíveis.

A disponibilidade de água com desnível, que permita a construção de barragens, leva as usinas hidráulicas para localidades que exigem, geralmente, a construção de longos sistemas de transmissão, como também, é relevante o inconveniente do alagamento de áreas férteis, perda de terrenos produtivos e possíveis modificações no clima da micro-região.

As térmicas também necessitam de água para condensação do vapor; contudo, em quantidade bem menor do que as hidráulicas, permitindo maior liberdade para sua localização. Esta característica permite redução nos investimentos em sistemas de transmissão. Entretanto, estas apresentam o inconveniente da emissão de poluentes e resíduos da combustão à natureza, além do uso de combustíveis não renováveis.

É importante mencionar que, sempre que houver a disponibilidade de energia hidráulica, a opção de maior economia é a de usinas hidrelétricas.

Por outro lado, o uso de turbinas a gás vem conquistando espaço, como também, o "uso múltiplo", onde o vapor produzido na caldeira é utilizado para o acionamento da turbina a vapor que produz eletricidade, sendo que sua descarga libera vapor para aplicações industriais. Dessa forma, o rendimento de todo o processo aumenta muito, viabilizando-se sua utilização em grandes indústrias ou grandes centros de consumo. 
Existe também a "cogeração", em que indústrias de grande porte geram sua própria energia elétrica e vendem os excedentes.

Quatro grandes bacias classificam o Brasil como um dos maiores potenciais hidráulicos do mundo, ou sejam:

- Bacia Amazônica;

- Bacia do São Francisco;

- Bacia do Tocantins;

- Bacia do Paraná.

A última, por sua localização mais próxima dos centros consumidores, é a mais explorada. A exploração da bacia amazônica, apesar do grande potencial hidráulico, exige a construção de um sistema de transmissão bem oneroso, devido a seu afastamento dos centros de consumo (Kagan et al, 2005).

\subsubsection{Sistema de Transmissão}

Pode-se observar pela Figura 2.3 que o sistema de transmissão brasileiro funciona de forma interligada. São inúmeras as razões para existência de tal interligação, destacando-se a possibilidade de intercâmbio entre áreas. Tal intercâmbio é necessário devido, por exemplo, aos ciclos hidrológicos diferentes entre regiões. As chuvas de verão em São Paulo permitem que seja transmitida energia elétrica para o Paraná devido ao período de estiagem nessa região. Da mesma forma, as chuvas de inverno no Paraná permitem que seja enviada energia elétrica para São Paulo devido a estiagem de inverno nessa região.

No Brasil, desenvolveram-se sistemas de transporte de energia elétrica de grande porte, permitindo a transmissão de grandes montantes de energia elétrica a grandes distâncias. Isso ocorreu devido ao esgotamento das reservas hídricas próximas dos centros de consumo. 
A transmissão por meio de elos de corrente contínua foi outra área que ganhou forte impulso no Brasil. Estes são atendidos por estação retificadora do lado da usina e inversora do lado do centro de consumo.

Rigorosos critérios de projeto e de operação permitem elevada confiabilidade nos sistemas de transmissão, uma vez que estes são responsáveis pelo atendimento dos grandes centros de consumo (Kagan et al, 2005).

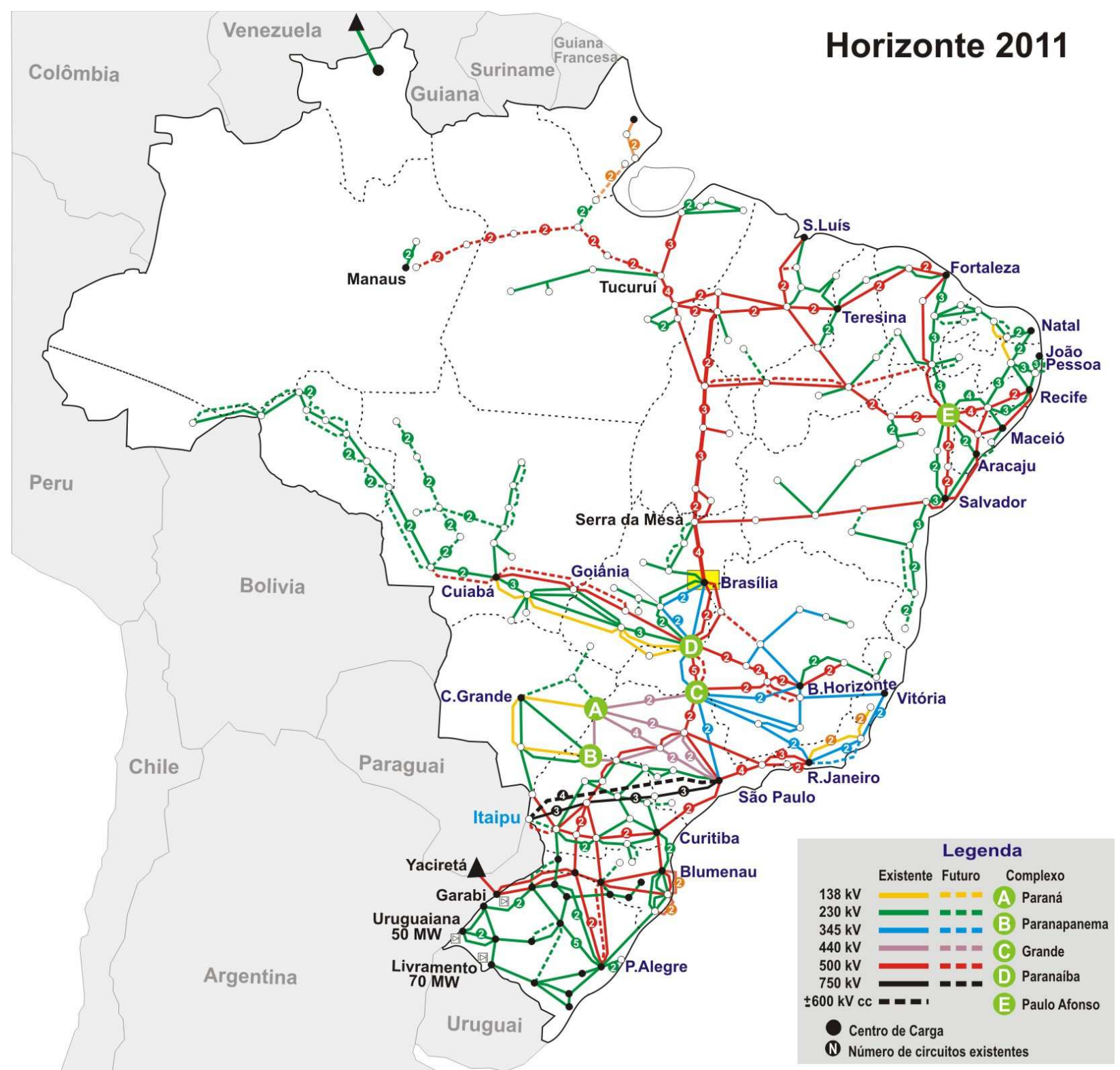

Figura 2.3 - Linhas de transmissão e bacias hidrográficas brasileiras (www.ons.org.br). 


\subsubsection{Sistema de Distribuição}

Para tratar do tópico de sistemas de distribuição, pode-se dividi-lo em (Kagan et al, 2005):

- Sistema de subtransmissão - este tem a função de captar a energia das subestações de subtransmissão e transferi-la para as subestações de distribuição e aos consumidores em tensão de subtransmissão. Os consumidores em tensão de subtransmissão são representados por grandes instalações industriais, estações de tratamento e bombeamento de água.

- Subestações de distribuição - são supridas pela rede de subtransmissão e são responsáveis pela transformação da tensão de subtransmissão para a de distribuição primária.

- Sistemas de distribuição primária - também conhecida como rede de média tensão, têm como ponto de partida as subestações de distribuição e atendem consumidores primários como indústrias de médio porte, conjuntos comerciais, instalações de iluminação pública, etc. Estas podem ser aéreas ou subterrâneas, as primeiras, pelo seu menor custo, são de uso mais difundido e, as segundas, são empregadas em áreas de maior densidade de carga ou onde existem restrições paisagísticas.

- Estações transformadoras - são constituídas por transformadores com a função de reduzir a tensão primária, ou média tensão, para aquela de distribuição secundária, ou baixa tensão. No Brasil, a tensão de distribuição secundária está padronizada nos valores $220 / 127 \mathrm{~V}$ e $380 / 220 \mathrm{~V}$, com predomínio da primeira nos estados do sul e sudeste e da segunda nos demais estados.

- Redes de distribuição secundária - também chamadas de redes de baixa tensão. Têm como ponto de partida as estações transformadoras e têm como função suprir consumidores residenciais, pequenos comércios e indústrias. Seu comprimento é 
da ordem de centenas de metros. Destaca-se o predomínio nessa rede de consumidores residenciais.

Assim, verifica-se que para cada segmento do sistema define-se implicitamente o grau de confiabilidade que dele é exigido, o qual está em função do montante de potência transportada. Como também é evidente nessa hierarquia, o primeiro elemento é a subestação de subtransmissão, que trata da transferência de potência da ordem de centenas de megawattampere, e o último é a rede de baixa tensão, onde a potência é da ordem de dezenas de quilowatt-ampere (Kagan et al, 2005).

\subsection{Aspectos de Previsão de Demanda de Energia Elétrica}

Sistemas elétricos de potência modernos consistem de centenas de geradores conectados a milhares de quilômetros de linhas de transmissão. Operações confiáveis e utilização econômica desse sistema requerem previsão de demanda de energia elétrica em diversos horizontes. Tais horizontes são classificados em previsão de longo prazo, médio prazo, curto prazo e curtíssimo prazo. Para cada um dos horizontes mencionados existe uma abordagem e um objetivo específico.

O horizonte de previsão de longo prazo trabalha com dados anuais e fornece para produtores e distribuidores a evolução da demanda, o que permite a definição de estratégias para aumentar a capacidade das linhas de transmissão ou construir novas plantas produtoras, ou ainda, determinar políticas para obter novos clientes. Previsões no longo prazo são ainda mais importantes para países em desenvolvimento do que países desenvolvidos, devido a seu crescimento da demanda ser mais acentuado. Para previsão no longo prazo são, normalmente, empregadas informações de carga e informações sócio-econômicas (Carmona, 2002). 
Previsões de demanda no médio prazo são aquelas com horizonte de algumas semanas ou meses. Esse horizonte de previsão é muito útil para o planejamento de manutenções nas redes, pesquisas de mercado para produtores e revendedores, planejamento na compra de combustíveis, negociações mais vantajosas de contratos com outras empresas e redução de riscos financeiros (Romera, 2008).

Previsão de curto prazo, ou de algumas horas ou dias à frente, é o horizonte de previsão com mais trabalhos publicados na literatura científica (Romera 2008). As variáveis de entrada mais importantes são carga, temperatura e preço. Este horizonte de previsão tem impacto importante para as concessionárias, pois muitas decisões operacionais, como agendamento de geração, manutenção de carga e avaliação da segurança do sistema, são baseados nele (Bashir, 2009). Seu papel é importante na operação segura e econômica de sistemas elétricos de potência (Tripathi, 2008).

Adicionalmente, um dos objetivos fundamentais no controle do sistema é manter a sintonia entre a demanda e a carga fornecida. O controle primário usado para atender esse objetivo é chamado Controle Automático de Geração. Para melhoria de seu desempenho, estratégias emergentes têm aplicado algoritmos de previsão no curtíssimo prazo.

Os horizontes de previsão já mencionados modelam relacionamentos entre carga, tempo, condições meteorológicas, informações sócio-econômicas, dentre outros fatores que afetam a demanda de energia elétrica. O horizonte de previsão de curtíssimo prazo requer uma abordagem diferente, em que são analisadas apenas as leituras de carga fornecida pelo sistema elétrico de potência. Os métodos de previsão de demanda de energia elétrica no curtíssimo prazo não são muito numerosos. Algumas técnicas incluem o modelo auto-regressivo (AR), o modelo auto-regressivo de médias móveis (ARMA) e redes neurais artificiais (Charytoniuk, 2000). 


\subsection{Principais Abordagens Inteligentes Utilizadas em Previsão de Demanda}

Não são muitas as técnicas empregadas na previsão de demanda de energia elétrica. Pode-se empregar sistemas fuzzy, ou redes neurais artificiais, mas a grande maioria delas emprega alguma abordagem híbrida composta por redes neurais artificiais e outra técnica inteligente, como algoritmos genéticos, PSO (Particle Swarm Optimization), etc.

\subsubsection{Redes Neurais Artificiais}

Nos últimos anos redes neurais artificiais têm sido empregadas em muitas áreas relacionadas à análise de sistemas elétricos de potência, como também, problemas de operação de controle. Isto inclui previsão de demanda, avaliação de segurança estática e dinâmica, modelagem de carga dinâmica, processamento de alarmes e diagnóstico de falhas. A disponibilidade de dados históricos nas concessionárias de energia tornou essa área altamente favorável à implementação de redes neurais artificiais (Tripathi, 2008).

Redes Neurais Artificiais são capazes de aprender o relacionamento entre variáveis do passado, do presente e do futuro, e são capazes de se adaptar e executar modelagens não lineares. Elas são particularmente atrativas por terem habilidade de tratar relacionamentos não-lineares entre dados e fatores que os afetam diretamente.

Outras características favoráveis são que redes neurais artificiais não necessitam da supervisão de especialistas para tomar decisões e elas podem se adaptar à mudanças nas séries por meio do auto-aprendizado (Romera, 2008).

Devido a tais fatores, são inúmeros os trabalhos (Charytoniuk, 2000; Carmona, 2002; Suzuki, 2007; Romera, 2008; Tripathi, 2008) que aplicam redes neurais artificiais em previsão de demanda de energia elétrica. 


\subsubsection{Sistemas Fuzzy}

Nas duas últimas décadas tem havido um grande crescimento no uso de controladores baseados em lógica fuzzy aplicados a sistemas elétricos de potência. Uma série recente de tutoriais da IEEE Power Engineering Society está inteiramente focada na aplicação de lógica fuzzy em sistemas elétricos de potência. Isso demonstra a importância dos modelos fuzzy no campo da energia (Mamlook, 2009).

Uma das tarefas mais importantes e desafiadoras em sistemas elétricos de potência é uma previsão precisa de demanda. O objetivo principal do trabalho de Mamlook (2009) foi desenvolver um modelo prático que possa atingir resultados de previsão precisos empregando-se lógica fuzzy.

As vantagens no uso de lógica fuzzy em previsão de demanda de energia elétrica são sua capacidade de condensar grandes montantes de dados em um conjunto pequeno de regras, pois este contem o conhecimento e infere as ações corretas a partir dos dados históricos.

Ainda, e segundo Mamlook (2009), previsão utilizando lógica fuzzy consistentemente resulta em um erro 5\% menor do que os métodos estatísticos de previsão convencionais.

\subsubsection{Sistemas Híbridos}

Uma das abordagens que vem sendo empregada na previsão de demanda de energia elétrica é aquela de sistemas híbridos. Na maioria dos casos, os sistemas híbridos são compostos por redes neurais artificiais e alguma outra técnica inteligente, mas existem outras formações.

Existem trabalhos como o de Pai e Hong (2005) que empregou-se máquinas de vetores de suporte (SVM) e algoritmos genéticos para resolver o problema com séries temporais de demanda de energia elétrica. Os algoritmos genéticos são empregados na determinação dos parâmetros livres do SVM. 
Em Azadeh et al (2007) foram empregados algoritmos genéticos e redes neurais artificiais para prever demanda de energia elétrica. Os algoritmos genéticos são empregados na estimação do modelo linear logarítmico que é função das variáveis independentes, ou seja, o preço, número de usuários e consumo dos períodos prévios.

No trabalho de Amjady e Keynia (2009) empregou-se um sistema híbrido composto por redes neurais artificiais, algoritmos evolutivos e transformada wavelet. Segundo seus autores, tal método é robusto e pode ser adaptado para qualquer sistema elétrico de potência.

O trabalho de Bashir e El-Hawary, também de 2009, empregou algoritmo de otimização por enxame de partículas (PSO) na fase de treinamento da rede neural artificial para obter um conjunto de pesos que irá minimizar a função de erro em um tempo menor. 


\section{Aspectos de Sistemas Neurofuzzy}

\subsection{Introdução}

Nesse tópico serão apresentados alguns aspectos de sistemas de inferência fuzzy como grau de pertinência fuzzy, operações e operadores fuzzy, regras de inferência fuzzy, agregação, defuzzificação, métodos de implicação Mandani, composição dos sistemas de inferência fuzzy e, finalmente, o sistema ANFIS.

\subsection{Aspectos de Sistemas de Inferência Fuzzy}

O conceito de grau de pertinência, criado por Lofti A. Zadeh em 1964, se tornou a espinha dorsal da teoria dos conjuntos fuzzy. Assim, tais conjuntos são caracterizados por funções de pertinência que associam a cada objeto um grau de pertinência entre zero e um (Zadeh, 1965).

A lógica fuzzy, que é baseada na teoria dos conjuntos fuzzy, foi em princípio desenvolvida a partir dos conceitos já estabelecidos pela lógica clássica. As noções de inclusão, união, intersecção, complemento, convexidade, etc. foram extendidas para tais conjuntos e várias propriedades no contexto de conjuntos fuzzy foram estabelecidas (Zadeh, 1965).

Teoria de conjuntos fuzzy e os conceitos de lógica fuzzy são ferramentas que podem ser utilizadas para transformar em termos matemáticos a informação imprecisa captada do meio externo.

Em um primeiro momento, a teoria fuzzy foi empregada na área de controle, porém, desde então, um aumento significativo da utilização de sistemas fuzzy tem se verificado em 
outras áreas, como por exemplo, mineração de dados, planejamento, otimização e previsão de séries temporais.

\subsubsection{Grau de Pertinência Fuzzy}

Na teoria clássica de conjuntos, um elemento pertence ou não pertence a um conjunto. Dado um universo de discurso $U$ e um elemento $x \in U$, o grau de pertinência $\mu_{A}(x)$ do elemento $x$, com relação ao conjunto $A \subseteq U$, é dado por:

$$
\mu_{A}(x)=\left\{\begin{array}{l}
1, \text { se } x \in A \\
0, \text { se } x \notin A
\end{array}\right.
$$

A função $\mu_{A}(x): U \rightarrow\{0,1\}$, na teoria clássica de conjuntos, é nomeada de função característica. Essa função na teoria clássica assume apenas valores discretos, sendo que a expressão (3.1) ilustra esse fato.

$\mathrm{Na}$ Figura 3.1(a) pode-se observar que o intervalo de dados tem pertinência 1 em relação ao conjunto $A$ considerado. Para elementos que pertencem ao conjunto universo $U$, e não pertencem a esse intervalo, o grau de pertinência tem valor 0. Essa é a representação de pertinência na lógica clássica. Na Figura 3.1(b) o caso preciso é apresentado e deste tem-se que o grau de pertinência vale 1 somente em determinado valor, sendo 0 para os demais valores.
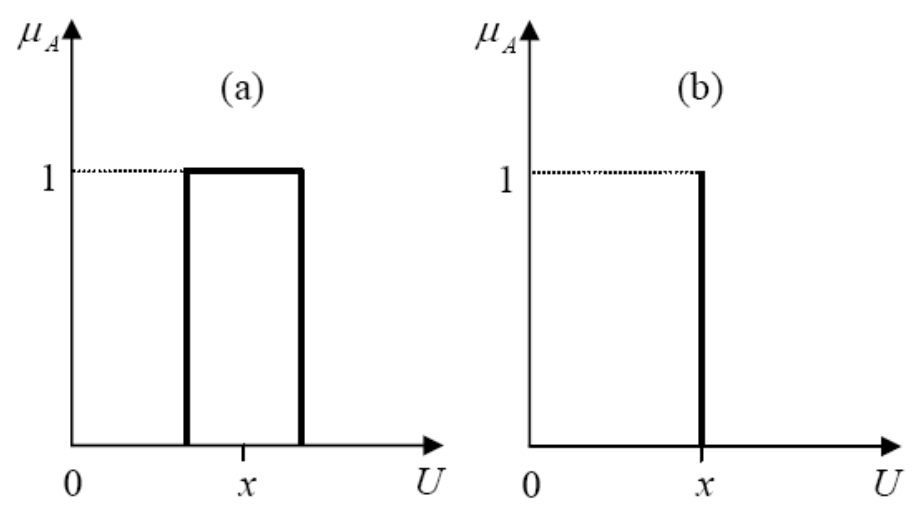

Figura 3.1 - Funções de pertinência. 
Já ao considerar um conjunto fuzzy, um elemento $x$ pertencente ao conjunto universo $U$, tem um determinado grau de pertinência com relação ao conjunto $A$, grau este que é definido no intervalo $[0,1]$ e é descrito por $\mu_{A}(x)$, onde 0 significa a exclusão total do elemento em relação ao conjunto, ao passo que o valor 1 significa a inclusão total do elemento, e qualquer valor entre esses dois representa uma pertinência parcial.

Zadeh (1973) propôs uma caracterização mais ampla, em que sugere que alguns elementos são mais membros de um conjunto do que outros. A função característica se torna contínua em seu domínio, pois o grau de pertinência pode assumir valores no intervalo [0,1]. A generalização da função característica aumenta seu poder de expressão. A Figura 3.2 ilustra a abordagem descrita nas formas de função triangular, trapezoidal e gaussiana. As funções triangular e gaussiana sugerem que quanto mais próximo de $x$, mais o elemento se identifica com o conceito representado por $x$ em relação ao conjunto $A$, ao passo que a função trapezoidal sugere que, entre os pontos $a$ e $b$, o elemento identifica totalmente com o conceito representados por $x$ em relação ao conjunto $A$.
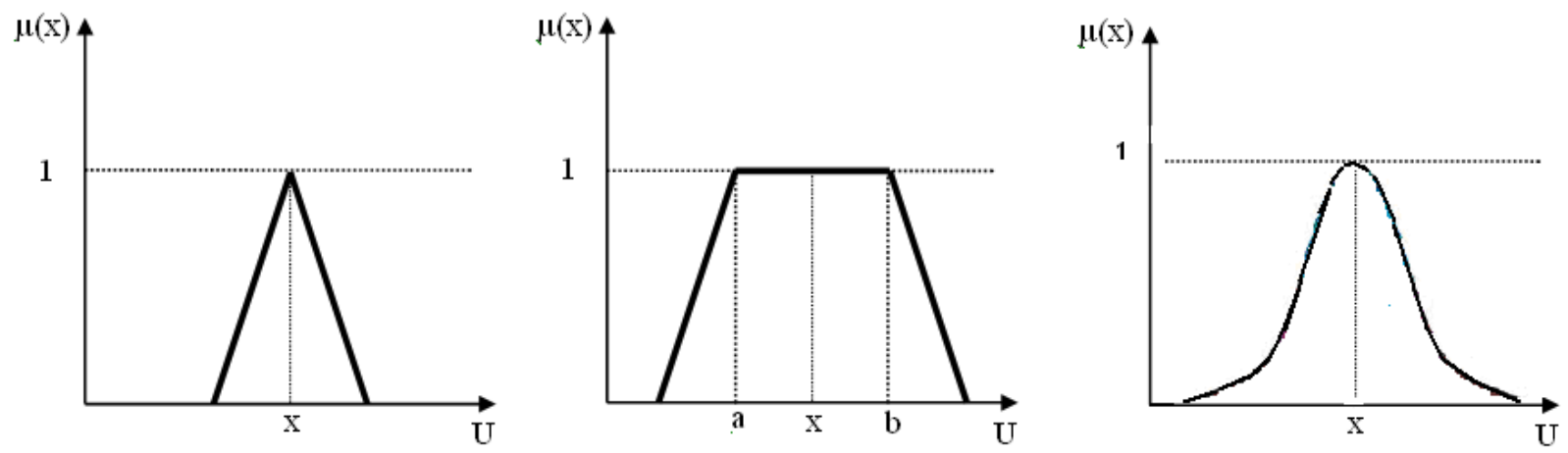

Figura 3.2 - Funções de pertinência fuzzy.

Assim, o grau de pertinência não é mais um dado binário, portanto, não faz sentido definir um conjunto apenas pelos seus elementos. A expressão (3.2) ilustra como são representados os conjuntos fuzzy, ou seja. por pares ordenados que indicam cada elemento com seu grau de pertinência. 


$$
A=\left\{\left(x, \mu_{A}(x)\right) \mid x \in U\right\}
$$

A função de pertinência fornece os conjuntos contínuos e estes podem ser representados conforme a expressão (3.3), onde a somatória representa a operação união (disjunção) e o termo $\mu_{A_{i}}\left(x_{i}\right) / x_{i}$, indica que o elemento $x_{i}$ pertence ao conjunto $A$ com grau de pertinência $\mu_{A}\left(x_{i}\right)$.

$$
A=\sum_{i} \mu_{A}\left(x_{i}\right) / x_{i}
$$

A lista dos elementos de conjuntos discretos apresenta apenas os elementos que possuem grau de pertinência diferente de zero.

\subsubsection{Operações e Operadores Fuzzy}

Sejam as funções de pertinência $\mu_{A}$ e $\mu_{B}$ que se referem, respectivamente, aos conjuntos $A$ e $B$ que pertencem ao universo de discurso $U$. Pode-se definir as operações formais que envolvem conjuntos do mesmo universo de discurso em união $(A \cup B)$, intersecção $(A \cap B)$ e o complemento $(\neg A)$ que são definidas de maneira formal pelas seguintes expressões:

$$
\begin{gathered}
\mu_{A \cup B}(u)=\mu_{A}(u) \Theta \mu_{B}(u) \\
\mu_{A \cap B}(u)=\mu_{A} \Gamma \mu_{B}(u) \\
\mu_{\neg A}(u)=1-\mu_{A}(u)
\end{gathered}
$$

onde $\Gamma$ é uma norma triangular ( $t$-norma) e $\Theta$ é uma co-norma triangular ( $s$-norma).

A s-norma é exemplificada pela a Expressão (3.7) e a Expressão (3.8) exemplifica a $t$-norma.

$$
\begin{gathered}
\mu_{A \cup B}=\max \left\{\mu_{A}(u), \mu_{B}(u)\right\} \\
\mu_{A \cap B}=\min \left\{\mu_{A}, \mu_{B}(u)\right\}
\end{gathered}
$$


Empregou-se, portanto, o operador "max" na representação da $s$-norma e o operador “min" na representação da $t$-norma (Zadeh, 1965).

\subsubsection{Regras de inferência Fuzzy}

É comum o uso de elementos qualitativos ao invés de valores quantitativos para expressar conceitos ou relacionamentos por intermédio de elementos da linguagem natural. Elementos lingüísticos típicos incluem expressões do tipo "mais ou menos”, "mais alto", "não muitos", etc. Estas idéias são capturadas pela definição de variáveis lingüísticas. Uma variável lingüística tem por característica assumir valores dentro de um conjunto de termos lingüísticos, ou seja, palavras ou frases. Assim, ao invés de assumir instâncias numéricas, estas variáveis assumem instâncias lingüísticas.

$\mathrm{Na}$ teoria fuzzy os parâmetros de entrada do sistema são mapeados em variáveis linguiísticas que são utilizadas na definição de regras para o processamento de variáveis de saída, também representadas por variáveis lingüísticas.

Por exemplo, uma variável lingüística "Temperatura” poderá assumir como valor um dos termos do conjunto \{"baixa", "média", "alta"\}. Para se atribuir um significado aos termos lingüísticos, associa-se a cada um destes termos um conjunto fuzzy definido sobre um universo de discurso comum, que neste exemplo será a "Temperatura"

A Figura 3.3 ilustra três possíveis termos lingüísticos para a variável lingüística representando a temperatura. 


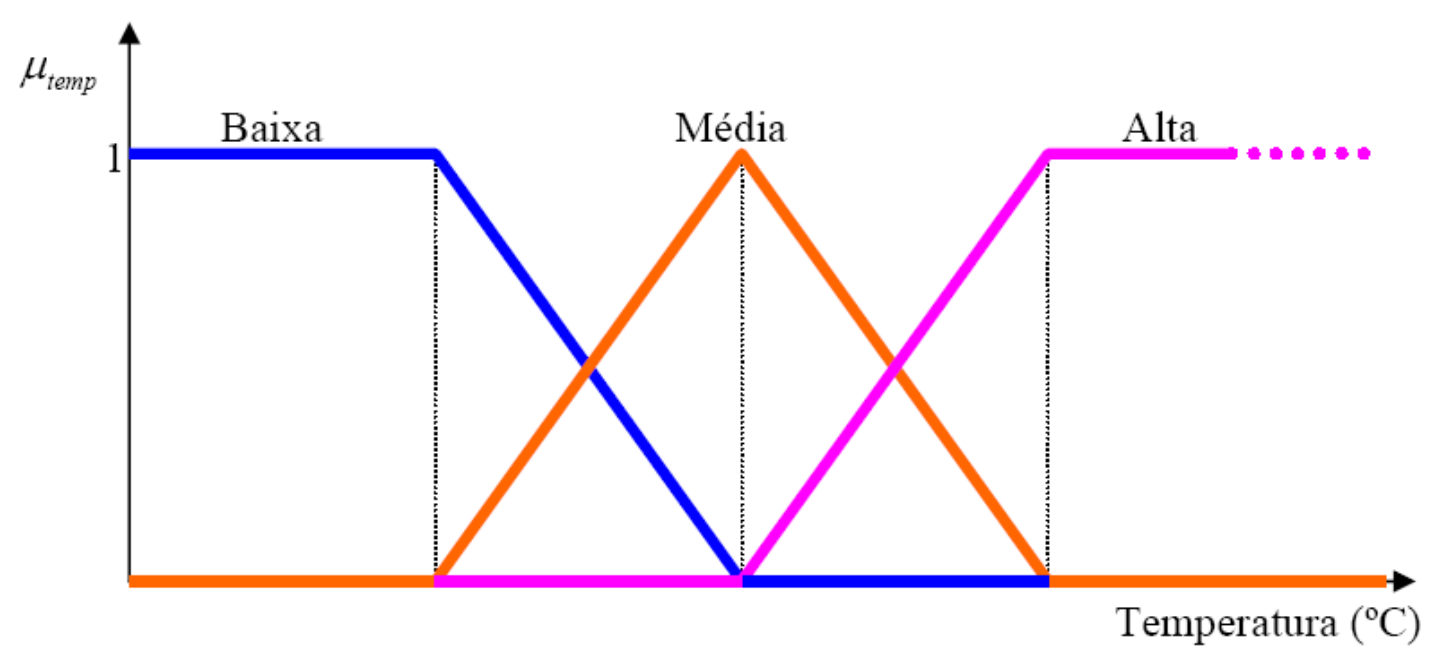

Figura 3.3 - Representação da variável ligüística temperatura.

A forma mais comum de expressar o conhecimento é por meio de regras do tipo condição-ação (Zadeh, 1973). As regras são formadas por antecedentes e conseqüentes:

\section{SE <antecedentes> ENTÃO <conseqüentes>}

As condições necessárias para que haja um determinado resultado são descritas pelos antecedentes. Os conseqüentes representam os resultados ou ações executadas se verificados tais antecedentes. Diferentemente da Teoria Clássica, uma regra fuzzy pode ser avaliada mesmo se os antecedentes não forem totalmente satisfeitos (Zadeh, 1973).

Um sistema de inferência fuzzy baseado em regras permite a combinação de múltiplas regras fuzzy. Esta combinação é obtida por meio do uso de ponderadores, ou seja, valores que se associam às regras e que determinam um grau de importância a cada uma delas.

Um sistema de inferência fuzzy baseado em regras é uma generalização do esquema lógico de raciocínio denominado modus ponens. Na lógica clássica, se o antecedente de uma regra é dito verdadeiro, então pode-se afirmar que o conseqüente dessa regra também o é. 
Um sistema de inferência fuzzy baseado em regras generaliza modus ponens para permitir que a conclusão da regra seja inferida pelo grau em que o antecedente é satisfeito. Essa é a essência dos sistemas de inferência fuzzy baseados em regras.

Uma regra fuzzy típica pode ser dada por:

$$
\begin{gathered}
\mu_{R_{i}}=\mu_{\left(A_{i} a n d B_{i} \rightarrow C_{i}\right)}(u, v, w) \\
\mu_{R_{i}}=\left[\mu_{A_{i}}(u) \text { and } \mu_{B_{i}}(v)\right] \rightarrow \mu_{C_{i}}(w)
\end{gathered}
$$

sendo $A_{i}, B_{i}, C_{i}$ são conjuntos fuzzy que pertencem aos universos de discursos $U, V$ e $W$, respectivamente, e o operador “ $\rightarrow$ ” indica uma função de implicação fuzzy.

Utilizando-se a regra de inferência composicional de Zadeh (1973) para uma relação to tipo $R_{\mathrm{A} \rightarrow \mathrm{B}}$, onde $A \in U$ e $B \in V$, e considerando-se um conjunto fuzzy de $U$ denotado por $A$ ' e um conjunto fuzzy $B^{\prime}$ de $V$, a inferência de $A^{\prime}$ é dada pela seguinte função de pertinência:

$$
\mu_{B^{\prime}}(v)=\max _{u}\left(\min \left(\mu_{A^{\prime}}(u), \mu_{R}(u, v)\right)\right\} ; u \in U, v \in V
$$

A ação de controle consistirá então da união de todas as funções fuzzy ativadas. O valor final, ou seja, aquele que será apresentado pelas saídas do sistema fuzzy, será determinado pelo processo de defuzzificação.

\subsubsection{Agregação}

Em uma base de regras, quando mais de uma regra é acionada, as contribuições das diversas regras após a inferência são combinadas pelo operador de agregação. Por exemplo,

supondo-se que $B_{1}, \ldots, B_{n}$ são todos os resultados derivados das diversas regras acionadas, todos relacionados a uma mesma variável lingüística, o resultado da implicação de todas as regras $B^{\prime}$ será: 


$$
B^{\prime}=\bigcup_{i}^{n} B_{i}^{\prime}
$$

onde o símbolo "U" representa o operador agregação. Um exemplo de função para o operador agregação é o operador união.

\subsubsection{Defuzzificação}

Realizado o processo de agregação das regras, tem-se como resultado um conjunto nebuloso representativo da saída do sistema de inferência fuzzy. Existe, em muitas aplicações, a necessidade de se expressar os resultados em valores numéricos, denominados "crisp". Surge-se então, a partir dessa necessidade, o processo de defuzzificação que se trata da interpretação quantitativa de uma variável de saída do sistema fuzzy.

São muitas as metodologias para se realizar esse processo, dentre as quais se destacam a média dos máximos e o centro de área. Seja $A$ um conjunto nebuloso definido no universo $W$, tem-se:

- Média dos máximos (MoM): Depois de identificados os valores do domínio correspondente ao máximo da função de pertinência, sua média define o valor crisp.

- Centro de Área (CoA): O valor crisp é obtido por meio do cálculo do centro de área:

$$
\hat{w}=\frac{\int_{w} \mu_{a}(w) w d w}{\int_{w} \mu_{a}(w) d w}
$$

\subsubsection{Método de Implicação de Mandani}

O sistema de inferência fuzzy do tipo Mandani (Jang e Sun, 1995) possui estrutura baseada no esquema ilustrado pela Figura 3.4. Definidas as funções de pertinência a serem utilizadas, é necessária a implementação da base de conhecimento do sistema de inferência a partir das definiçõoes das regras fuzzy, as quais são compostas por estruturas de decisão do tipo 
"Se-Então", como descrito na Seção 3.2.3. As construção de tais regras que descrevem os aspectos qualitativos em forma de sentenças lingüísticas torna o sistema compreensível, o que permite seu desenvolvimento e manutenção de forma simples.

As regras fuzzy são divididas em parcelas definidas como antecedente e conseqüente (Jang e Sun, 1995). No antecedente são realizadas, com as variáveis lingüísticas de entrada, as operações que podem ser do tipo AND ou OR. Essa operação implica em uma determinada ação para a parcela consequiente, onde será determinada a função de pertinência de saída. A Figura 3.4 descreve como se dá a implementação de uma regra fuzzy com duas entradas.

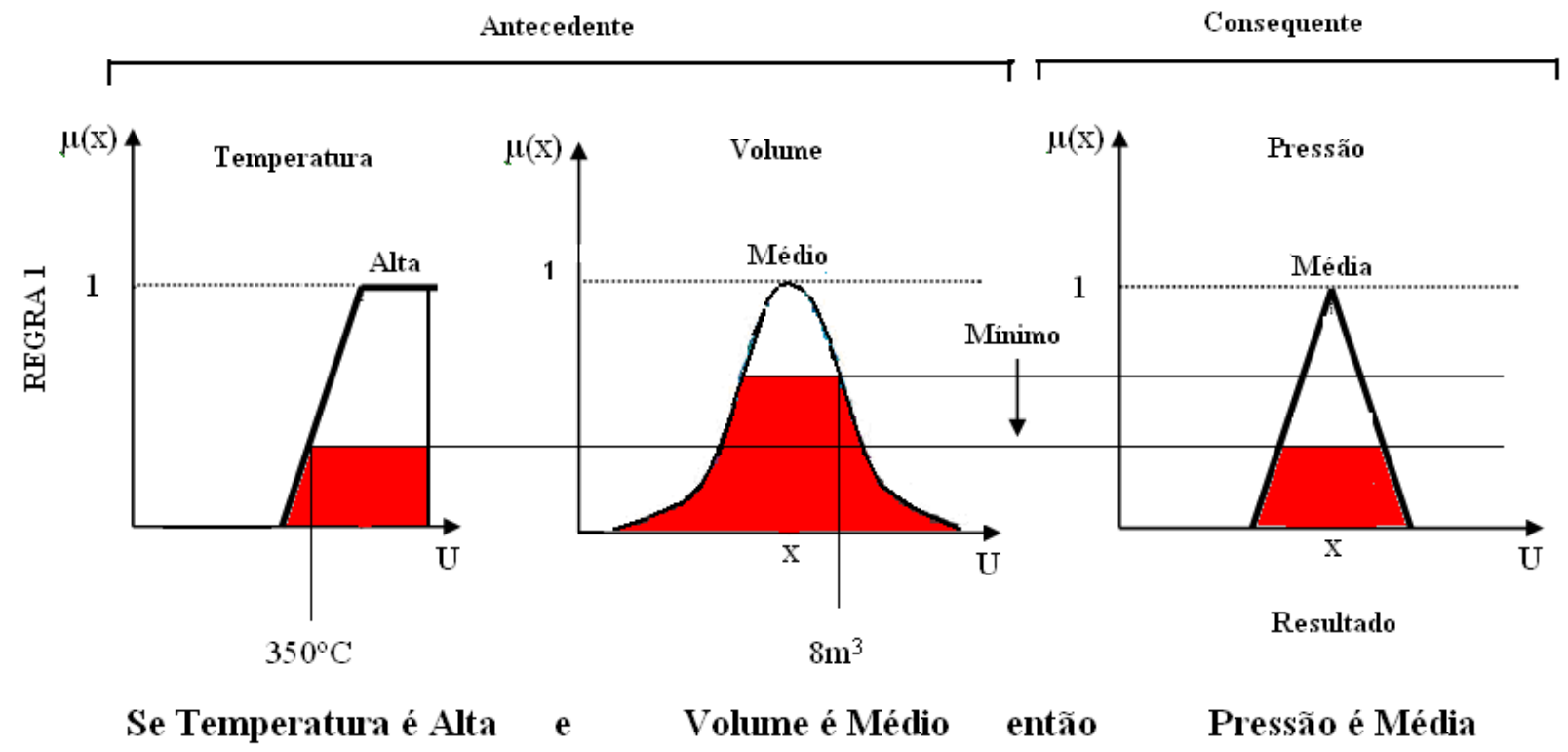

Figura 3.4 - Implementação de uma regra fuzzy

Como exemplo, a temperatura de $350^{\circ} \mathrm{C}$ e o Volume de $8 \mathrm{~m}^{3}$ ativam os termos lingüísticos "Alta" e "Médio" das variáveis lingüísticas "Temperatura" e "Volume", respectivamente, como ilustrado na Figura 3.4. Portanto, a regra lingüística "Se Temperatura da caldeira é alta e o volume é médio então a pressão é média” foi ativada. Como ilustrado na Figura 3.5, a operação AND faz o mínimo entre os graus de pertinência associado à variável lingüística "Temperatura" e "Volume". Na seqüência, a implicação Mandani faz um corte no termo lingüístico "Média" da variável de saída "Pressão". 
A região resultante representa a contribuição de uma das regras para a ação de variação da pressão interna da caldeira.
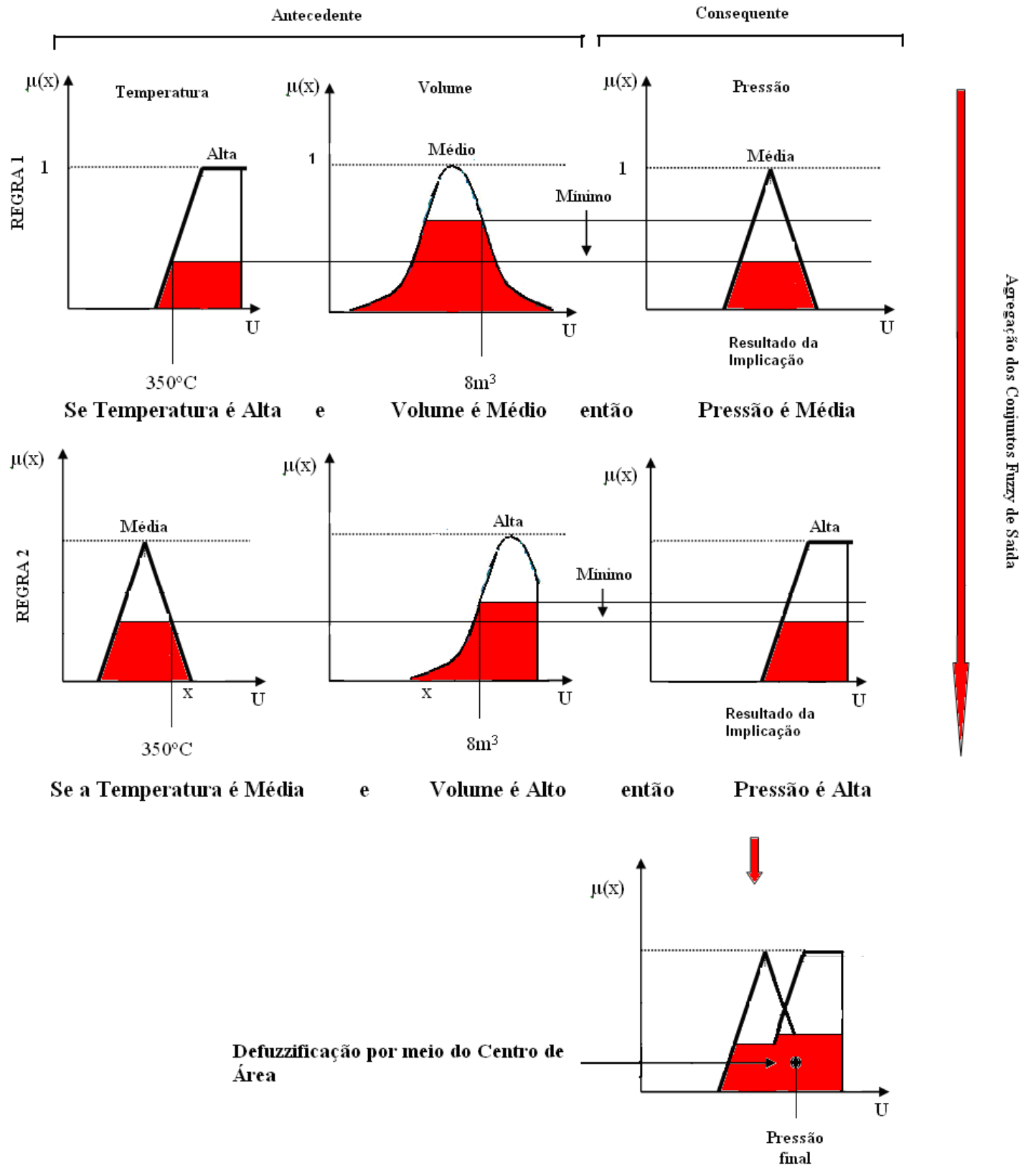

Figura 3.5 - Método de implicação Mandani.

Como conseqüência, uma única função de pertinência de saída é obtida a partir da agregação de todas as implicações provenientes de suas respectivas regras fuzzy. Dessa função de pertinência será extraído o valor preciso (crisp) da pressão na caldeira. Por fim, aplica-se 
um dos métodos de deffuzificação para determinar o valor de saída. No exemplo na Figura 3.5 aplicou-se o centro de área.

\subsection{Composição dos Sistemas de Inferência Fuzzy}

Uma vez descritos alguns dos aspectos de sistemas fuzzy, pode-se resumir o sistema de inferência fuzzy ou controlador fuzzy em três fases: fuzzificação, inferência e defuzzificação. A Figura 3.6 apresenta o sistema de inferência fuzzy e a forma de interligação entre as fases, sendo que a função de cada fase pode ser descrita da seguinte forma:

- Na fuzzificação, os valores não fuzzy são fornecidos ao sistema no formato numérico por sensores ou medidores, os quais são considerados como sendo o conjunto de dados de entrada no sistema. Dessa forma, se faz necessário mapear esses dados de entrada para o conjunto fuzzy, de modo que o sistema possa determinar as variáveis lingüísticas, as quais esses dados pertencem, e a pertinência dos mesmos a essas variáveis. $\mathrm{Na}$ defuzzificação ocorre também a ativação das regras fuzzy relevantes para o sistema.

- Na fase de inferência, os valores lingüísticos, resultantes da fuzzificação, são combinados de forma a gerar valores lingüísticos de saída de acordo com regras de inferência fuzzy determinadas. Em um controlador fuzzy, as regras têm um papel relevante, pois o bom desempenho do sistema está vinculado à produção de regras consistentes. A base do conhecimento pode ser fornecida por especialistas através de termos lingüísticos. Esse processo pode ser complicado, mas, independente do conhecimento do especialista, como alternativas para a formação das bases de regras, tem-se a mineração de dados numéricos ou a integração entre sistemas de inferência fuzzy e redes neurais artificiais. 
- Por fim, tem-se a defuzzificação, que de posse do conjunto de saída adquirido por meio do processo de inferência, é responsável pela interpretação dessa informação para saídas numéricas precisas. Isso se faz necessário, uma vez que em aplicações práticas são normalmente requeridos valores crisp.

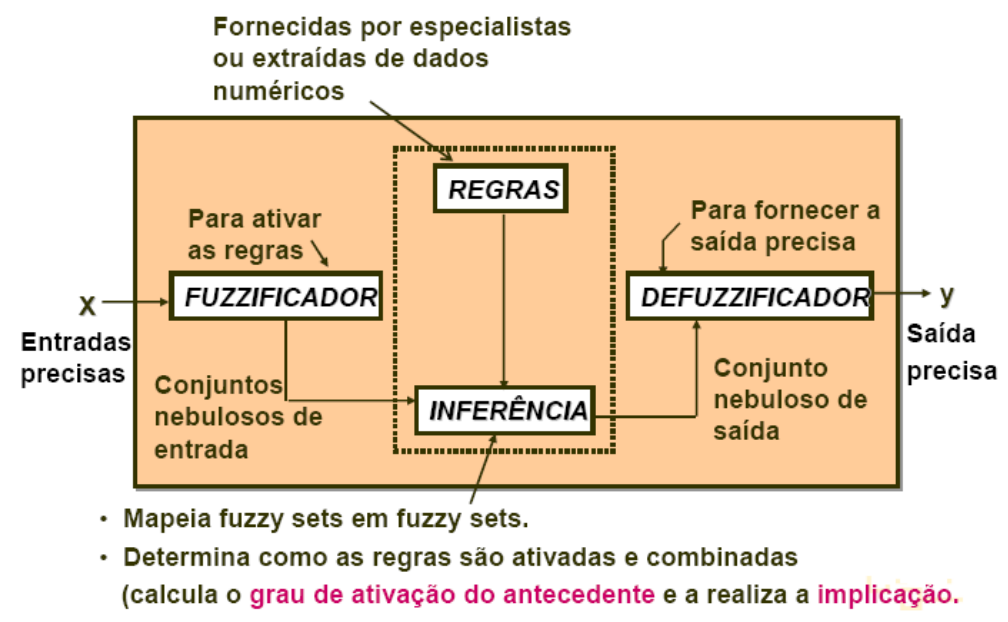

Figura 3.6 - Sistema fuzzy.

\subsection{Sistema de Inferência no Modelo de Takagi-Sugeno}

O sistema ANFIS adotado nesse trabalho utiliza o modelo de Inferência de TakagiSugeno (Jang., 1993; Jang e Sun, 1995) para criação das regras e ajuste das funções de pertinência.

O modelo de Takagi-Sugeno, como também outros modelos de inferência, consiste em obter todas as contribuições individuais provenientes de cada uma das regras ativadas, sendo que a função de pertinência de saída do método de Takagi-Sugeno pode ser uma função linear ou função constante.

Considerando-se o modelo de Takagi-Sugeno, deve-se primeiramente fuzzificar todas as entradas, encontrar as regras ativadas e determinar os valores individuais provenientes das funções de saída de Takagi-Sugeno. De posse desses valores de saída, deve-se então realizar a ponderação entre os mesmos a fim de produzir uma resposta final. 
A fim de sintetizar esses conceitos, assume-se que o sistema de inferência fuzzy considerado tem duas entradas $x$ e $y$ e uma saída $z$. Para um modelo Sugeno de primeira ordem, um conjunto típico de duas regras com “se-então" pode ser expresso como:

$$
\begin{aligned}
& \text { Regra 1: } \quad \text { Se } x \text { é } A_{1} \text { e } y \text { é } B_{1} \text { então } f_{1}=p_{1} x+q_{1} y+r_{1} \\
& \text { Regra 2: } \quad \text { Se } x \text { é } A_{2} \text { e } y \text { é } B_{2} \text { então } f_{2}=p_{2} x+q_{2} y+r_{2}
\end{aligned}
$$

sendo que o resultado final é obtido por meio da média ponderada de todos os resultados de saída, considerando-se os graus de pertinência de cada regra ativada, conforme a expressão (3.13):

$$
y=\frac{\sum_{i=1}^{N} \mu_{i} \cdot y_{i}}{\sum_{i=1}^{N} \mu_{i}}
$$

onde $y$ é a saída final, $N$ representa o total de regras ativadas, e $\mu_{i}$ é o grau de pertinência em relação à contribuição de cada regra ativada.

A Figura 3.7 ilustra os procedimentos internos associados ao modelo Takagi-Sugeno quando aplicado a um sistema que possui duas variáveis como dados de entrada.

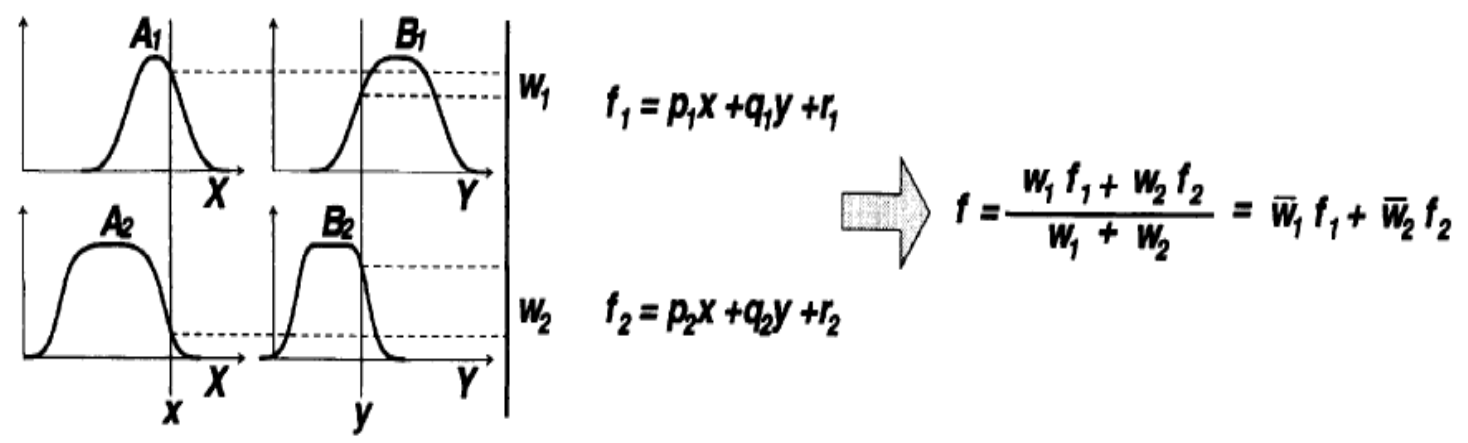

Figura 3.7 - Mecanismo de raciocinio para este modelo Sugeno.

\subsection{Sistema ANFIS (Adaptive Neuro-Fuzzy Inference System)}

O ANFIS (Adaptive Neuro-fuzzy Inference System) é um sistema de inferência fuzzy implementado com o framework de redes adaptativas. Por meio do uso de um procedimento 
de aprendizado híbrido, o ANFIS pode construir um mapeamento entrada-saída baseado no conhecimento humano (na forma de regras "se-então") ou em pares entrada-saída determinados. O ANFIS pode ser empregado na modelagem de funções não lineares, na identificação de componentes online de um sistema de controle e na previsão de séries temporais, sendo que este último é o objetivo desse trabalho.

Portanto, o ANFIS é uma arquitetura que irá construir um conjunto de regras fuzzy "se-então" com funções de pertinência apropriadas para gerar pares entrada-saída determinadas. Funcionalmente, quase não há restrições quanto às funções de uma rede adaptativa, exceto que elas sejam diferenciáveis.

Estruturalmente, a única limitação na configuração da rede é que esta deve ser do tipo feedforward. Devido a essas mínimas restrições, as redes adaptativas estão inseridas em várias áreas.

\subsubsection{Arquitetura ANFIS}

A arquitetura do modelo ANFIS correspondente ao modelo Sugeno descrito na Seção 3.4 é ilustrada na Figura 3.8, onde os nós das mesmas camadas têm as mesmas funções. Denota-se o nó de saída $i$ da camada $l$ como $O_{l, i}$.

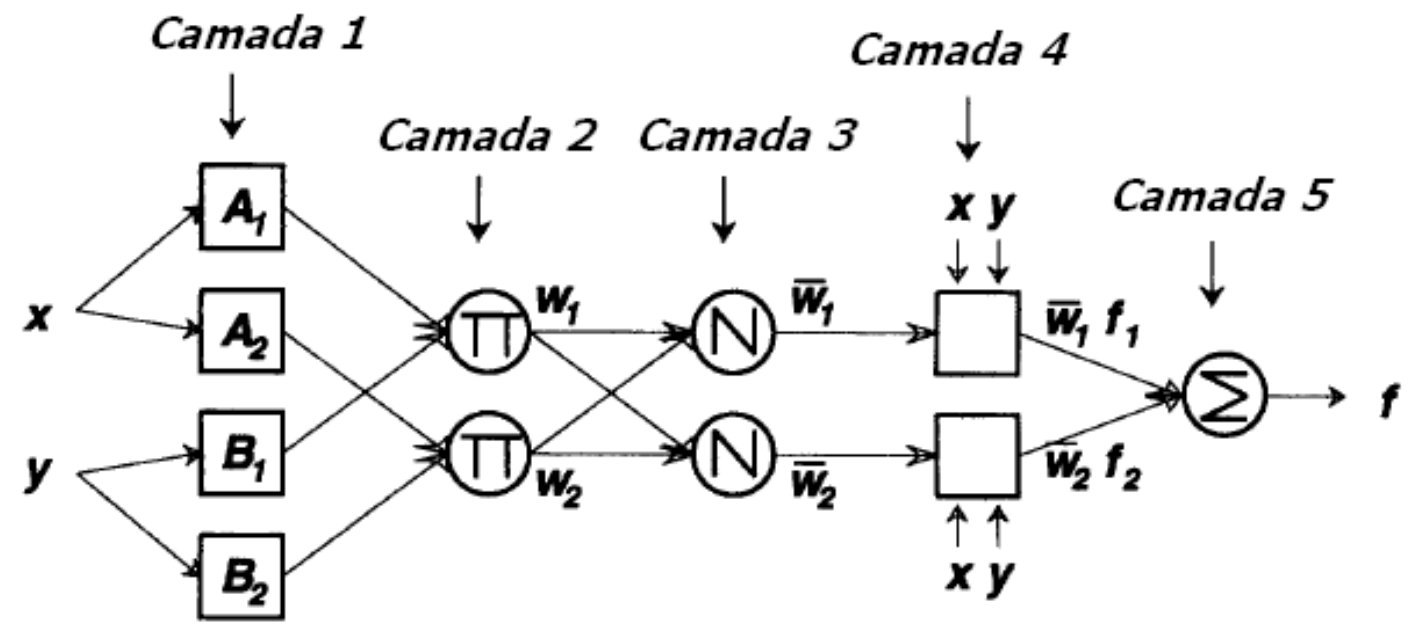

Figura 3.8 - Arquitetura ANFIS equivalente. 
Camada 1: cada nó $i$ desta camada é um nó adaptativo com a saída definida por (Jang, 1993; Jang e Sun, 1995):

$$
\begin{array}{ll}
O_{l . i}=\mu_{A i}(x), & \text { Para } i=1,2, \\
O_{l, i}=\mu_{B i-2}(y), & \text { Pa }
\end{array}
$$

onde $x$ (ou $y$ ) é a entrada do nó e $A_{i}$ (ou $B_{i-2}$ ) é o conjunto fuzzy associado a este nó. Em outras palavras, as saídas desta camada são os valores das funções de pertinência da parte anterior. Por exemplo, $A_{i}$ pode ser caracterizado pela função Sino:

$$
\mu_{A i}=\frac{1}{1+\left[\left(\frac{x-c_{i}}{a_{i}}\right)^{2}\right]^{b_{i}}}
$$

onde $a_{\mathrm{i}}$ é a metade da largura da função de pertinência, $b_{i}$ controla a inclinação no ponto onde a função de pertinência é igual a 0,5 e $c_{i}$ determina o centro da função de pertinência.

Camada 2: Cada nó dessa camada é fixo e rotulado por П, o qual multiplica os sinais de entrada e apresenta o produto como saída (Jang, 1993; Jang e Sun, 1995). Por exemplo:

$$
O_{2, i}=w_{i}=\mu_{A i}(x) \times \mu_{B i}(y), i=1,2 .
$$

Cada nó de saída representa a ativação de uma regra. (De fato, qualquer outro operador tnorma que faça um E fuzzy pode ser usado como função dos nós dessa camada.)

Camada 3: Cada nó dessa camada é rotulado de N. O $i$-ésimo nó calcula a razão entre a ativação da $i$-ésima regra pela ativação de todas regras (Jang, 1993; Jang e Sun, 1995).

$$
O_{3, i}=\overline{w_{i}}=\frac{w_{i}}{w_{1}+w_{2}}, i=1,2
$$

Por conveniência, as saídas desta camada serão chamadas ativações normalizadas. 
Camada 4: Cada nó $i$ nesta camada é um nó adaptativo com a função:

$$
O_{4, i}=\overline{w_{i}} f_{i}=\overline{w_{i}}\left(p_{i} x+q_{i} y+r_{i}\right)
$$

onde $\overline{w_{i}}$ é a saída da camada 3 e $\left\{p_{i}, q_{i}, r_{i}\right\}$ é o conjunto de parâmetros. Os parâmetros nesta camada serão referenciados por parâmetros do conseqüente.

Camada 5: O único nó dessa camada, rotulado por $\Sigma$, calcula a saída global como somatório de todos os sinais de entrada (Jang, 1993; Jang e Sun, 1995).

$$
O_{5, l}=\sum_{i} \overline{w_{i}} f_{i}=\frac{\sum_{i} w_{i} f_{i}}{\sum_{i} w_{i}}
$$

Dessa maneira constrói-se uma rede adaptativa que tem exatamente a mesma função do modelo fuzzy Sugeno da Figura 3.7 (Jang, 1993; Jang e Sun, 1995). 


\section{Previsão de Demanda de Energia Elétrica Utilizando o Sistema}

ANFIS

\subsection{Introdução}

Nesse tópico serão apresentados alguns aspectos da aplicação do ANFIS na previsão de demanda de energia elétrica. Aspectos sobre o uso da validação cruzada para determinação da melhor arquitetura a ser empregada no processo de previsão das séries temporais são também analisados.

\subsection{Abordagem ANFIS Para Previsão de Demanda de Energia Elétrica}

\subsubsection{Aspectos sobre a Validação Cruzada}

Segundo Haykin (1999) a idéia principal da aprendizagem por retropropagação é ajustar os pesos sinápticos e limiares de um perceptron multicamadas de acordo com um mapeamento de entrada-saída. Espera-se que a rede, uma vez que bem treinada, aprenda o suficiente sobre o passado para generalizar o futuro. A aprendizagem se torna a determinação dos melhores parâmetros da rede para este conjunto de dados, ou seja, pode-se interpretar tal problema de seleção de rede como a escolha, dentre um conjunto de estruturas candidatas (parametrizações), a melhor de acordo com determinado critério.

Nesse contexto, uma ferramenta padrão de estatística conhecida como validação cruzada fornece um princípio orientador atraente. Inicialmente, o conjunto de dados é dividido de forma aleatória em um conjunto de treinamento e em um conjunto de teste. $\mathrm{O}$ conjunto de treinamento é subdividido em dois conjuntos disjuntos:

- Subconjunto de estimação, usado para selecionar o modelo. 
- Subconjunto de validação, usado para testar ou validar o modelo.

Essa subdivisão tem por objetivo validar o modelo com um conjunto de dados distinto do que foi utilizado para estimar os parâmetros. Pode-se então usar o conjunto de treinamento para avaliar o desempenho de inúmeros modelos candidatos a fim de se escolher o melhor. Contudo, existe a possibilidade de que o modelo selecionado dessa forma ajuste excessivamente o subconjunto de validação. Para evitar essa possibilidade, o poder de generalização do modelo selecionado é determinado por meio de um conjunto do teste distinto do conjunto de validação.

O uso da validação cruzada foi atrativo neste trabalho para a determinação dos parâmetros estruturais e de treinamento do ANFIS com o objetivo de se obter uma capacidade de generalização apropriada.

O procedimento de seleção do modelo baseado na validação cruzada fornece uma abordagem bem-fundamentada para determinar o número de neurônios ocultos de um perceptron multicamadas (Haykin, 1999) e nesse trabalho foi empregado com sucesso na determinação da melhor arquitetura ANFIS para previsão de demanda de energia elétrica no curtíssimo prazo.

\subsubsection{Metodologia por meio da validação cruzada}

Neste trabalho, a validação cruzada se deu de forma muito semelhante àquela das Redes Neurais Artificiais com aprendizagem por retropropagação, descrita na Seção 4.2.1 e foi empregada como descrita no fluxograma da Figura 4.1 e pelos seguintes passos:

- A seleção das variáveis de entrada se resume ao uso exclusivo da série temporal de carga mensurada, pois, segundo Charytoniuk e Chen (2000), previsão de demanda de energia elétrica no curtíssimo prazo exige uma abordagem cujo foco deve ser 
voltado para o padrão apresentado pelas últimas leituras observadas, e não para a relação da demanda com fatores que a influenciariam como condições meteorológicas, sociais e econômicas.

- Normalização dos dados entre -1 e 1, pois para minimizar o tempo de aprendizagem deve-se evitar o uso de entradas com média diferente de zero (Haykin, 1999).

- Divisão dos dados em conjuntos de treinamento, validação e teste na proporção de 4 dias para treinamento, 1 dia para validação e 1 dia para testes.

- Determinação da melhor formação para os padrões de entrada e saída.

- Determinação do número de funções de pertinência.

- Escolha das melhores funções de pertinência de entrada e saída.

- Determinação do melhor método de otimização.

- Determinação do melhor número de ciclos de treinamento.

Como se pode observar no Fluxograma da Figura 4.1 os padrões de entrada e saída são determinados por meio de um ciclo onde, na medida em que o erro diminui (Erro Menor $=$ Sim), é incrementado o número de entradas até que o erro não diminua mais.

A partir do ciclo em que o erro não diminui mais em função da variação do número de entradas $($ Erro Menor $=$ Não $)$ o fluxograma retorna para o passo de escolha dos parâmetros de configuração do ANFIS (Existem novas configurações=Sim) para, por meio de uma modificação em tais parâmetros, tentar diminuir ainda mais o erro.

Esgotadas todas as possibilidades quanto à formação dos padrões de entrada e quanto às configurações (Existem novas configurações=Não), o fluxograma segue para determinação do número adequado de ciclo de treinamento, ou seja, número de ciclos onde o erro de treinamento se torna constante. 


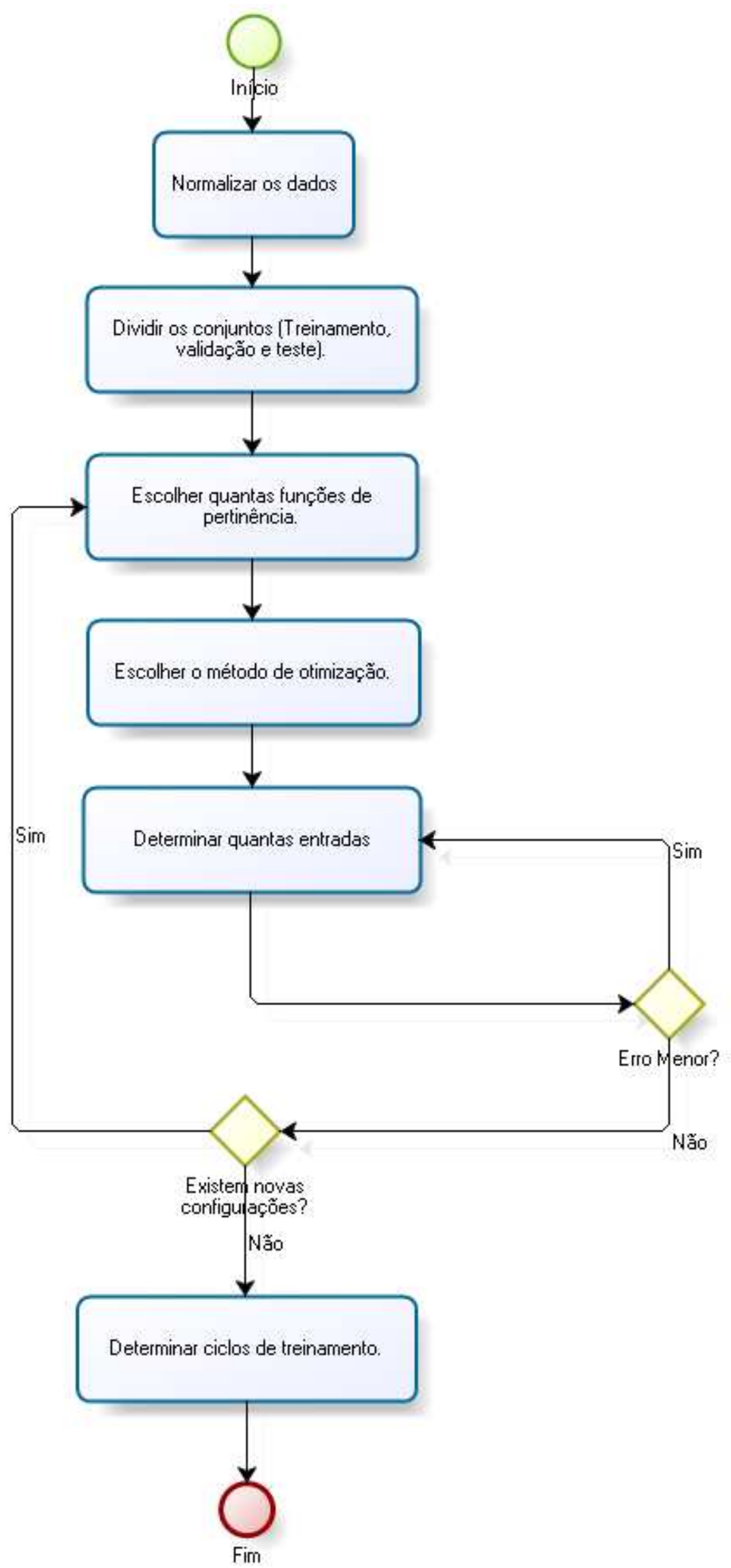

Figura 4.1 - Fluxograma da validação cruzada empregada nesse trabalho 


\subsubsection{MAPE}

As diversas topologias foram avaliadas calculando-se o erro relativo percentual médio (MAPE - Mean Average Percentage Error) para o conjunto de teste, isto é

$$
M A P E=\frac{1}{N} \sum_{i=1}^{N}\left|\frac{d_{i}-o_{i}}{d_{i}}\right| \times 100 \%
$$

onde $d_{i}$ é a saída desejada, $o_{i}$ é a saída obtida e $N$ é o número de padrões de teste.

A metodologia empregada na determinação da melhor arquitetura ANFIS foi, portanto, a de validação cruzada.

\subsection{Aspectos dos Dados Utilizados na Previsão de Demanda de Energia Elétrica}

As séries temporais de demanda de energia elétrica utilizadas foram medidas ao longo de uma semana, iniciando na segunda-feira e terminando no domingo, em intervalos de 5 minutos, em subestações de Cordeirópolis, Mogi-Guaçu, Ubatuba e Votuporanga, cidades localizadas no estado de São Paulo.

Observando-se a Figura 4.2, verifica-se que as séries temporais de Mogi-Guaçu, Ubatuba e Votuporanga têm comportamento sazonal bem evidente, ou seja, nas primeiras horas da madrugada o consumo de energia é baixo, aumenta durante a manhã até se ter uma pequena queda no início da tarde. Volta então a aumentar e atinge pico máximo no início da noite. Depois desse pico, com o entardecer, o consumo vai diminuindo até atingir seu ponto mínimo durante a madrugada. Pode-se verificar também um comportamento sensivelmente distinto para os dois últimos dias por se tratarem de sábado e domingo, ou seja, final de semana. 
A série temporal de Cordeirópolis apresenta comportamento sazonal com altos e baixos, mas com variações ao longo dos dias da semana. Na segunda e terça-feira o consumo é menor do que nos outros dias da semana e, no final de semana, seu comportamento identifica o consumo doméstico de energia naquela cidade.
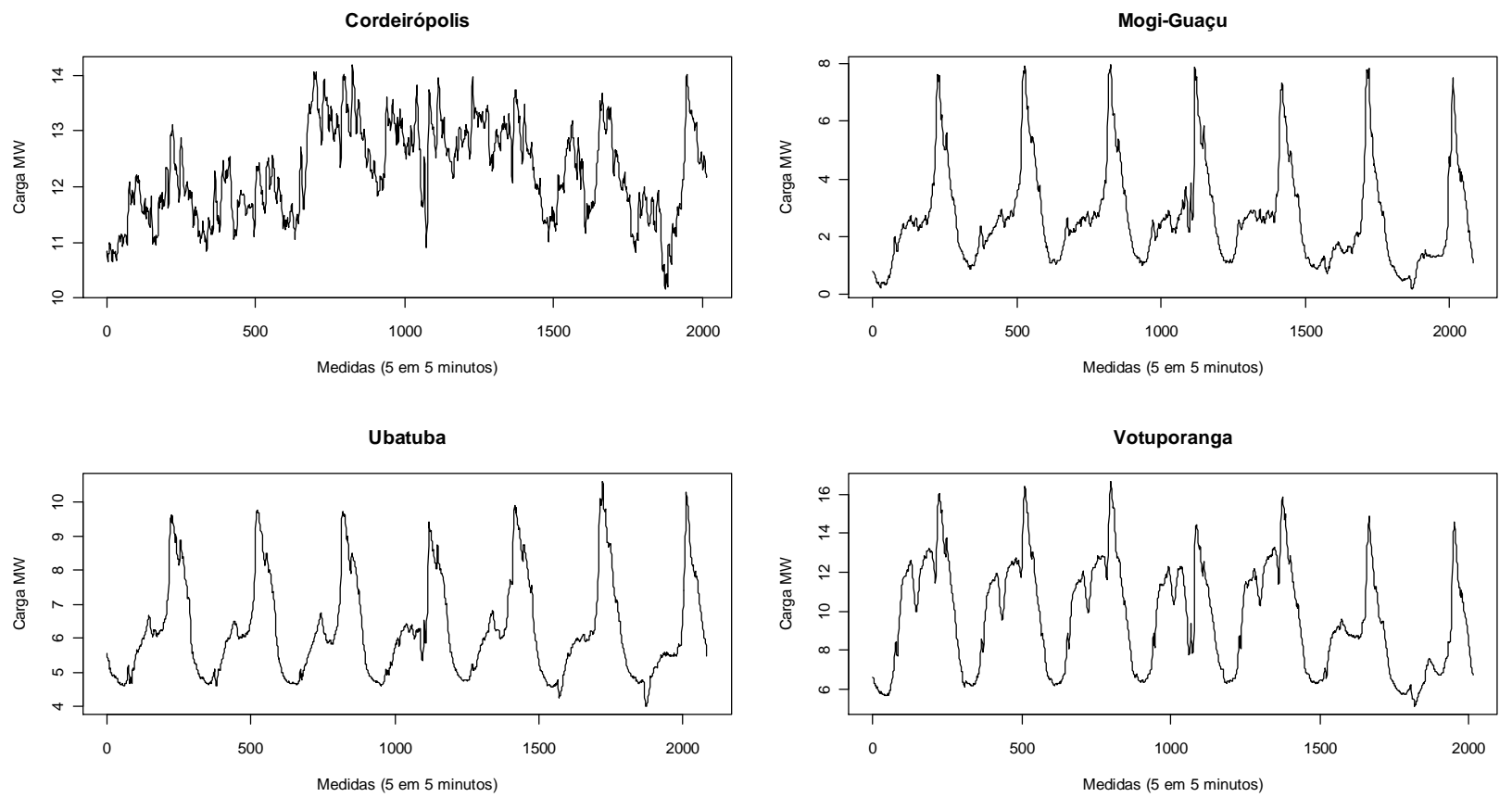

Figura 4.2 - Séries temporais mensuradas nas subestações de Cordeirópolis, Mogi-Guaçu, Ubatuba e Votuporanga

\subsection{Resultados da Aplicação da Abordagem ANFIS}

Para analisar o desempenho do ANFIS para previsão das séries temporais mensuradas nas substações de Cordeirópolis, Mogi-Guaçu, Ubatuba e Votuporanga, foram desenhados os gráficos de treinamento para cada uma delas. Também foram comparados o gráfico da série temporal mensurada com o gráfico da série temporal prevista, para as quatro subestações. Para uma análise mais precisa foi também compilado o histograma dos erros relativos, com o qual se pode identificar o comportamento destes como um todo, assim como, o erro máximo obtido. 


\subsubsection{Gráficos e histograma dos resultados de Cordeirópolis}

O gráfico da Figura 4.3 mostra o comportamento do erro quadrático médio durante os 350 ciclos de treinamento. Pode-se verificar que não ocorrem oscilações na curva de erro de treinamento em azul tracejado, mas ocorrem pequenas oscilações no gráfico de erro de validação entre os ciclos de número vinte e cinco e cem. O erro quadrático médio caiu rapidamente e as curvas de treinamento se estabilizaram por volta do centésimo ciclo de treinamento. Outra particularidade foi a de que o erro final de validação foi menor do que o erro de treinamento.

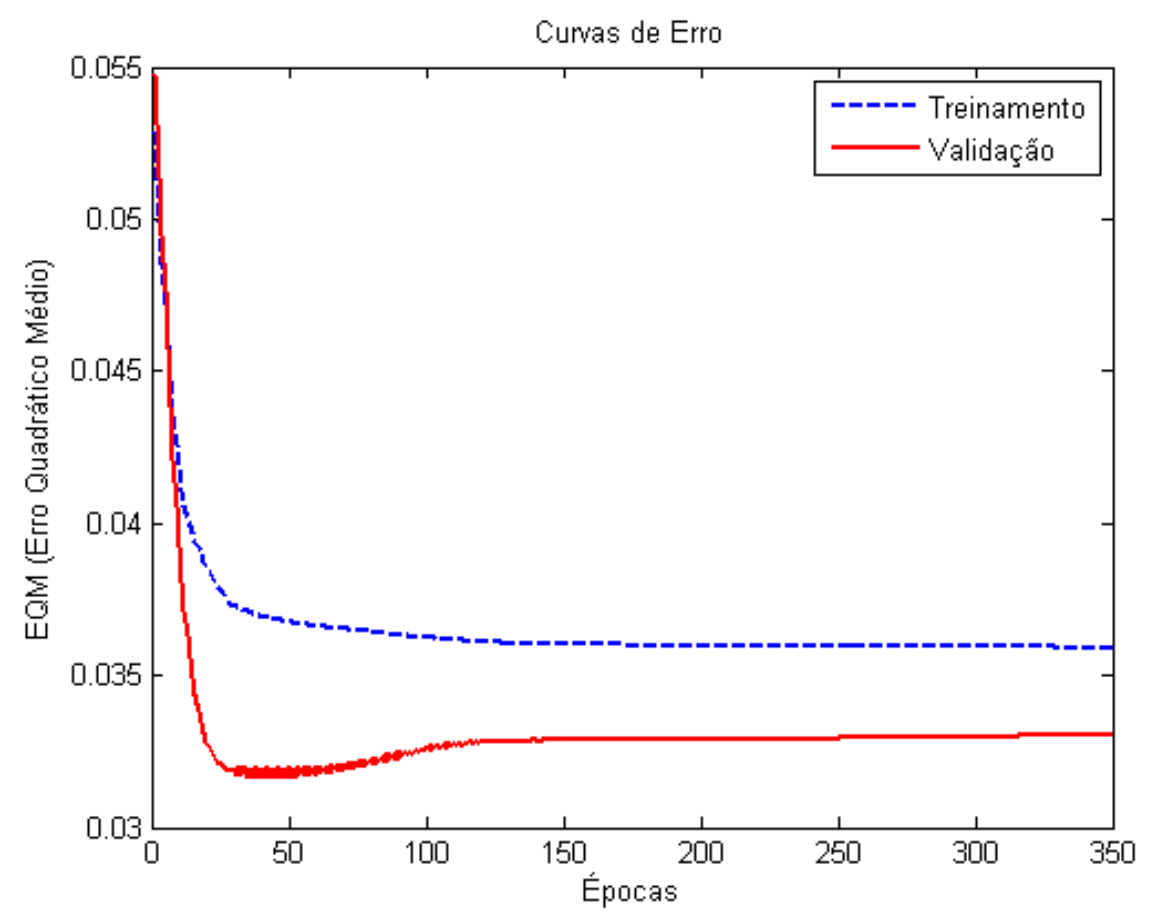

Figura 4.3 - Gráfico das curvas de treinamento do ANFIS para Cordeirópolis

O gráfico da Figura 4.4 apresenta as curvas mensurada, em azul tracejado, e prevista, em vermelho contínuo, para que se possa verificar que as séries têm um comportamento bem parecido, a menos de um trecho contendo por volta de 60 medidas que apresenta um comportamento um pouco distinto. 


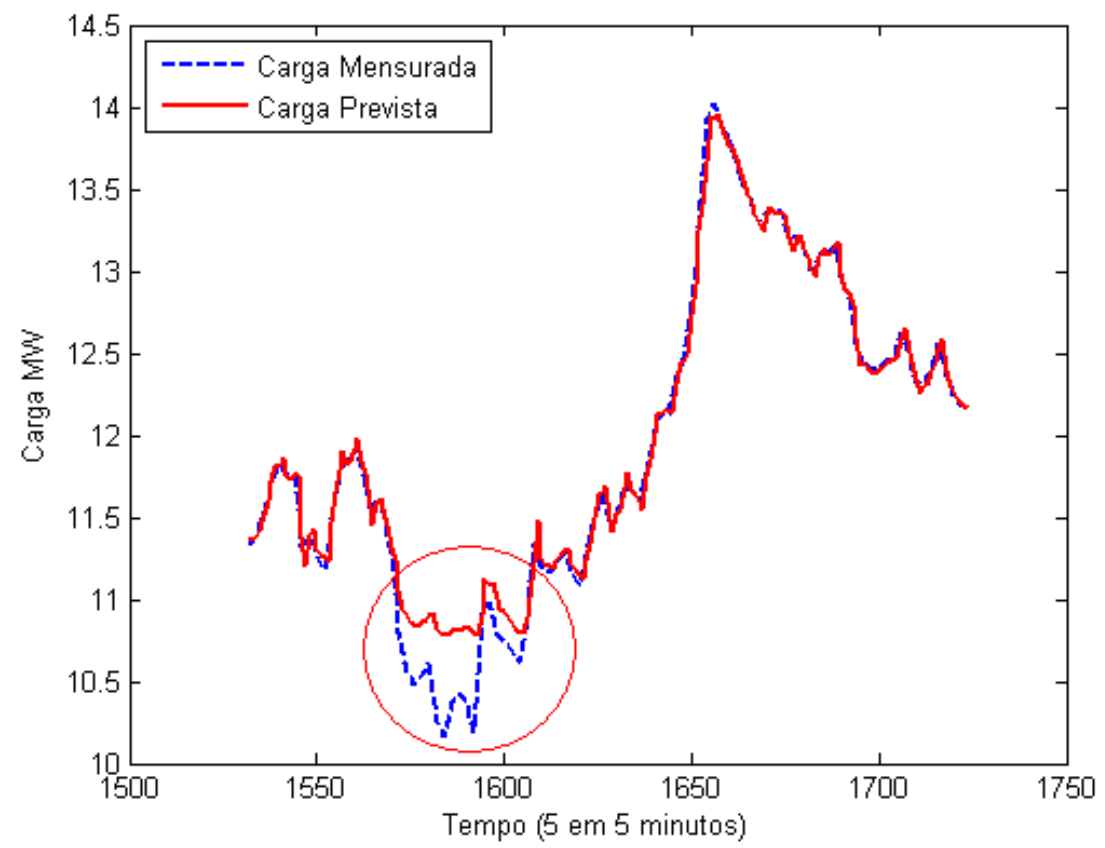

Figura 4.4 - Gráfico das curvas mensurada e prevista para Cordeirópolis

Apesar do comportamento distinto nesse trecho pode-se verificar por meio do histograma dos erros, apresentado na Figura 4.5, que a sua grande maioria ficou bem próximo de zero e que o maior erro obtido foi inferior a $6 \%$.

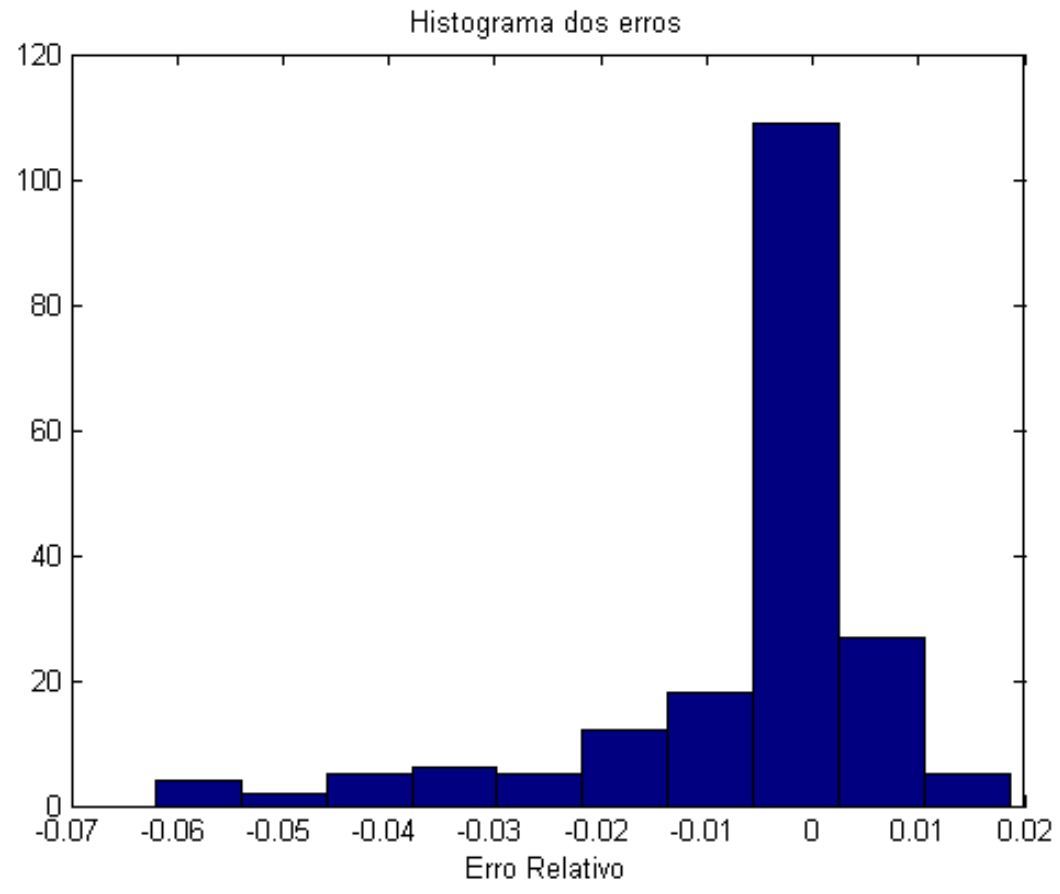

Figura 4.5 Histograma dos erros relativos para Cordeirópolis 
Outro resultado importante é aquele do MAPE para três treinamentos distintos, apresentado na Tabela 4.1. O resultado foi muito próximo para os três treinamentos e a média obtida sobre eles foi de $0,84 \%$. A variância calculada sobre os erros foi de $2,025 \times 10^{-4}$ para os três treinamentos, sendo considerado um valor bem baixo, mostrando-se que não ocorreu nenhum erro mais significativo.

\subsubsection{Gráficos e histograma dos resultados de Mogi-Guaçu}

As curvas de treinamento de Mogi-Guaçu, ilustradas na Figura 4.6, mostram que no início do treinamento do ANFIS, apesar do erro de treinamento cair rapidamente, o erro de validação oscilou bastante. Essa oscilação perdurou até o ciclo de treinamento de número 200 e ficou estabilizada a partir desse ponto. O erro quadrático médio, após todo ciclo de treinamento, foi menor para os dados de treinamento do que para a validação.

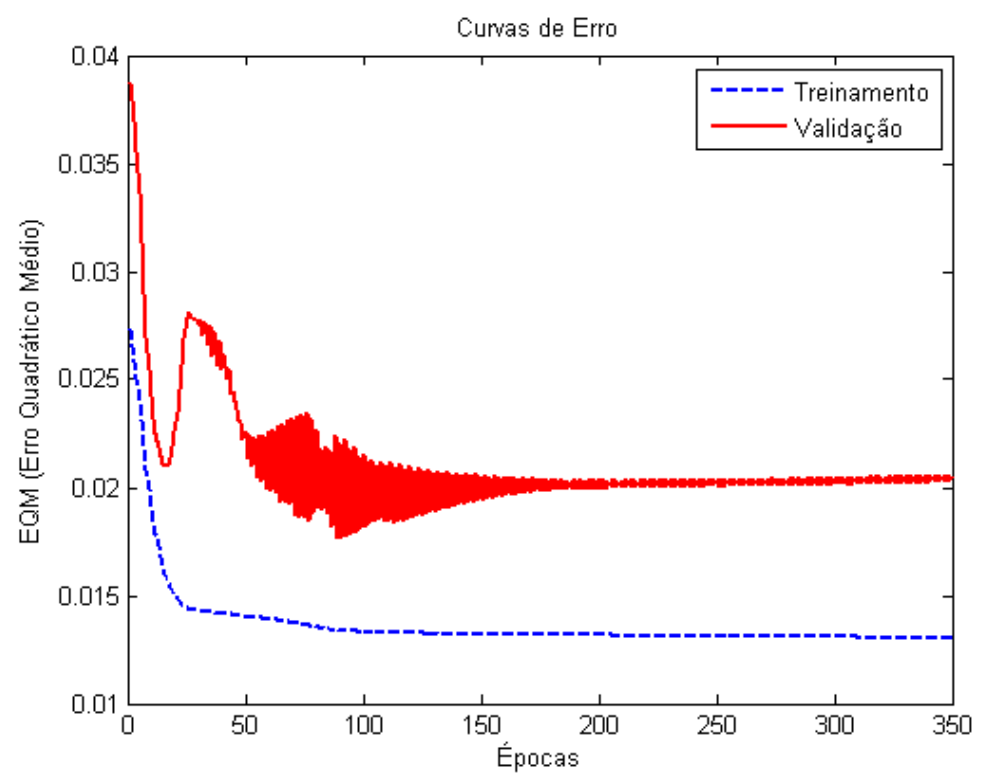

Figura 4.6 - Gráfico das curvas de treinamento do ANFIS para Mogi-Guaçu.

O gráfico da Figura 4.7 apresenta as séries temporais de teste. A série mensurada na subestação está em azul tracejado e a série em vermelho contínuo foi a obtida por meio da previsão com uso do ANFIS. Pode-se constatar que as séries estão praticamente justapostas, o que demonstra que o ANFIS apresentou bom desempenho. 


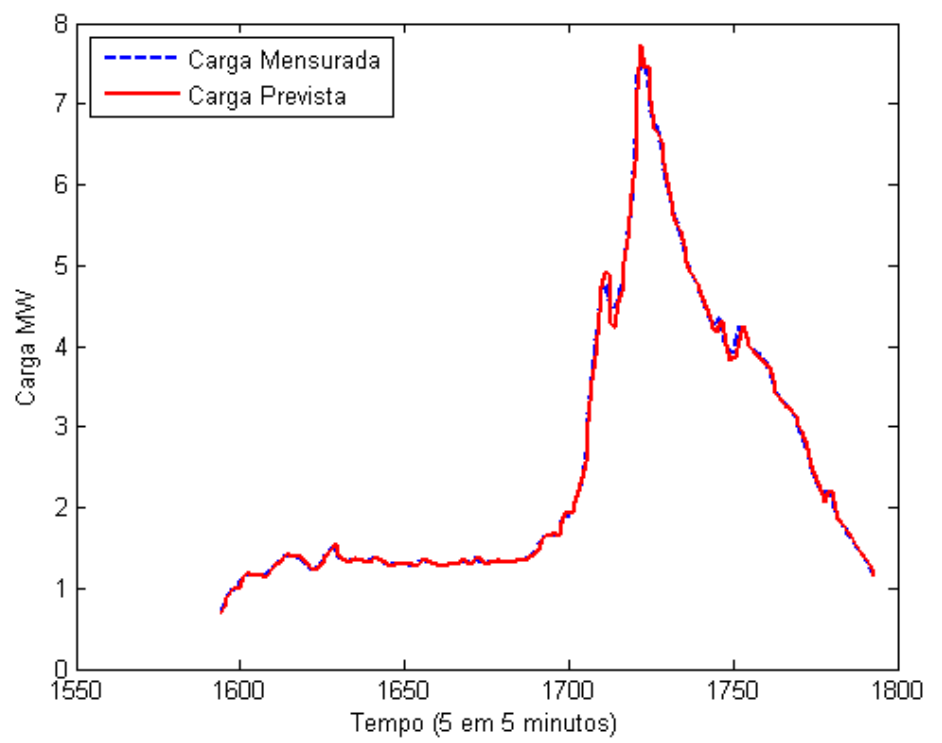

Figura 4.7 - Gráfico das curvas mensurada e prevista para Mogi-Guaçu

A Figura 4.8 apresenta o histograma dos erros para Mogi-Guaçu. Pode-se verificar que os erros, em sua maioria, são bem próximos de zero e que, no pior caso, o erro é inferior a 8\%. Os dados da Tabela 4.1 para Mogi-Guaçu apresentam um MAPE médio, entre três

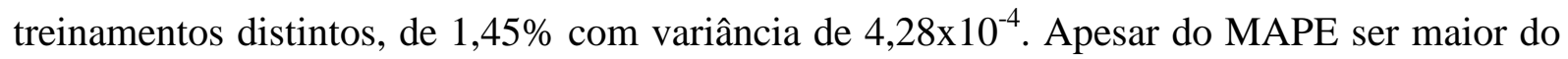
que no caso de Cordeirópolis, o seu valor ainda é bem baixo.

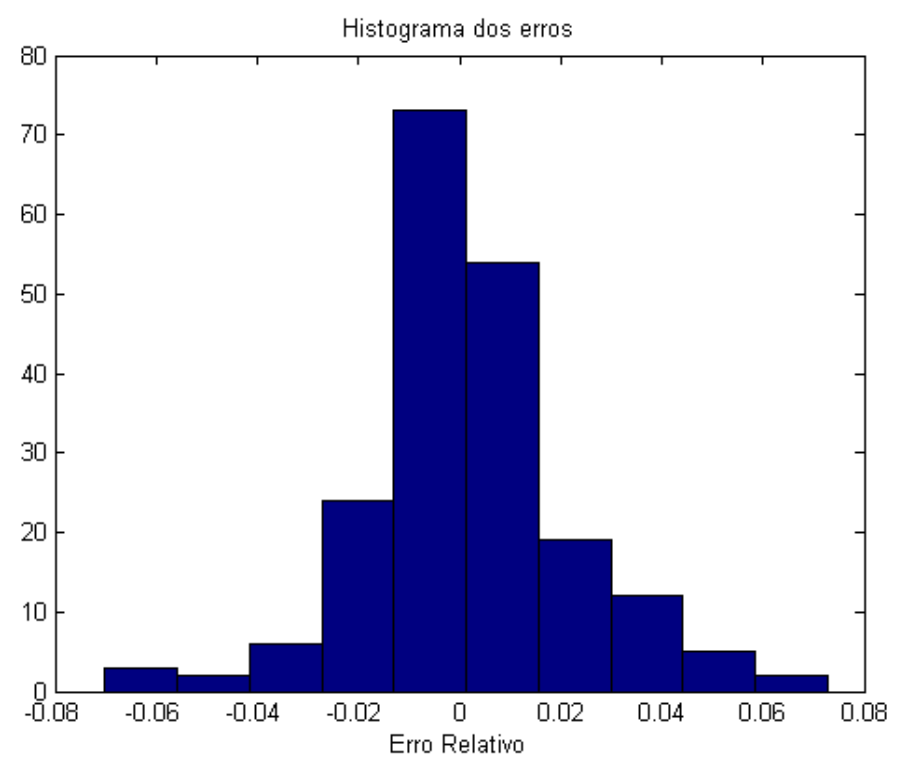

Figura 4.8 - Histograma dos erros relativos para Mogi-Guaçu 


\subsubsection{Gráficos e histograma dos resultados de Ubatuba}

Pode-se observar, pelos gráficos de treinamento, ilustrados na Figura 4.9, que ocorreu uma acentuada queda do erro quadrático médio de treinamento nas primeiras épocas. No caso do erro de validação, pode-se constatar que foram necessários quase 350 épocas para seu erro quadrático médio se estabilizar. Também, ocorreram oscilações por volta do ciclo de treinamento de número 60 com a validação e um pequeno crescimento do erro quadrático médio entre as épocas 60 e 330.

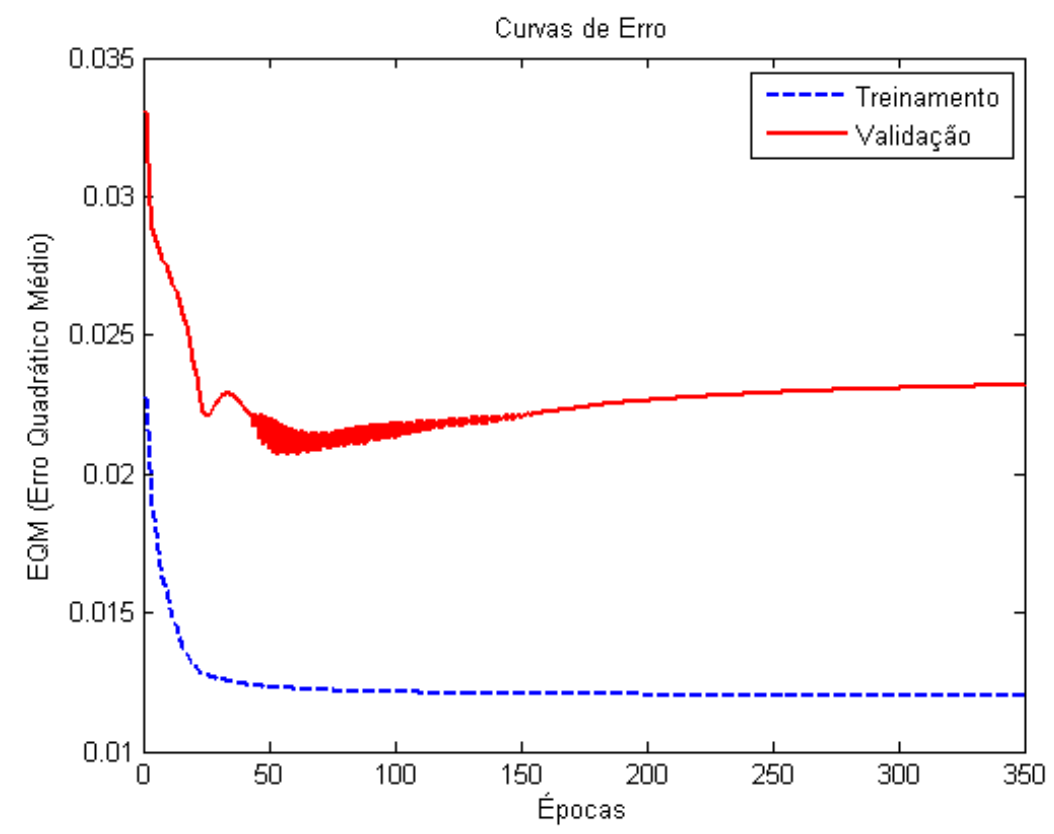

Figura 4.9 - Gráfico das curvas de treinamento para Ubatuba

A Figura 4.10 apresenta as séries temporais mensurada, em azul tracejado, e prevista, em vermelho contínuo. Pode-se observar que estas apresentam comportamento muito semelhante, o que demonstra que os erros relativos em cada um dos pontos foi muito pequeno. Não ocorrem trechos com comportamento distintos, inclusive em pontos de difícil previsão como nos picos e vales. 


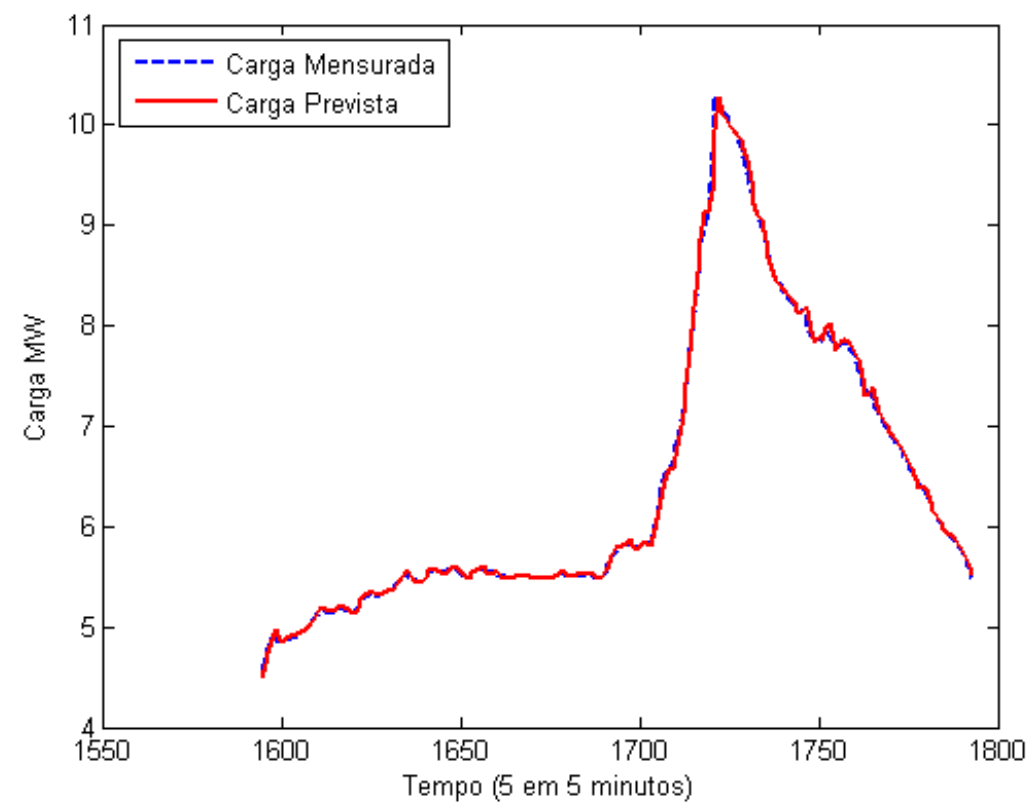

Figura 4.10 - Gráfico das curvas mensurada e prevista para Ubatuba

O histograma dos erros para Ubatuba é apresentado na Figura 4.11. Pode-se observar, por meio deste, que os erros relativos são, em sua maioria, bem próximos de zero. $\mathrm{O}$ histograma também mostra que o maior erro relativo encontrado é menor do que $4 \%$. Outros dados importantes estão na Tabela 4.1, que apresenta uma média no MAPE para três treinamentos distintos com valor de $0,47 \%$ e variância de $0,46 \times 10^{-5}$.

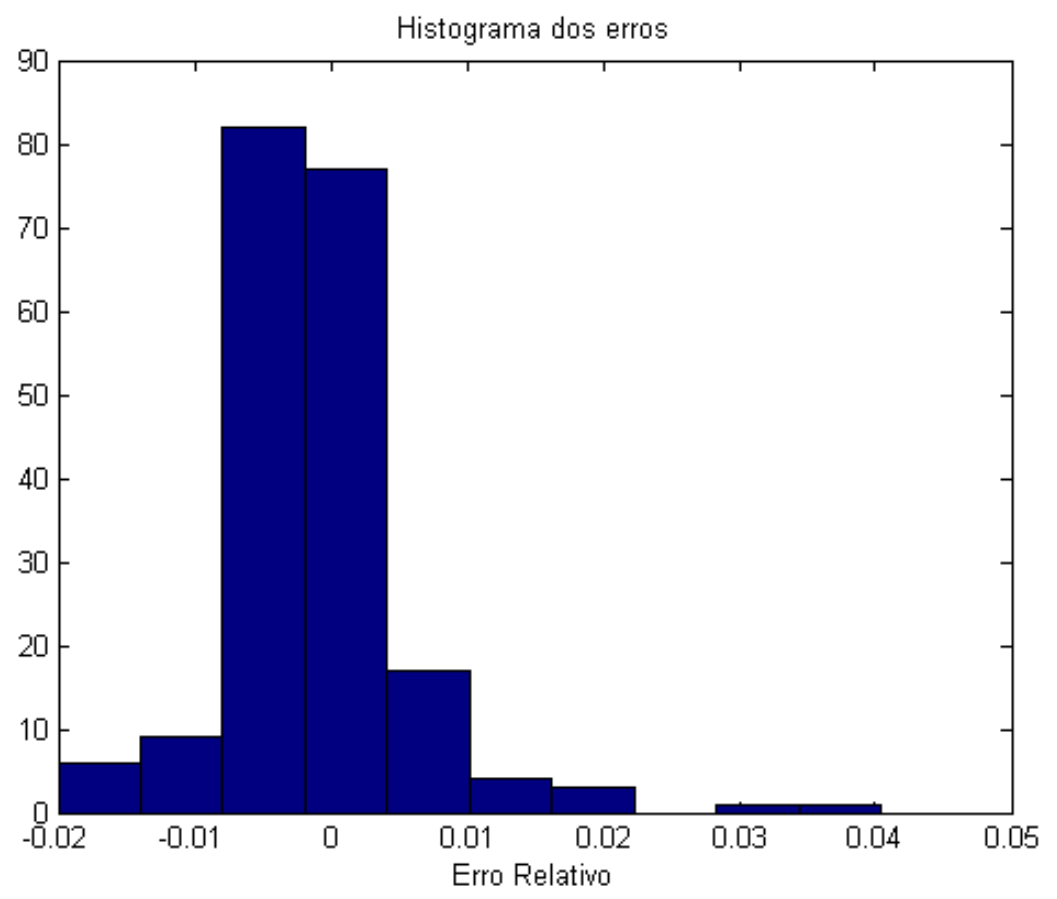

Figura 4.11 - Histograma dos erros relativos para Ubatuba 


\subsubsection{Gráficos e histograma dos resultados de Votuporanga}

O gráfico da Figura 4.12 apresenta as curvas do erro quadrático médio de treinamento para a série temporal da subestação de Votuporanga. Pode-se observar que, apesar da queda acentuada do erro de treinamento, o erro de validação oscila bastante, apresentando-se um crescimento entre as épocas de número 50 e 280. Após a época 280, o erro de validação volta a decrescer se estabilizando na seqüência. Foi empregado um número de épocas superior a 350, mas esse não apresentou melhora no MAPE calculado para o conjunto de teste de Votuporanga.

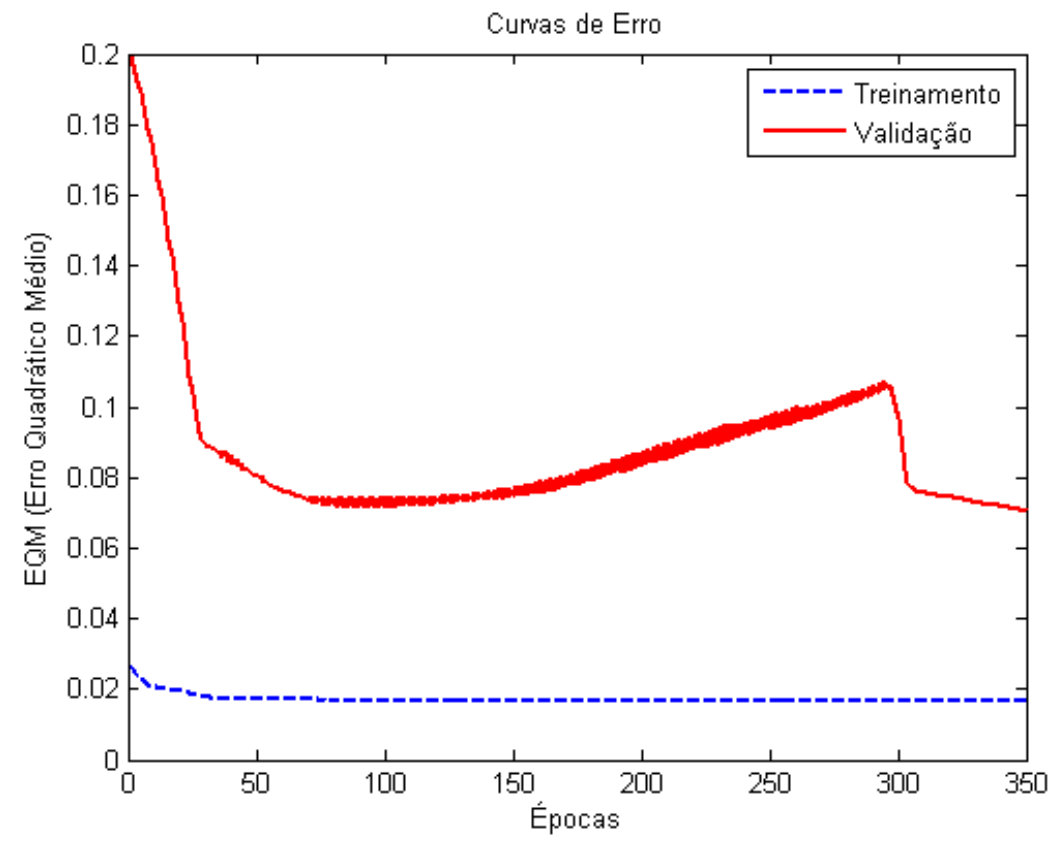

Figura 4.12 - Gráfico das curvas de treinamento para Votuporanga

As curvas mensurada, em azul tracejado, e prevista, em vermelho contínuo, para o conjunto de teste de Votuporanga são apresentadas na Figura 4.13. Pode-se observar que estas apresentam comportamento muito semelhante, a menos do seu início onde elas apresentam um trecho sensivelmente distinto. De qualquer forma, a previsão apresentou um resultado muito bom, inclusive para os picos que podem ser observados nos gráficos. 


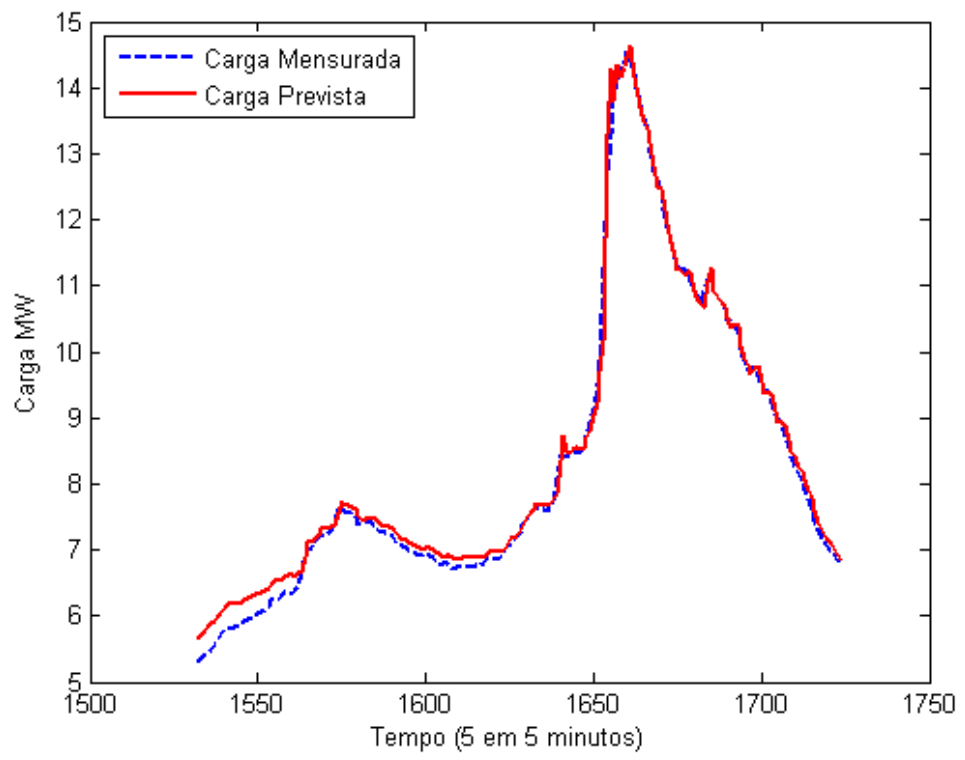

Figura 4.13 - Gráfico das curvas mensurada e prevista para Votuporanga

O histograma dos erros relativos para a série temporal mensurada na subestação de Votuporanga é apresentado na Figura 4.14. Pode-se verificar, por meio deste, que a maioria dos erros estão bem próximos de zero e que o maior erro encontrado ficou por volta de $10 \%$. Outros dados importantes para a previsão de Votuporanga estão na Tabela 4.1. Esta apresenta o MAPE médio para três treinamentos distintos com valor de $1,89 \%$ e variância de $4,81 \times 10^{-4}$.

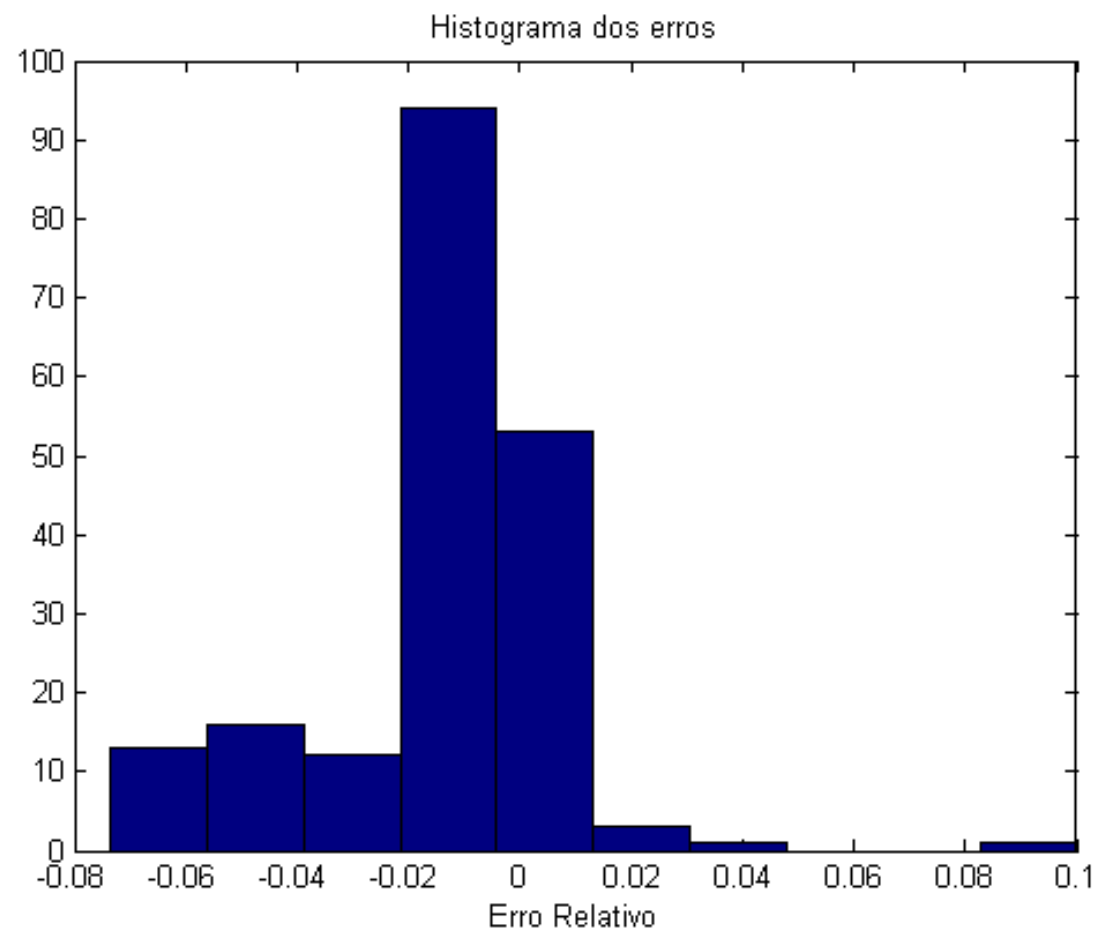

Figura 4.14 - Histograma dos erros relativos de Votuporanga 


\subsubsection{Tabela com o MAPE e variância}

A Tabela 4.1 apresenta o MAPE e a variância dos erros para três treinamentos distintos para cada uma das subestações onde as medidas foram coletadas. Pode-se notar que, tanto o MAPE quanto a variância apresentaram valores muito semelhantes para cada uma dos três treinamentos. No caso de Cordeirópolis o MAPE ficou bem próximo de $0,84 \%$, com variância de $2,03 \times 10^{-4}$. No caso de Mogi-guaçu o MAPE foi um pouco maior, $1,45 \%$, e

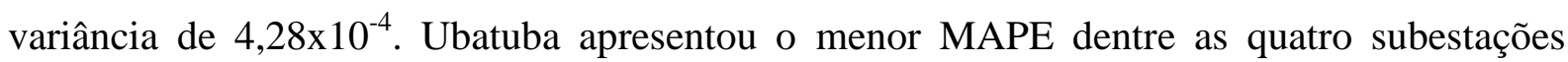
estudadas, com valor de $0,47 \%$ e variância de $0,67 \times 10^{-5}$. O pior resultado dentre as quatro subestações estudadas ficou com Votuporanga, com MAPE de 1,88\%, que ainda é um MAPE bem baixo, e variância de $4,81 \times 10^{-4}$.

Tabela 4.1- Tabela dos erros e variância para Cordeirópolis, Mogi-Guaçu, Ubatuba e Votuporanga

\begin{tabular}{|l|r|c||r|r||}
\cline { 2 - 5 } \multicolumn{1}{c|}{} & \multicolumn{2}{c||}{ Cordeirópolis } & \multicolumn{2}{c||}{ Mogi-Guaçu } \\
\cline { 2 - 5 } \multicolumn{1}{c|}{} & MAPE & Variância & MAPE & Variância \\
\hline \hline Treinamento 1 & 0,8388 & $2,0253 \mathrm{E}-04$ & 1,4530 & $4,2884 \mathrm{E}-04$ \\
\cline { 2 - 5 } Treinamento 2 & 0,8287 & $2,0253 \mathrm{E}-04$ & 1,4528 & $4,2884 \mathrm{E}-04$ \\
\cline { 2 - 5 } Treinamento 3 & 0,8388 & $2,0253 \mathrm{E}-04$ & 1,4530 & $4,2884 \mathrm{E}-04$ \\
\hline Média & 0,8354 & $2,0253 \mathrm{E}-04$ & 1,4529 & $4,2884 \mathrm{E}-04$ \\
\hline \hline
\end{tabular}

\begin{tabular}{||r|r|r|r|r||}
\cline { 2 - 5 } \multicolumn{1}{c|}{} & \multicolumn{2}{c||}{ Ubatuba } & \multicolumn{2}{c||}{ Votuporanga } \\
\cline { 2 - 5 } \multicolumn{1}{c|}{} & MAPE & Variância & MAPE & Variância \\
\hline \hline Treinamento 1 & 0,4678 & $4,6761 \mathrm{E}-05$ & 1,8884 & $4,8107 \mathrm{E}-04$ \\
Treinamento 2 & 0,4678 & $4,6761 \mathrm{E}-05$ & 1,8885 & $4,8107 \mathrm{E}-04$ \\
\cline { 2 - 5 } Treinamento 3 & 0,4679 & $4,6761 \mathrm{E}-05$ & 1,8884 & $4,8107 \mathrm{E}-04$ \\
\hline Média & 0,4678 & $4,6761 \mathrm{E}-05$ & 1,8884 & $4,8107 \mathrm{E}-04$ \\
\hline \hline
\end{tabular}

\subsection{Considerações Sobre os Resultados Obtidos}

No tópico de introdução dessa dissertação foram apresentados resumos dos trabalhos publicados nos últimos anos, com as mais variadas técnicas de previsão de demanda de energia elétrica para todos os horizontes. Na grande maioria desses trabalhos, os erros de 
previsão foram também calculados por meio do MAPE (Mean Average Percentage Error), o que permite, portanto, verificar se os resultados obtidos aqui são bons quando comparados com àqueles presentes em tal literatura.

Retomando-se os trabalhos publicados pode-se verificar que o método aplicado aqui, ou seja, a previsão por meio do ANFIS apresentou desempenho melhor ou igual aqueles presentes na literatura, pois:

- Rahman e Hazim (1993), que empregaram um algoritmo baseado em conhecimento e dados estatísticos para fazer previsão no horizonte de curto prazo, obtiveram um MAPE resultante de seu trabalho que ficou entre $1,22 \%$ e 2,7\%.

- Charytoniuk e Chen (2000), que empregaram redes neurais artificiais para previsão no curtíssimo prazo, resultou num MAPE entre 0,66\% e 1,05\%.

- González e Zamarreño (2004), que se basearam em redes neurais artificiais recorrentes e informações de previsão de temperatura, obtiveram um MAPE médio de $1,95 \%$.

- Beccali et al. (2004), que fizeram previsão de demanda de energia elétrica no curto prazo, empregando redes neurais artificiais e dados meteorológicos, obtiveram um MAPE entre $0,09 \%$ e $3,81 \%$.

- Mandal et al. (2004) obtiveram um MAPE entre 0,98\%, para um passo à frente, e $2,43 \%$ para seis passos à frente.

- Pai e Hong (2005) aplicaram Support Vector Machines e algoritmos genéticos para determinar o ajuste dos pesos entre os nós de uma rede neural recorrente de Jordan. O MAPE obtido por eles ficou entre $0,75 \%$ e $1,90 \%$.

- Yang et al. (2006) obtiveram um MAPE médio de 0,88\% para previsões com freqüência de quinze minutos, e horizonte de um dia, e um MAPE de 0,89\% com essa freqüência, mas horizonte de duas semanas. 
- Yap et al. (2006) combinaram uma nova rede neural híbrida, conhecida como Gaussian Regression com dinamic decay (GRD) para previsão de demanda de energia elétrica no curto prazo. Os autores obtiveram como resultado um MAPE de 1,2\% para previsão de 30 minutos à frente e um MAPE médio de 1,65\% para previsão de um dia (24 horas) à frente.

- Romera et al (2006) dividiram a previsão de demanda de energia elétrica no médio prazo em duas etapas complementares: previsão de tendência e previsão de flutuação da série temporal. Em seguida, aplicaram redes neurais para previsão de cada uma delas. O MAPE resultante em seu trabalho foi de 2,03\%.

- Ghiassi et al., (2006) fizeram uso de um modelo de rede neural artificial dinânica e o empregaram em previsão de demanda de energia elétrica no médio prazo. O MAPE de um passo à frente ficou entre $0,80 \%$ e 2,86\%.

- Campbell (2007) empregou sistemas inteligentes para previsão de demanda de energia elétrica no curtíssimo prazo e obteve um MAPE entre 0,89\% e 2,96\%.

- Romera et al., também em 2007, empregaram redes neurais perceptron multicamadas com algoritmo de aprendizado Levenberg-Marquadt para previsão de demanda de energia elétrica no médio prazo. Obtiveram um MAPE de $2 \%$ e MAPE menor do que $7 \%$ no pior caso.

- O MAPE obtido no trabalho de Tripathi et al. (2008) foi de 2,34\% e 2,96\% com uso da GRNN (Generalized Regression Neural Network) e PNN (Probabilistic Neural Network), respectivamente.

- Romera et al. (2008) fizeram uma comparação entre o uso de redes neurais artificiais, o modelo ARIMA e séries de Fourier para previsão da flutuação da demanda de energia elétrica e obtiveram os resultados de $2,11 \%, 4,1 \%$ e $1,74 \%$, respectivamente. 
- Abdel-Aal (2008) empregou abductive networks e redes neurais artificiais para previsão de demanda de energia elétrica no médio prazo. O MAPE obtido ficou entre $3,2 \%$ e $3,8 \%$.

- Mamlook et al. (2009) aplicaram inferência fuzzy para previsão de demanda de energia elétrica no curto prazo com obtenção de um MAPE entre 1,2\% e 3,2\%.

- Amjady e Keynia (2009) propuseram um método híbrido para previsão de demanda de energia elétrica no curto prazo, composto de transformada wavelet, redes neurais artificiais e algoritmos evolutivos. O MAPE obtido por eles ficou entre $0,61 \%$ e $0,94 \%$ para uma hora à frente e entre $1,41 \%$ e $2,56 \%$ para seis horas à frente.

- Bashir e Hawary (2009) fizeram previsão de demanda de energia elétrica no curto prazo e obtiveram um MAPE de $2 \%$ com uso de carga, temperatura e umidade como entradas para sua rede neural.

O MAPE obtido, nesse trabalho, para previsão de demanda de energia elétrica no curtíssimo prazo em um passo à frente foi, conforme Tabela 4.1, de $0,84 \%$ para a subestação de Cordeirópolis, de 1,45\% para a subestação de Mogi-Guaçu, de 0,47\% para subestação de Ubatuba e, finalmente, de $1,88 \%$ para subestação de Votuporanga. Portanto, valores que demonstram que o desempenho do ANFIS, nesse trabalho, é equivalente ou melhor que os resultados encontrados na literatura nos últimos anos. 


\section{Conclusões Gerais e Trabalhos Futuros}

\subsection{Conclusões Gerais}

Nesse trabalho foi efetuada uma revisão da literatura relacionada à previsão de demanda de energia elétrica com o objetivo de se obter informações sobre os métodos empregados e sobre os horizontes investigados nos últimos anos. A partir das informações de tais trabalhos pôde-se determinar que são poucos aqueles de previsão de demanda de energia elétrica no curtíssimo prazo, ou de minutos à frente. A maioria dos trabalhos se concentra na pesquisa em horizontes de curto prazo ou horas à frente. Tais trabalhos extraem informações de dados relacionados com a demanda por energia elétrica para esse horizonte, como fatores meteorológicos ou econômicos. No caso do horizonte de curtíssimo prazo, a literatura afirma que toda informação para se fazer a previsão está contida na própria série temporal da carga mensurada no sistema elétrico de potência. Intuitivamente, pode-se verificar que tal informação é pertinente, pois as mudanças no clima e razões sociais não podem influenciar, significativamente, o comportamento dos dados que serão mensurados alguns minutos à frente.

Outra conclusão em que se pode chegar, baseando-se nas informações contidas nos trabalhos publicados nos últimos anos, é a de que apenas um trabalho empregou o ANFIS em previsão de demanda de energia elétrica.

Portanto, considerando-se as informações obtidas da literatura, esse trabalho empregou o Adaptive Neuro Fuzzy Inference System (ANFIS) para previsão de demanda de energia elétrica no curtíssimo prazo para um passo à frente, obtendo resultados equivalentes ou melhores do que aqueles encontrados na literatura nos últimos anos. Foi adotado o método de 
validação cruzada para se determinar a melhor formação para os conjuntos de entrada e saída, como também, para determinação dos parâmetros necessários para se empregar o ANFIS, como número de funções de pertinência e seu tipo etc.

\subsection{Trabalhos Futuros}

Dentre os trabalhos que podem ser desenvolvidos em previsão de demanda de energia elétrica no curtíssimo prazo, existe aquela de previsão de múltiplos passos à frente, uma vez que nesse trabalho desenvolveu-se a previsão de apenas um passo à frente. 


\section{Referências Bibliográficas}

Abdel-Aal, R. E. (2007). Univariate Modeling and Forecasting of Monthly Energy Demand Time Series Using Abductive and Neural Networks, Computers \& Industrial Engineering, vol. 54, pp. 903-917.

Alsayegh, O., Almatar, O., Fairouz, F., Al-Mulla Ali A. (2007). Prediction of the Long-Term Electric Power Demand Under the Influence of A/C Systems, Journal of Power and Energy, vol. 221, pp. 67-75.

Amjady, N., Keynia, F. (2009). Short-Term Load Forecasting of Power Systems by Combination of Wavelet Transform and Neuro-Evolutionary Algorithm, Energy, vol. 34, pp. 46-57.

Azadeh, A., Ghaderi, S. F., Tarverdian, S., Saberi, M. (2007). Integration of Artificial Neural Networks and Genetic Algorithm to Predict Electrical Energy Consumption, Applied Mathematics and Computation, pp. 1731-1741.

Bashir, Z. A., El-Hawary, M. E. (2009). Applying Wavelets to Short-Term Load Forecasting Using PSO-Based Neural Networks, IEE Transactions On Power Systems, vol. 24, pp. 2027.

Beccali, M., Cellura, M., Lo Brano, V., Marvuglia, A. (2004). Forecasting Daily Urban Electric Load Profiles using Artificial Neural Networks, Energy Conversion and Management, vol. 45, pp. 2879-2900.

Campbell, P. R. J. (2007). A Hybrid Modelling Technique for Load Forecasting, IEEE Canada Electrical Power Conference, pp. 435-439.

Carmona, D., Jaramillo, M. A., González, E., Alvarez, J. D. (2002). Electric Energy Demand Forecasting with Neural Networks, Procedings of IEE IECOM, pp. 1860-1865. 
Cavallaro, F. (2005). Electric Load Analysis Using an Artificial Neural Network, International Journal of Energy Reserach, vol. 29, pp. 377-392.

Charytoniuk, W., Chen, M. (2000). Very Short-Term Load Forecasting Using Artificial Neural Networks, IEEE Transactions on Power Systems, vol. 15, pp. 263-268.

Cottet, R., Smith, M. (2003). Baysean Modeling and Forecasting of Intraday Electricity Load, Journal of the American Statistical Association, vol. 98, pp. 839-849.

Erdogdu, E., (2007). Electricity Demand Analysis Using Cointegration and ARIMA Modeling: A Case Study of Turkey, Energy Police, vol. 35, pp. 1129-1146.

Findlay, R., Liu, Fang (2006). Prediction Of Ontario Hourly Load Demands and Neural Network Modeling Techniques, Canadian Conference on Electrical and Computer Engineering., pp. 372-375.

Ghiassi, M., Zimbra, D. K., Saidane, H. (2006). Medium Term System Load Forecasting with a Dynamic Artificial Neural Network Model, Electric Power Systems Research, vol. 76, pp. 302-316.

González, P. A., Zamarreño, J. M. (2004). Prediction of Hourly Energy Consumption in Buildings Based on a Feedback Artificial Neural Network, Energy and Building, vol. 37, pp. 595-601.

Haydari, Z., Kavehnia, F., Askari, M., Ganbariyan, M. (2007). Time-Series Load Modelling and Load Forecasting Using Neuro-Fuzzy Techniques, $9^{\text {th }}$ International Conference. Electrical Power Quality and Utlisation, pp. 1-6.

Haykin, S. (1999). Neural Networks - A Conprehensive Foundation, Prentice Hall, Upper Saddle River, NJ.

Hippert, H. S., Bunn, D. W., Souza, R.C. (2005). Large Neural Networks for Electricity Load Forecasting: Are They Overfitted?, International Journal Of Forecasting, vol. 21, pp. 425434. 
Jang, J. (1993). ANFIS:Adaptive-Network-Based Fuzzy Inference System, IEEE Transactions on Systems, vol. 23, pp. 665-685.

Jang, J., Sun C., (1995). Neuro-Fuzzy Modeling and Control, Proceedings of The IEEE, vol. 83, pp. 378-406.

Kagan, N., Oliveira, C. C. B., Robba, E. J. (2005). Introdução aos Sistemas de Distribuição de Energia Elétrica, Edgard Blücher, São Paulo, SP, Brasil.

Karayiannis, N. B., Balasubramanian, M., Malki, H. A. (2003). Evaluation o Cosine Radial Basis Function Neural Networks on Electric Power Load Forecasting, Proceedings of the International Joint Conference on Neural Networks. vol. 3, pp. 2100-2105.

Karayiannis, N. B., Balasubramanian, M., Malki, H. A. (2005). Short-Term Power Load Forecasting Based on Cosine Radial Basis Function Neural Networks: An Experimental Evaluation, International Journal of Intelligent Systems, vol. 20, pp. 591-605.

Kawauchi, S., Sugihara, H., Sasaki, H. (2004). Development of Very-Short-Term Load Forescating Based on Chaos Theory, Electrical Engineering in Japan, vol. 148, pp. 55-63.

Khoa, T. Q. D., Phuong, L. M., Binh, P. T. T., Lien, N. T. H. (2004). Application of Wavelet and Neural Network to Long-Term Load Forecasting, International Conference on Power System Technology. vol. 1, pp. 840-844.

Mamlook, R., Badran, O., Abdulhadi, E. (2009). A Fuzzy Inference Model for Short-Term Load Forecasting, Energy Policy, vol. 37, pp. 1239-1248.

Mandal, P., Senjyu, T., Uezato, K., Funabashi, T. (2004). Forecasting Several-Hours-Ahead Eletricity Demand Using Neural Network, IEE International Conference on Electric Utility Deregulation, Restructuring and Power Technologies, vol. 2, pp. 515-521.

Methaprayoon, K., Lee, W. J., Rasmiddatta, S., Liao, J. R., Ross, R. J. (2007). Multistage Artificial Neural Network Short-Term Load Forecasting Engine With Front-End Weather Forecast, IEEE Transactions on Industry Applications, vol. 43, pp. 1410-1416. 
Mizutani, A., Yukawa, T., Numa, K., Kuze, Y., lizaka, T., Yamagish T., Matsui, T., Fukuyama, Y. (2005). Improvement of Input-Output Correlations of Electric Power Forecasting By Scatter Search, Proceedings of the 13th International Conference on Intelligent Systems Application to Power Systems, pp. 429-433.

Nahi S. (2006). Load Forecasting on Special Days \& Holidays in Power Distribution Substation Using Neural\&Fuzzy Networks, IEEE International Conference on Computational Intelligence for Modeling Control, pp. 118-123.

Pai, P. F., Hong, W. C. (2005). Forecasting Regional Electricity Load on Recurrent Support Vector Machines with Genetic Algorithms, Electric Power Systems Research, vol. 74, pp. 417-425.

Papalexopoulos, A. D., Hesterberg, T. C. (1990). A Regression-Based Approach to ShortTerm Load Forecasting, IEEE Transactions on Power Systems, vol. 5, pp. 1535-1543.

Phinphachan, S., Chamnongthai, K., Kumhom, P., Jittiwarangkul, N., Sangswang, A. (2004). Energy and Peak Load Forecasting Models Using Neural Network for Fast Developing Area, International Symposium on Communications and Information Technologies, vol. 1, pp. 389-393.

Rahman, S., Hazim, O. (1993). A Generalized Knowledge-Based Short-Term LoadForecasting Technique. IEEE Transactions on Power Systems, vol. 8, pp. 508-514.

Romera, E. G., Morán, M. A. J., Fernandez, D. C. (2008). Monthly Electric Energy Demand Forecasting With Neural Networks and Fourier Series, Energy Conversion and Management, vol. 49, pp. 3135-3142.

Romera, G. E., Moran, M. A. J., Fernandez, D. C. (2007). Forecasting of the Electric Energy Demand Trend and Monthly Fluctuation with Neural Networks. Computers \& Industrial Engineering, vol. 52. pp. 336-343. 
Romera, E. G., Morán, M. Á. J., Fernández, D. C. (2006). Monthly Electric Energy Demand Forecasting Based on Trend Extraction, IEEE Transactions on Power Systems, vol. 21, pp. 1946-1953.

Saksornchai, T., Lee, W., Methaprayon, K., Liao, J., Ross R. (2004). Improve the Unit Commitment Scheduling by Using the Neural Network Short Term Load, IEEE Industrial and Commercial Power Systems Technical Conference, pp. 33-39.

Schulte, R. P. (1996). An Automatic Generation Control Modification For Present Demands on Interconnected Power Systems, IEEE Transactions on Power Systems, vol. 11, pp. 1286-1294.

Senjyu, T., Takara, H., Uezato, K,. Funabash T. (2002). One-Hour-Ahead Load Forecasting Using Neural Network, IEEE Transactions on Power Systems, vol. 17, pp. 113-118.

Soares, L. J., Medeiros, M. C. (2008). Modeling and Forecasting Short-Term Electricity Load: A comparison of Methods with an Application to Brazilian Data, International Journal of Forecasting, vol. 24. pp. 630-644.

Suzuki, O., Wu, G., Minakawa, T. (2007). A Local Demand Forecast by NN Method for Distributed Autonomous Voltage and Reactive Control System. Electrical Engineering in Japan , vol. 159, pp. 1261-1269.

Taylor, J. W. (2003). Short-term Electricity Demand Forecasting using Double Seasonal Exponential Smoothing, Journal of the Operational Research Society, vol. 54. Pp. 799805.

Topalli, A. K., Erkmen, I. (2003). A Hybrid Learning for Neural Networks Applied to Short Term Forecasting, Neurocomputing, vol. 51, pp. 495-500.

Tripathi, M. M., Upadhyay, K. G., Singh (2008). Short-Term Load Forecasting Using Generalized Regression and Probabilistic Neural Networks in the Electricity Market, The Electricity Journal, vol. 21, pp. 24-34. 
Trudnowski, D. J., McReynolds, W. L., Jonhson J. M. (2001). Real-Time Very Short-Term Load Prediction for Power-System Automatic Generation Control, IEEE Transactions on Control System Technology, vol. 9, pp. 254-260.

Xiao, Z., Ye Shi-Jie, Zhong, B., Sun Cai-Xin (2009). BP Neural Network With Rough Set For Short Term Load Forecasting, Expert Systems with Applications, vol. 36, pp. 273-279.

Yang, H. Y., Ye, H., Wang, G., Khan, J., Hu, T. (2006). Fuzzy Neural Very-Short-Term Load Forecasting Based On Chaotic Dynamics Recostruction. Chaos Solitions \& Fractals, vol. 29, pp. 462-469.

Yao, Y., Lian, Z., Hou, Z., Liu, W. (2006) An Innovative Air-conditioning Load Forecasting Model Based on RBF Neural Network and Combined Residual Error Correction, vol. 29, pp. 528-538.

Yap, K. S., Abidin, I. Z., Lim, C. P., Shah, M. S. (2006). Short Term Load Forecasting Using a Hybrid Neural Network, First International Power and Energy Conference PECon, pp. 123-128.

Zadeh, L. A. (1965). Fuzzy Sets, Information and Control, vol. 8, pp. 338-353, Junho de 1965.

Zadeh, L. A. (1973). Outline of a New Approach to the Analysis of Complex Systems and Decision Processes, IEEE Transactions on Systems, Man and Cybernetics, vol. SMC-3, pp. 28-44, January 1973. 
Apêndice A

Uma vez que esse trabalho foi desenvolvido com o apoio do Matlab, seguem-se alguns aspectos dessa ferramenta no que se refere a seu toolbox de ANFIS.

\section{A.1 Aspectos do ANFIS no Matlab}

Existe um componente ANFIS no Matlab que permite o ajuste das funções de pertinência e a geração das regras fuzzy.

Uma interface gráfica do ANFIS no Matlab, ilustrada da Figura A.1, permite a determinação dos parâmetros que deverão ser inseridos para que o sistema faça a inferência. Essa interface é gerada por meio do comando anfisedit.

Os dados normalizados devem estar contidos em uma matriz formada pelas colunas de entrada e uma coluna de saída. Por meio do botão load data, os dados de treinamento, checagem ou validação e teste podem ser carregados.

Uma vez que os dados de entrada foram carregados, deve-se determinar parâmetros como número de funções de pertinência de cada nó e o tipo de funções de pertinência dos nós de entrada e saída. Tais parâmetros são determinados a partir da janela apresentada na Figura A.2 que é apresentada clicando-se no botão Generate FIS da janela principal, apresentada na Figura A.1 (Mathworks, 2007).

Nesse trabalho foi empregada a opção grid partition, que consiste em agrupar os dados representativos do sistema a ser mapeado em classes que contenham alguma similaridade.

Uma vez determinados os parâmetros de inicialização do sistema fuzzy (número de funções de pertinência para cada entrada, tipo de funções de pertinência, e tipo de função de pertinência de saída), determina-se o número de épocas para se executar o treinamento e/ou o 
erro mínimo que se deseja obter com o treinamento. Ambos são considerados critérios de parada do treinamento.

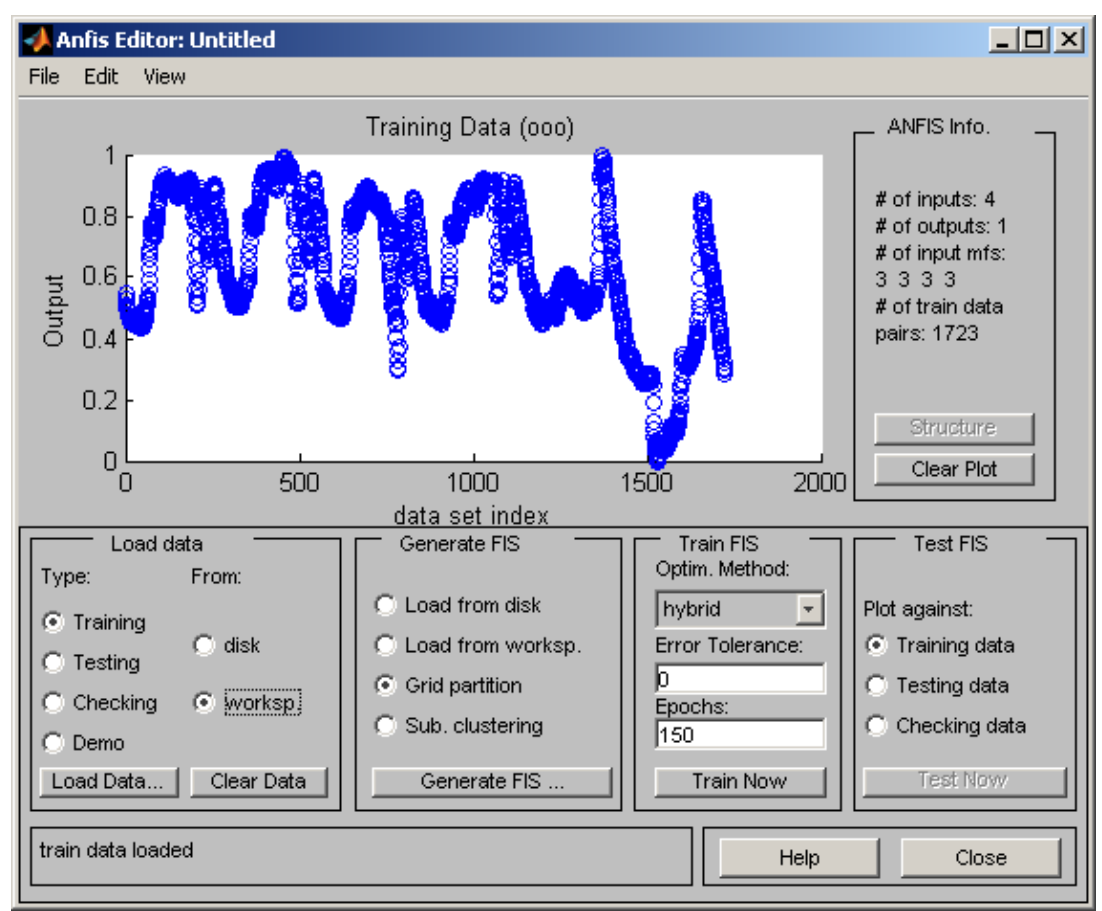

Figura A.1 - Interface gráfica do ANFIS no Matlab

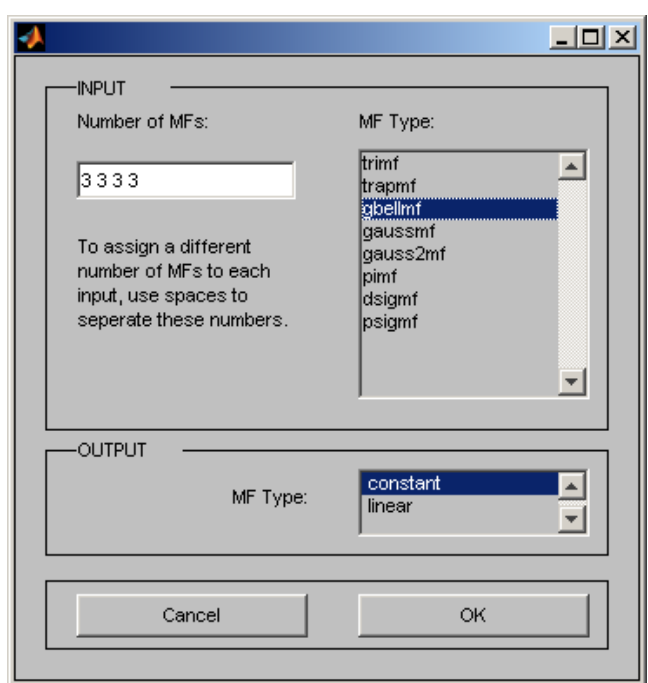

Figura A.2 - Parâmetros de inicialização do sistema de inferência fuzzy

Como opções de algoritmo de treinamento do ANFIS tem-se o backpropagation e um método híbrido, que consiste na combinação da estimação dos mínimos quadrados com backpropagation, para estimar os parâmetros da função de pertinência. Neste trabalho, os 
resultados foram obtidos com uso do algoritmo de treinamento híbrido, pois foram mais promissores do que com o backpropagation.

Determinadas as configurações necessárias, o treinamento irá efetuar o ajuste das funções de pertinência como também da base de regras.

A arquitetura ANFIS é apresentada na Figura A.3.

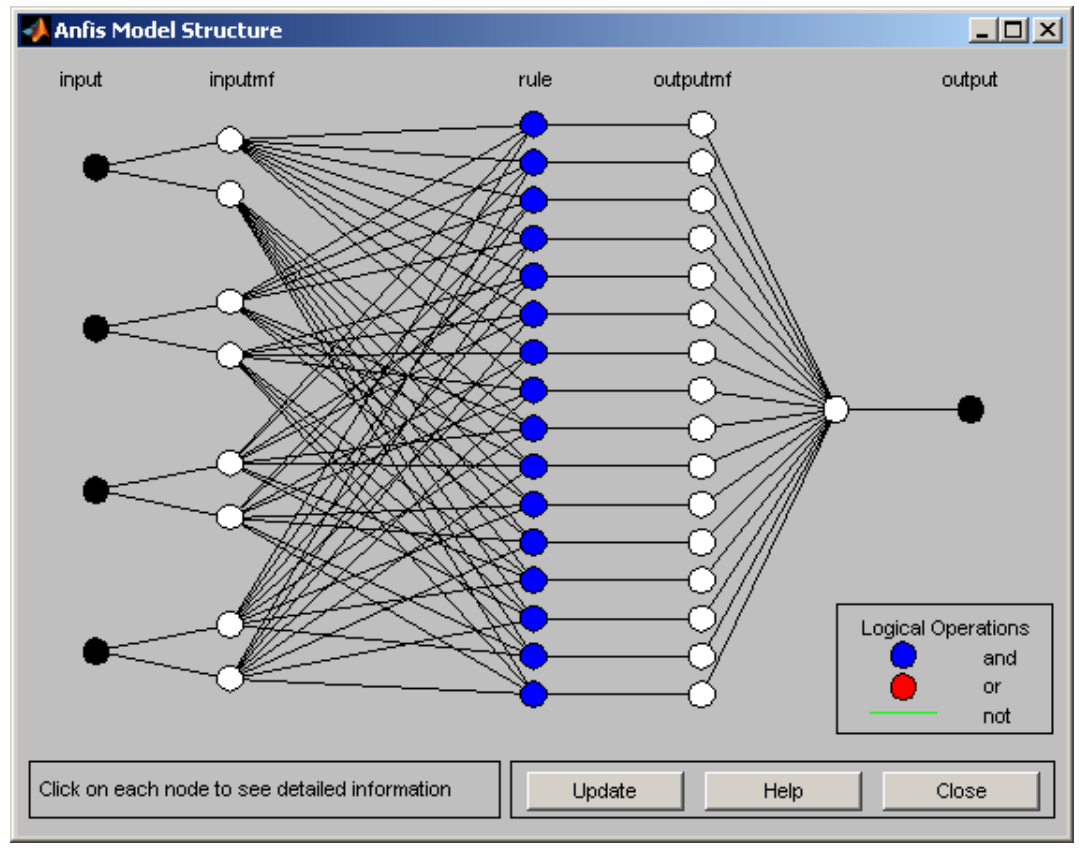

Figura A.3 - Estrutura do ANFIS

O ANFIS possui algumas limitações de aplicação devido ao fato de empregar o modelo de inferência Takagi-Sugeno (Mathworks, 2007). Uma delas é a exigência de se ter apenas uma variável de saída, a qual é obtida utilizando-se a defuzzificação pela média ponderada dos pesos. Outra limitação é que todas as funções de pertinência de saída devem ser do mesmo tipo, linear ou constante.

\section{A.2 Toolbox Fuzzy Logic no Matlab}

O ambiente Matlab também permite visualizar e ajustar o sistema fuzzy. Havendo essa necessidade, pode-se utilizar a toolbox Fuzzy Logic. As janelas que compõem o sistema fuzzy são apresentadas na Figura A.4 e podem ser visualizadas a partir das opções Edit e View do 
menu da janela principal do anfisedit, apresentado na Figura A.1, ou por meio do comando fuzzy do Matlab (Mathworks, 2007).

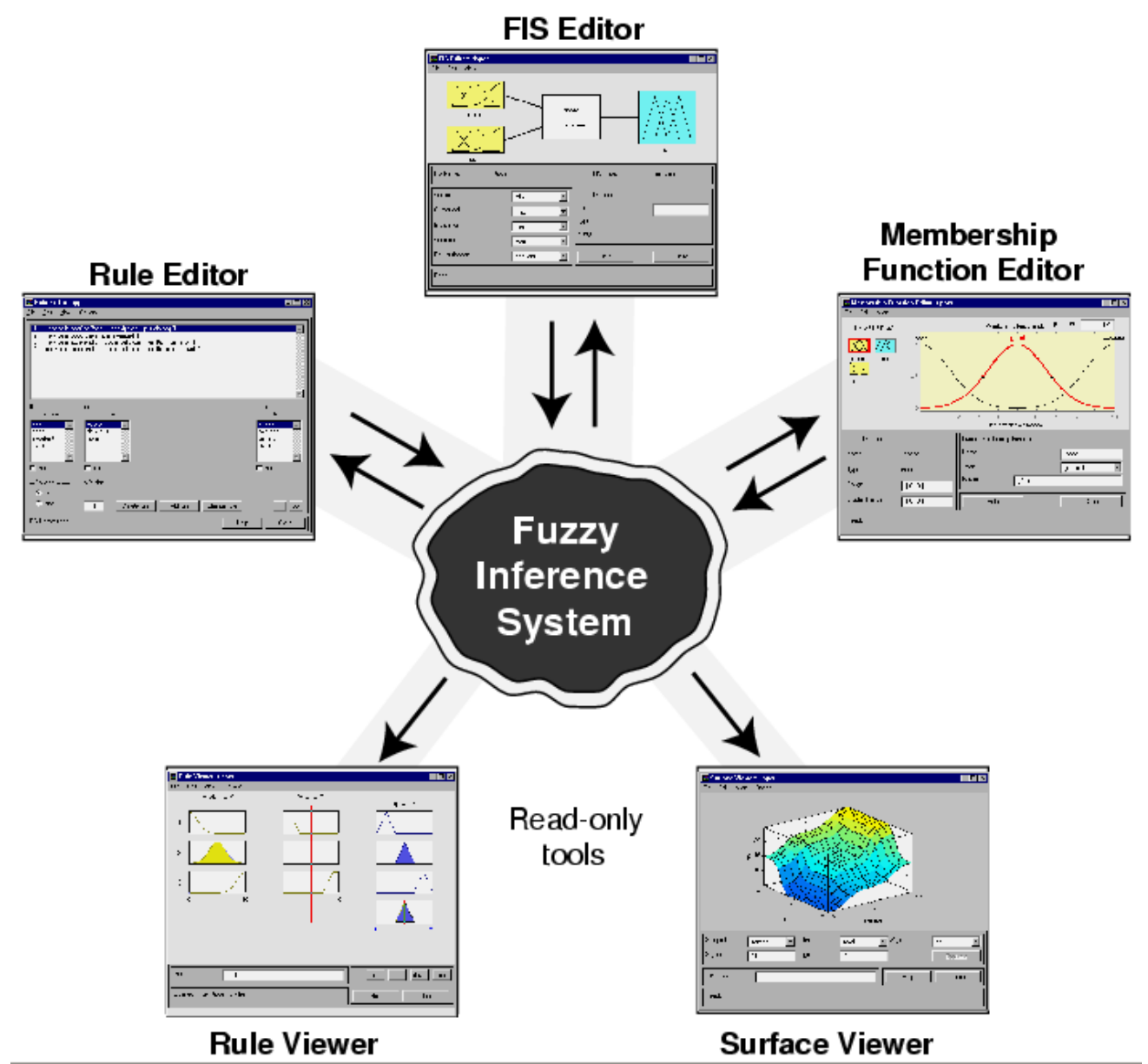

Figura A.4 - Esquema do Toolbox Fuzzy Logic do Matlab

O primeiro componente a ser abordado é o Editor FIS. Sua finalidade é, de forma resumida, ilustrar as informações referentes a um sistema de inferência fuzzy. Tal sistema de inferência fuzzy pode ser obtido a partir da técnica $A N F I S$, ou seja, o ajuste das funções de pertinência e a criação das regras são determinados pelo ANFIS.

Essa interface também permite determinar como devem ser efetuadas as operações AND e OR nos antecedentes e qual será o método de implicação, agregação e defuzzificacão (Mathworks, 2007). 


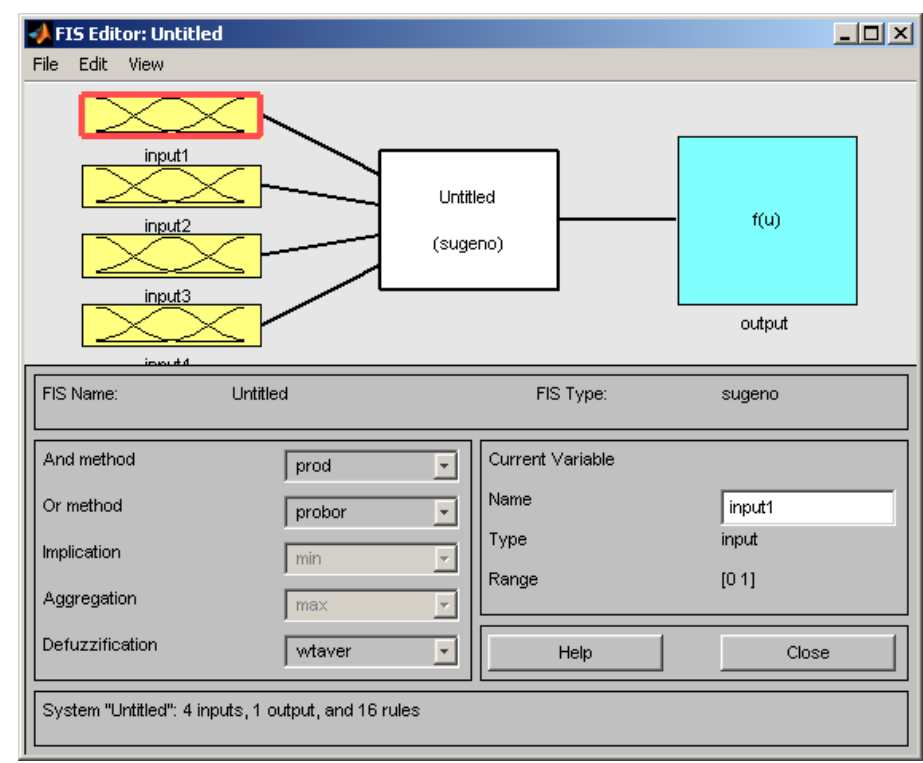

Figura A.5 - Editor FIS

Por meio do editor de funções de pertinência é possível gerenciar os atributos das funções de pertinência do sistema fuzzy, ou seja, é possível editar e visualizar todas suas características. Pode-se verificar na Figura A.6 que é possível se visualizar as funções de pertinência dos quatro nós de entrada e do nó de saída (Mathworks, 2007).

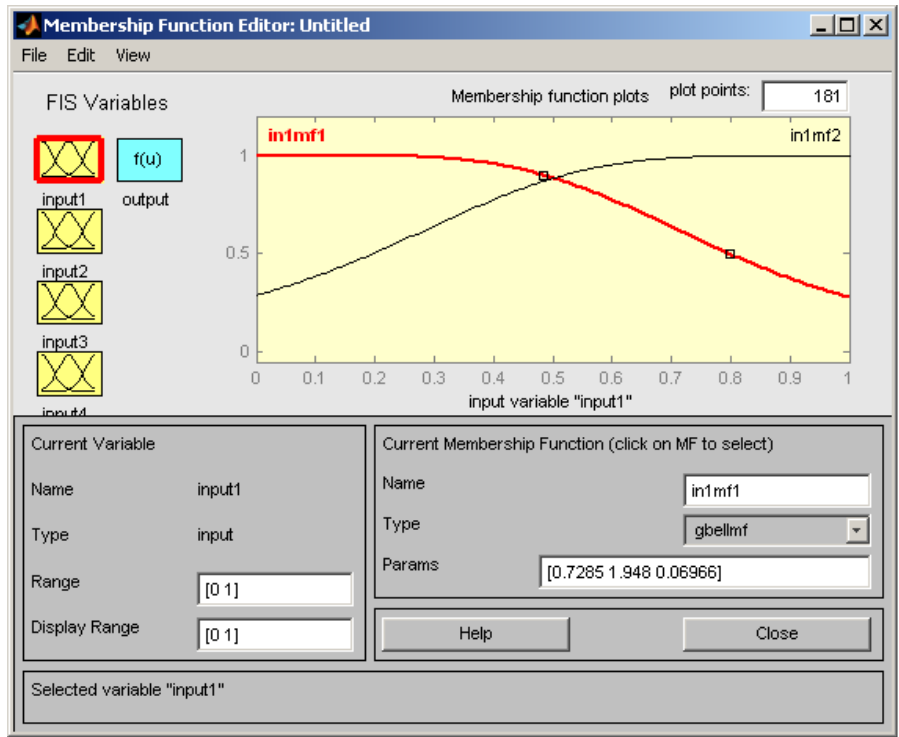

Figura A.6 - Editor das funções de pertinência

O Editor de Regras proporciona um ambiente para se trabalhar com as regras do sistema fuzzy, permitindo adicionar, modificar, apagar ou ignorar regras. Como pode-se observar no exemplo da Figura A.7, as regras são compostas de quatro entradas, por isso quatro antecedentes compõem cada uma das regras (Mathworks, 2007). 


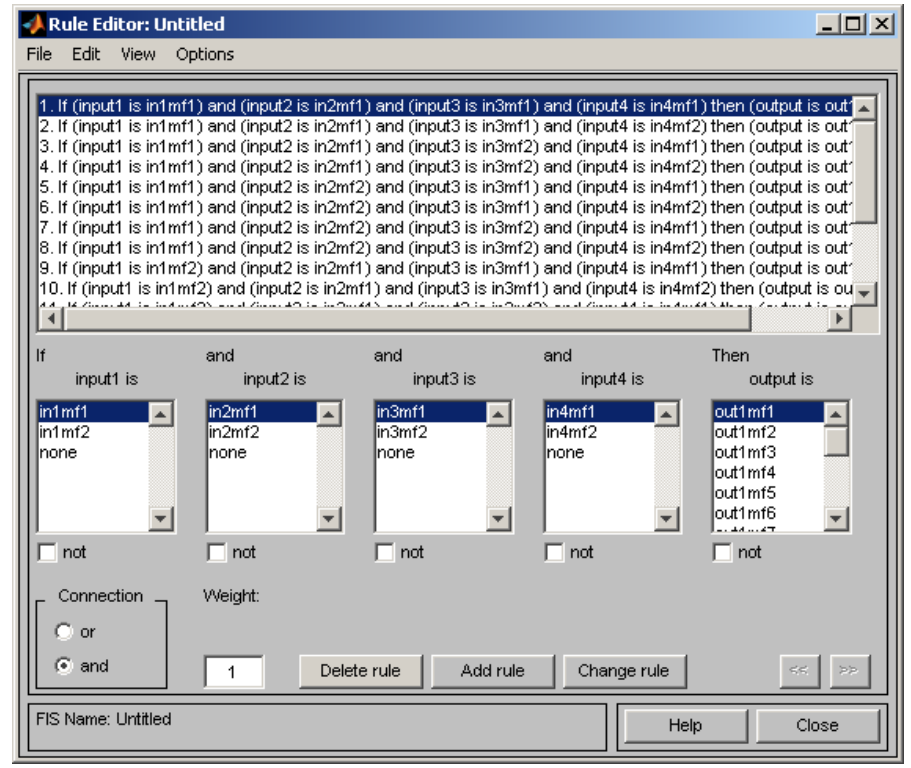

Figura A.7 - Editor de regras

Pode-se visualizar as regras do sistema fuzzy por meio do componente do toolbox conhecido como visualizador de regras apresentado na Figura A.8.

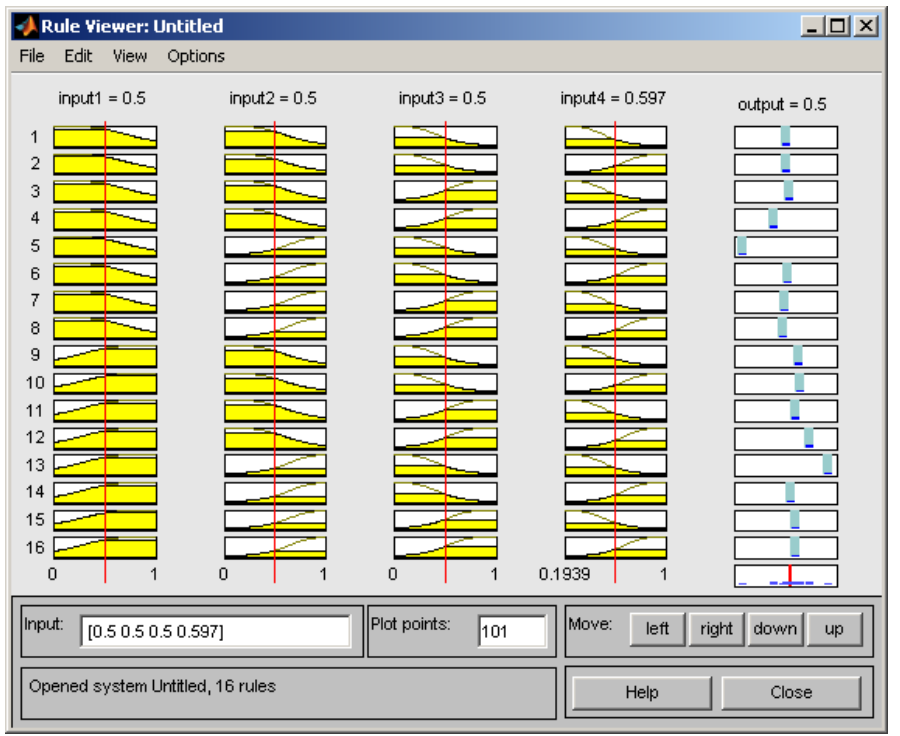

Figura A.8 - Visualização das regras

O toolbox Fuzzy Logic do Matlab também possui um ambiente para se visualizar as superfícies de saída do sistema. Este ambiente tem por objetivo criar uma curva tridimensional de saída que representa o mapeamento das entradas do sistema fuzzy. Uma vez que não se pode visualizar uma superfície com mais de três dimensões, o ambiente permite 
selecionar entradas duas a duas para se desenhar a curva, sendo que as demais são consideradas constantes. Dessa forma, a Figura A.9 apresenta o ambiente Surface Viewer (Mathworks, 2007).

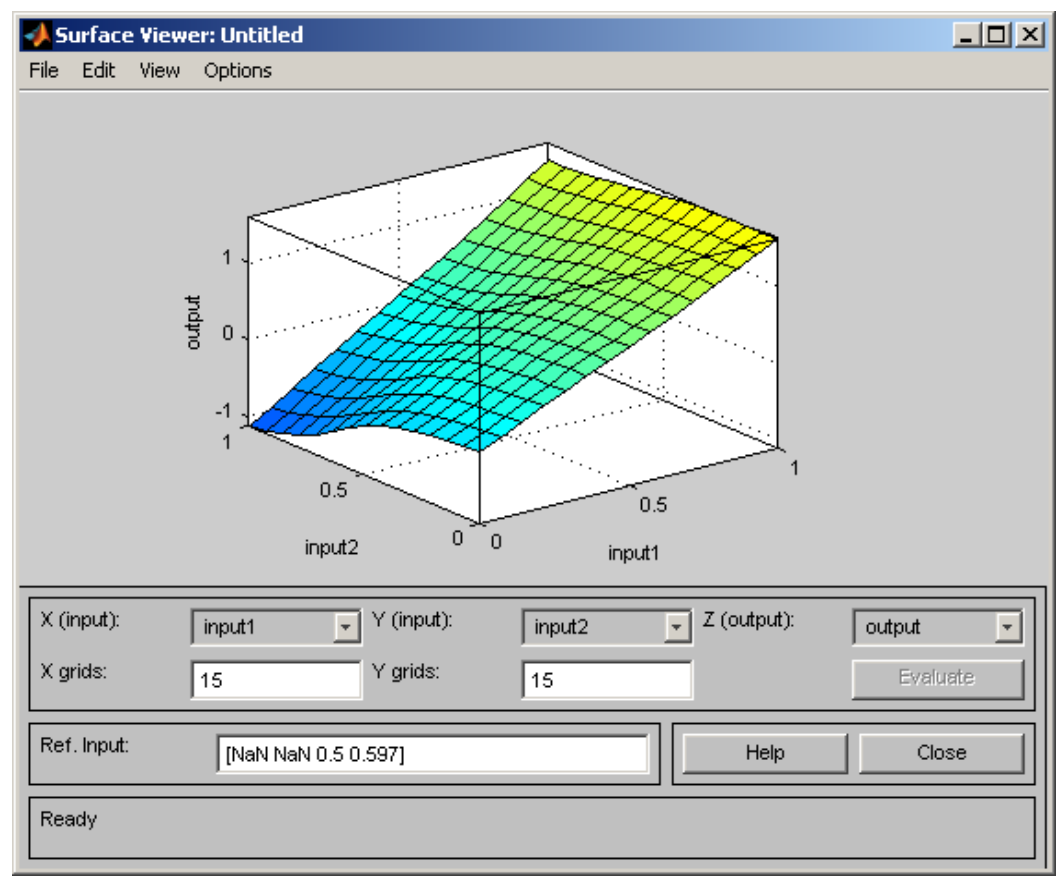

Figura A.9 - Visualizador de Superfícies 